\title{
Environmental Health-Risk Assessment for Tritium Releases at the National Tritium Labeling Facility at Lawrence Berkeley National Laboratory
}

\section{by}

Thomas E. McKone* and Kevin P. Brand ${ }^{* *}$

Health and Ecological Assessment Division

Lawrence Livermore National Laboratory

Chao Shan

Earth Sciences Division

Lawrence Berkeley National Laboratory

University of California

April 1997

\section{University of California Ernest Orlando Lawrence Berkeley National Laboratory Berkeley, California}

* Currently at University of California, Berkeley, School of Public Health

** Currently at Harvard University 


\section{DISCLAIMER}

This document was prepared as an account of work sponsosed by the United States Government. While this document is believed to contain correct information, neither the United States Government nor any agency thereof, nor The Regents of the University of California, nor any of their employees, makes any warranty, express or implied, or assumes any legal responsibility for the accuracy, completeness, or usefulness of any information, apparatus, product, or process disclosed, or represents that its use would not infringe privately owned rights. Reference herein to any specific commercial product, process. or service by its trade name, trademark, manufacturer, or otherwise, does not necessarily constitute or imply its endorsement. recommendation. or favoring by the United States Government or any agency thereof. or The Regents of the University of California. The views and opinions of authors expressed herein do not necessarily state or reflect those of the United States Government or any agency thereof, or The Regents of the University of California.

Available to DOE and DOE Contractors

from the Office of Scientific and Technical Information

P.O. Box 62, Oak Ridge, TN 37831

Prices available from $(615) \quad 576-8401$

Available to the public from the

National Technical Information Service

U.S. Department of Commerce

5285 Port Royal Road, Springfield, VA 22161

Ernest Orlando Lawrence Berkeley National Laboratory is an equal opportunity employer.

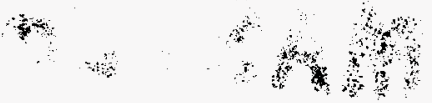




\section{DISCLAMIER}

Portions of this document may be illegible in electronic image products. Images are produced from the best available original document. 


\section{DISCLAIMER}

This report was prepared as an account of work sponsored by an agency of the United States Government. Neither the United States Government nor any agency thereof, nor any of their employees, make any warranty, express or implied, or assumes any legal liability or responsibility for the accuracy, completeness, or usefulness of any information, apparatus, product, or process disclosed, or represents that its use would not infringe privately owned rights. Reference herein to any specific commercial product, process, or service by trade name, trademark, manufacturer, or otherwise does not necessarily constitute or imply its endorsement, recommendation, or favoring by the United States Government or any agency thereof. The views and opinions of authors expressed herein do not necessarily state or reflect those of the United States Government or any agency thereof. 


\section{Contents}

1 Introduction and Summary of Results

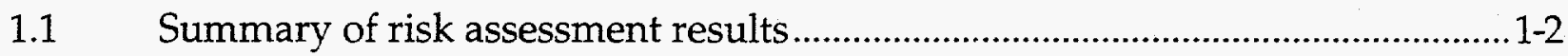

$1.2 \quad$ Organization of this chapter ......................................................................... 1-2

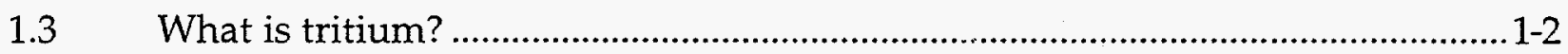

1.4 Why is tritium used at Lawrence Berkeley National Laboratory? ...................... 1-3

1.5 What are tritium's radiological characteristics? .................................................... 1-3

1.6 What steps are necessary to assess tritium risk?

1.7 Does the tritium at LBNL escape into the environment? ..................................1-4

1.8 How might someone be exposed to tritium from LBNL? ..................................1-7

1.9 Is tritium hazardous to human health? What do we know? ..............................1-8

1.10 How much radiation are workers exposed to from the NTLF? .........................1-9

1.11 What are the estimated risks due to tritium exposure? ....................................1-10

1.12 What is the likelihood that a worker or community member will suffer a health effect as a result of exposure to background natural radiation?

1.13 What are the risks from LBNL tritium to workers near the NTLF?..................1-12

1.14 What are the risks from LBNL tritium exposure to other LBNL workers and nearby facilities and residences?

1.15 Does LBNL tritium make it risky to live in Berkeley, or to wade or swim in Strawberry Creek or relax along its banks?

1.16 Is it more likely that this study overstates or understates risk? $1-14$

1.17 Does LBNL tritium pose a significant risk to workers and the community?

1.18 How reliable is this risk assessment? ........................................................1-16

1.19 Organization of the rest of this report ..............................................................1-17

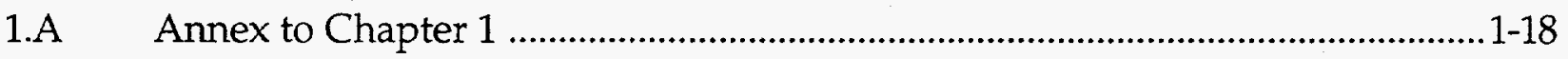


1A.1 Radiological Health Branch, California Department of Health Services.

1A.2 Agency for Toxic Substances and Disease Registry.

1A.3 US Environmental Protection Agency, Region IX Office in San Francisco.

2.1 What Is Radiation?

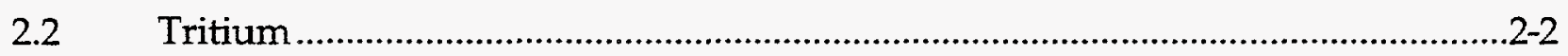

2.2.1 Sources of Environmental Tritium ....................................................2-3

2.2.2 Health Effects of Tritium .........................................................................2-3

2.2.3 How People Come in Contact with Tritium ……...................................2-3

2.2.4 Potential Risks .................................................................................2-4

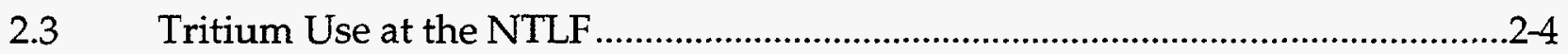

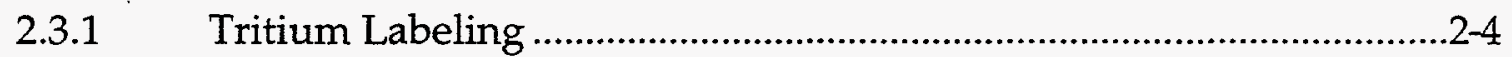

2.3.2 Tritium Releases at the NTLF .......................................................

3 How the Risk Assessment Was Done 3-1

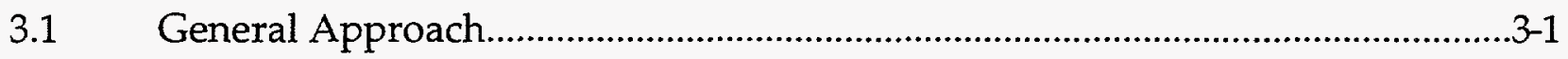

3.2 Computer Modeling Used in the Risk Assessment ................................................

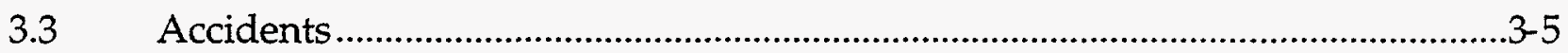

4 Technical Details $\quad$ 4-1

4.1 Overview of the Risk Assessment Process ..........................................................

$4.2 \quad$ Tritium Properties and Sources .......................................................................

4.2.1 Physical and Chemical Properties of Tritium ........................................4-3

4.2.2 Sources of Tritium Release in the Environment .................................4-4

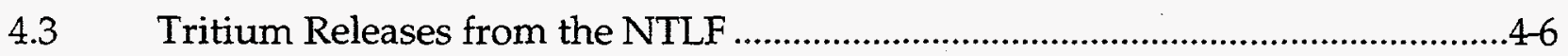

4.4 Environmental Distribution of Tritium Releases from the NTLF.......................4-7

4.4.1 Model Structure ...............................................................................4-8

4.4.1.1 Steady State Mass Balance Equations ..................................4-9

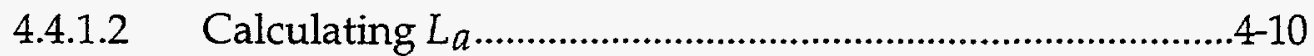

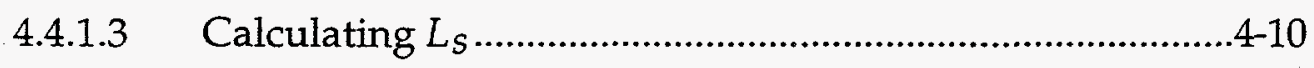

4.4.2 Solutions for the Tritium Inventories..............................................4-10 
4.4.3 Air Dispersion Model for Zone 3 .......................................................4-11

4.5 Human Contact with Tritium Releases.................................................................4-11

4.5.1 Intake and Uptake ............................................................................

4.5.2 Exposure Factors........................................................................... $4-12$

4.5.2.1 Exposure Duration and Averaging Time...........................4-12

4.5.2.2 Anatomical Properties, Inhalation, and Ingestion.............................................................................. 4 -13

4.5.2.3 Activity Patterns and Exposure Times...............................4-14

4.5.2.4 Dermal Uptake from Air .....................................................4-14

4.5.2.5 Dermal Uptake from Water ................................................. 4-15

4.6 The Relation Between Tritium Exposure, Radiological Dose and Health Effects

4.6.1 Health Risks Associated with Tritium ...........................................4-15

4.6.2 Tritium Metabolism and Dosimetry …............................................4-16

4.6.3 Regulatory Guidance Relevant to Tritium..........................................4-19

4.6.4 Risk Factors: The Relation Between Radiological Dose and Health Effects ...............................................................................4-20

4.6.4.1 The Risk Factor for Cancer, $R_{\text {HTO }}^{\text {can }}$..................................... 4-21

4.6.4.2 The Risk Factor for Heritable Genetic Effects, R

4.6.4.3 The Risk Factor for Developmental and Reproductive Effects, $R_{\mathrm{HTO}}^{\text {rep }}$ $4-23$

4.7 Estimated Health Risks for Tritium Releases from the NTLF $4-24$

4.7.1 Tritium Concentrations in Air, Water, and Soil of the

NTLF Environment.

4.7.1.1 Source Term................................................................ 4-27

4.7.1.2 Source Area and Mixing Height of the Atmosphere Near the NTLF....

4.7.1.3 Predicted Concentrations in the Vicinity of the NTLF, Zone 1 .................................................................4-27

4.7.1.4 Predicted Concentrations in Zone 2..................................4-28

4.7.1.5 Predicted Concentrations in Zone 3...................................4-30

4.7.2 Generic Calculations of Intake, Uptake, Body Burdens, and Dose 4-32

4.7.2.1 Average Intake by Inhalation 4-32

4.7.2.2 Average Dermal Uptake 4-33 
4.7.2.3 Average Intake by Ingestion of Homegrown

Foods.

4.7.2.4 Average Ingestion Intake of Surface Water

During Recreation

4.7.2.5 Total Body Burden of Tritiated Water

4-34

4.7.2.6 Estimated Live-Born Infant Body Burden 4-34

4.7.2.7 Potential Infant Intake and Body Burden through Breast Feeding. 4-34

4.7.2.8 Total Dose, Population Risk, and Individual Risk. 4-35

4.7.3 Estimated Doses and Risks in Zone 1 4-36

4.7.4 Estimated Doses and Risks in Zone 2 4-37

4.7.5 Estimated Doses and Risks in Zone 3 . $4-38$

4.7.6 Step-by-Step Calculations. $4-40$

4.8 Summary and Discussion $4-42$

\section{APPENDICES}

A Two-Compartment Environmental Transport Model for Tritium

A.1 General Issues A-1

A.1.1 Tritium in Air A-1

A.1.2 Tritium in Soil. A-2

A.1.3 Tritium in Surface Waters.................................................................

A.1.4 Tritium Uptake in Biota ..................................................................

A.1.5 Why Only Two Compartments?..........................................................

A.2 Steady State Mass Balance Equations .................................................................4-4

A.2.1 Transfer Rate Constants..............................................................

A.2.2 Solutions for the Compartment Inventories ……….............................

B Human Anatomical and Intake Factors Used in the Exposure Assessment Calculations

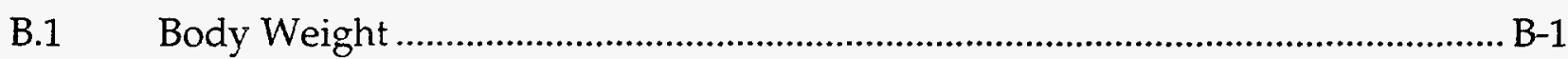

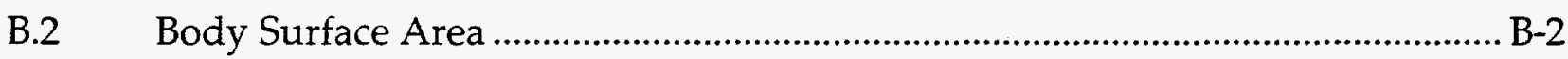

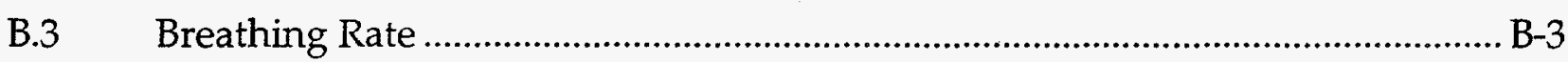

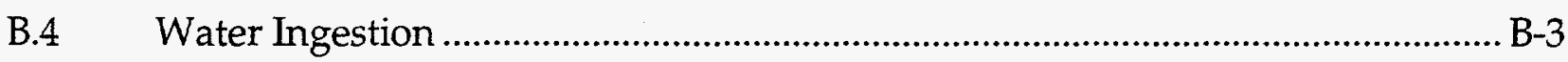

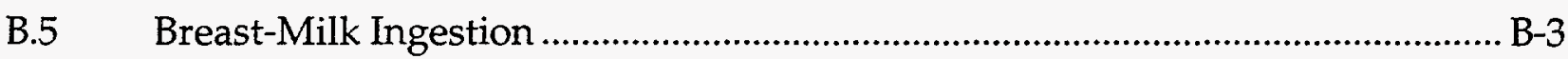


B.6 Ingestion of Homegrown Fruits, Vegetables, and Grains

C Landscape, Climate and Hydrology Parameters

C.1 Wind Speed

C.2 Temperature

C.3 Humidity

C.4 Depth of Soil Compartment

C.5 Moisture Content of Soil.

C.6 Precipitation

C.7 Evapotranspiration

C.8 Runoff

C.9 Infiltration to Ground Water

C.10 Rain Scavenging Efficiency

D Evaluating the Potential Legacy of Past Elevated HTO Emissions

D-1

E Results of the Risk Assessment Carried Out for NTLF Releases, Using the EPA CAP88 Computer Model

F Validation of the Input Data for Risk Assessment

F.1 Comparison of Risk Assessment Estimates to Measured Air

Quality Data.

F.2 Comparison of Risk Assessment Estimates to Measured Rain

Water Data

F.3 Comparison of Risk Assessment Estimates to Measured Surface

Water Data

F.4 Comparison of Risk Assessment Estimates to Measured Soil and Sediment Data

F.5 Comparison of Risk Assessment Estimates to Measured Ground Water Data

F.6 Comparison of Risk Assessment Estimates to Measured

Vegetation Data

F.7 Analysis of Urine Data. 
G Conversion Table for Radiation Units

H Review Comments

I Questions and Answers About Tritium

J Reviewers' Letters

Glossary of Technical Terms

Glo-1

References

Ref-1 


\section{Chapter 1}

\section{Introduction and Summary of Results}

In talking with community members about operations at Lawrence Berkeley National Laboratory (LBNL) (the Laboratory), we found that people are concerned about a radioactive substance, tritium, used at the Laboratory. State, federal and international agencies all have standards for limiting human exposure to tritium in both occupational and non-occupational populations. LBNL has always maintained exposure to tritium well below the regulatory levels (see Table 1-3 for a comparison). Nevertheless, LBNL continues to evaluate and implement new methods to further reduce the emission of tritium to the environment.

In response to the community's concern about the risk ${ }^{1}$ of being exposed to tritium released from LBNL, the Laboratory conducted a formal analysis, known as a "risk assessment," of potential health impact from tritium exposure. This first chapter presents a brief non-technical summary of the results of the risk assessment, and Chapter 2 contains basic information about tritium, radiation, and the National Tritium Labeling Facility (NTLF). The other chapters provide detailed information and equations showing how the risk assessment was done. If you have questions about the information presented here, you may call Ronald Kolb in LBNL's Public Communications Department at 510-486-7586.

LBNL also prepared a fact sheet, "Questions and Answers about Tritium," which was distributed in the winter of 1992-1993. The fact sheet is included as Appendix I of this document, and some of the text is repeated below. You may request additional copies of the fact sheet by telephoning Ronald Kolb.

In this report we use both SI and US units. Readers can use the table in Appendix G to make conversions.

${ }^{1}$ Words in boldface type are defined in the Glossary at the end of this book. 


\subsection{Summary of risk assessment results}

This risk assessment calculates the probability of experiencing health effects, including cancer incidence due to tritium exposure for three groups of people: (1) LBNL workers near the LBNL facility-Building 75-that uses tritium; (2) other workers at LBNL and nearby neighbors; and (3) people who use the UC Berkeley campus area, and some Berkeley residents. All of these groups share the same probability of health effects from the background radiation from natural sources in the Berkeley area environment, including an increased risk of developing a cancer of 11,000 chances per million. In calculating risk we assumed continuous operation in Building 75 for at least a human lifetime. Under this assumption, LBNL workers located near Building 75 have an additional risk of 60 chances out of one million to suffer a cancer; other workers at LBNL and people who live near LBNL have an additional risk of six chances out of one million over a lifetime of exposure; and users of the UC Berkeley campus area and other residents of Berkeley have an additional risk of less than one chance out of one million over a lifetime. These risk estimates are discussed further in Sections 1.13 through 1.17 .

\subsection{Organization of this chapter}

The sections that follow in this chapter look at:

- Facts about tritium: what it is, how it is used at LBNL, and its radiological characteristics

- Steps in a risk assessment

- How workers and community members might be exposed to LBNL tritium

- Potential health effects of tritium exposure

- The probable risk from tritium exposure

- Uncertainty in the risk assessment

- Validity of the input tritium concentrations for risk assessment

- Subsequent chapters of the report

- Responses to reviewers' comments on the draft version of this document

\subsection{What is tritium?}

Tritium is a radioactive form of hydrogen. Since tritium behaves like hydrogen chemically, it is usually found attached to molecules in place of hydrogen. For example, a water molecule may exchange one of its hydrogen atoms for a tritium atom, resulting 
in "tritiated water." Tritiated water is sometimes referred to as "HTO" to distinguish it from $\mathrm{H}_{2} \mathrm{O}$, ordinary water with two ordinary hydrogen atoms in each molecule.

Tritium is produced both by a natural process, the interaction of cosmic rays with the atmosphere, and by man-made processes (in nuclear reactions). About 80 percent to 90 percent of tritium in the environment today was released in the 1950s and early 1960s by above-ground nuclear weapons testing in many countries. Tritium is also used in a variety of consumer products, such as illuminated watches, thermostat dials, and airplane exit lights. Both the natural and man-made sources have contributed (and continue to contribute) to a world-wide "background" level of tritium.

The half-life of tritium is 12.3 years. This means that the concentration of tritium in the environment is reduced by one-half every 12 years, disregarding newly generated tritium.

\subsection{Why is tritium used at Lawrence Berkeley National Laboratory?}

At LBNL, the NTLF (Building 75 in Figure 1-1) uses tritium. The NTLF helps biomedical researchers develop new ways to study cell metabolism and test new products that can be useful in curing diseases. Researchers "label" pharmaceuticals and other materials with tritium by replacing a hydrogen atom with a tritium atom in materials used in experiments. For example, a potential cancer drug might be labeled so that researchers can study the transport of the tritium-labeled drug in a cell culture and evaluate its effectiveness in treating a particular type of cancer.

\subsection{What are tritium's radiological characteristics?}

When tritium undergoes radioactive decay, it is transformed into nonradioactive helium through the emission of a "beta" particle, or electron, from its nucleus (see Figure 1-2). The very low energy radiation emitted by tritium is too weak to present a radiation hazard outside of the human body. The radiation from tritium can only travel about 5 millimeters in air and can be stopped completely by a sheet of paper or by ordinary clothing.

Tritium can deliver a radiation dose, however, if it is taken inside the body. Such an intake could occur by breathing tritiated water vapor in the air, or by eating or drinking tritium-contaminated foods or water. Even though tritium radiation cannot penetrate skin, tritiated water vapor in air, like regular water vapor in air, may be absorbed through the skin. Likewise, a person might absorb small amounts of tritiated water through the skin when swimming or wading in contaminated water. A developing fetus could also receive tritium absorbed into its mother's body through one of these routes. 
Most tritium taken into the body is rapidly distributed throughout the body as tritiated water, HTO. Since these HTO molecules behave just like normal water molecules, they are subject to the normal rate of removal of water from the body. Thus, the amount of tritium entering the body is reduced by half about every two weeks. A small portion of tritium in the body may be "organically bound tritium," tritium that has been incorporated into molecules that make up plant or body cells. Organically bound tritium is metabolized differently than HTO and can be retained for somewhat longer periods, with the amount being reduced by half about every seven weeks.

\subsection{What steps are necessary to assess tritium risk?}

For the purpose of estimating risk from tritium emissions, risk assessment involves four interrelated steps: 1) determining the amount of tritium released and how it is released; 2) based on step 1, determining the levels of tritium to which people could be exposed and the routes through which they could be exposed;3) determining the potential health effects of exposure to these levels of tritium; and 4) arriving at an estimate for the probability of experiencing a health effect, given the foregoing information.

\subsection{Does the tritium at LBNL escape into the environment?}

Small quantities of tritium are emitted from the ventilation stack at Building 75 to the environment in forms of molecular tritium $\left(\mathrm{T}_{2}\right.$ or $\left.\mathrm{HT}\right)$ and tritiated water (HTO). HTO is taken up by organisms and environmental media far more readily than molecular tritium. Therefore, to make the risk assessment health protective, we assume that all tritium emissions are in the form of HTO. The dose that a member of the public could receive from the contribution of these emissions to the air is approximately 100 times lower than the limit permitted by federal regulations. LBNL takes samples from stack emissions, air, local rainfall, ground water, streams, and sewers to check for tritium. The Laboratory publishes these monitoring results annually in environmental reports that are provided to all regulatory agencies and are available at public libraries.

LBNL has detected tritium in soil, rainwater, and ground water in the immediate area of Building 75. Occasionally, the levels detected in rainwater and ground water at some locations around Building 75 have been slightly above the drinking water standard established by the U.S. Environmental Protection Agency (EPA). However, none of this water is used for drinking, and none flows into any sources of drinking water for Berkeley. The tritium levels are very low in other drainage channels on site. The creeks flowing out of the Laboratory area also are monitored for tritium. Tritium has been detected occasionally in Strawberry and Blackberry Creeks, but at levels that are much less than the EPA drinking water standard. 


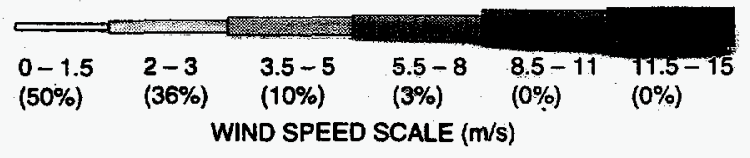

NOTE: Wind direction is the direction the wind is blowing from.

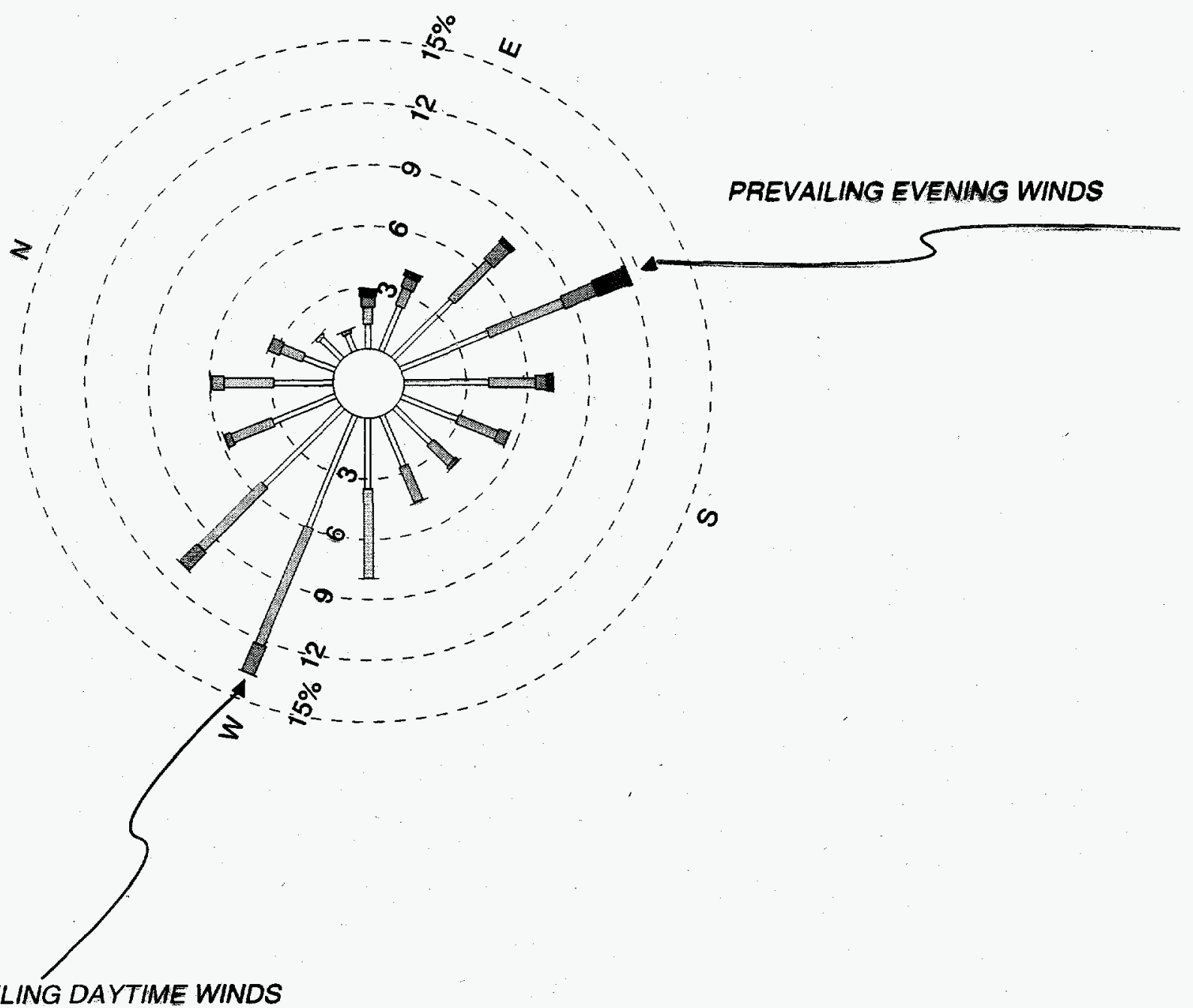

PREVAILING DAYTIME WINDS 


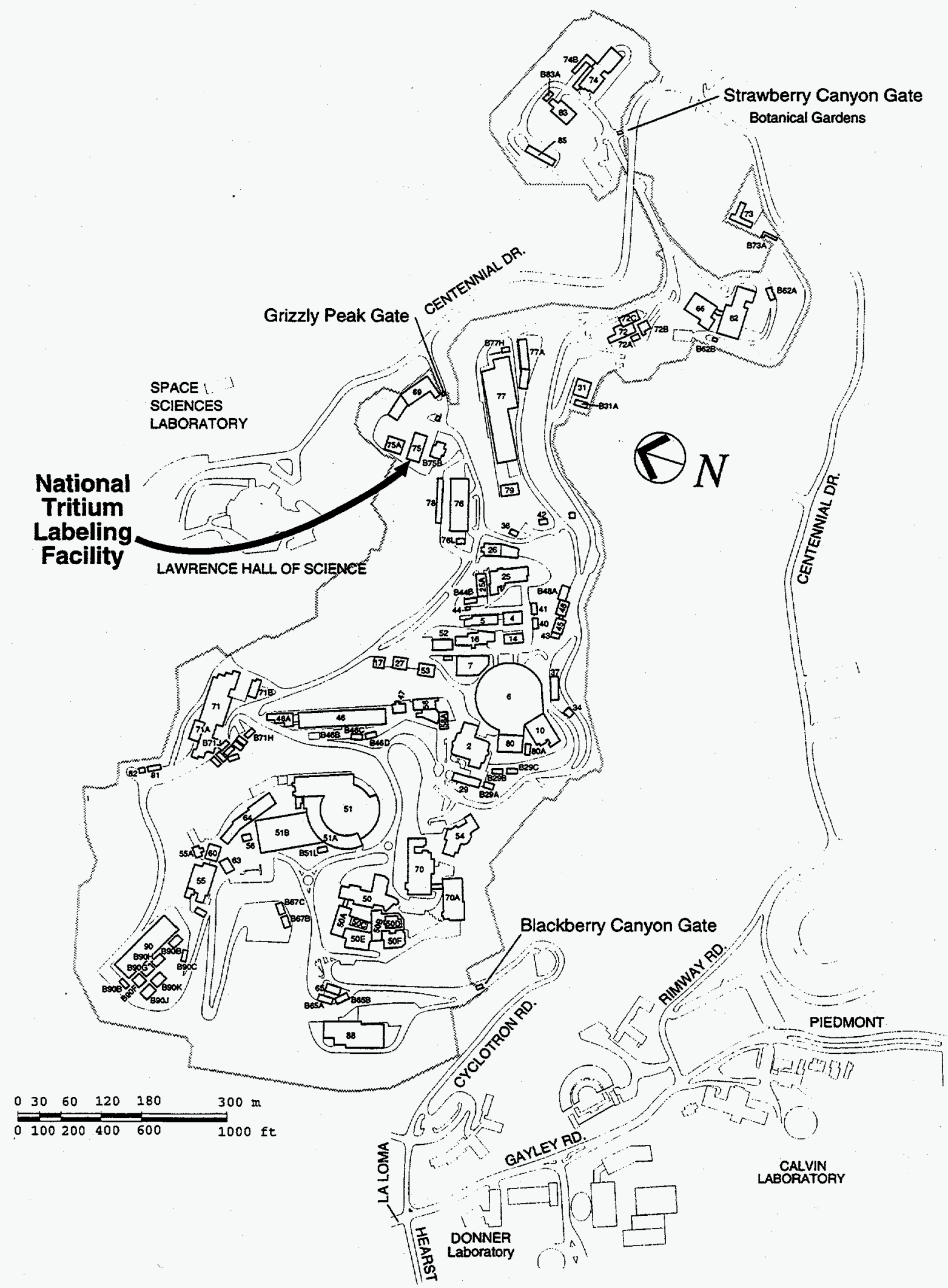

Figure 1-1. Location map. The NTLF is located in Building 75 on the LBNL site. 


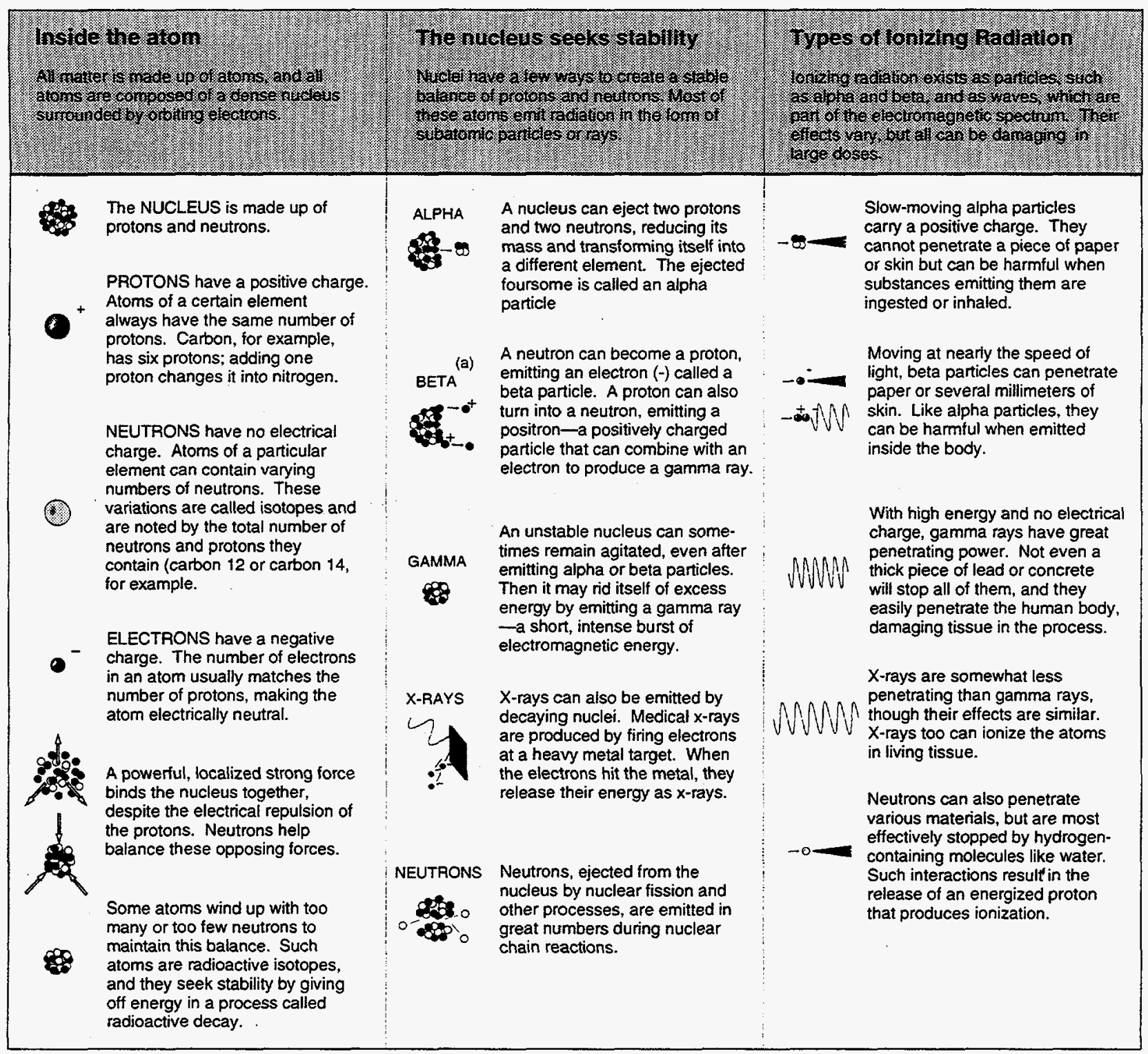

\section{Note to Figure 1-2:}

(a) While some beta particles can penetrate human skin, tritium's beta particles do not have enough energy to do so. Their maximum depth of penetration is .006 millimeters, compared to the thickness of human skin ranging from one to three millimeters.

Figure 1-2. Types of ionizing radiation (from Health Risks Associated with Low Doses of Radiation, report prepared by S. Cohen and Associates and ICF Kaiser Engineers for the Electric Power Research Institute, August 1994, EPRI TR-104070, Palo Alto, CA. Used by permission of the Electric Power Research Institute). 


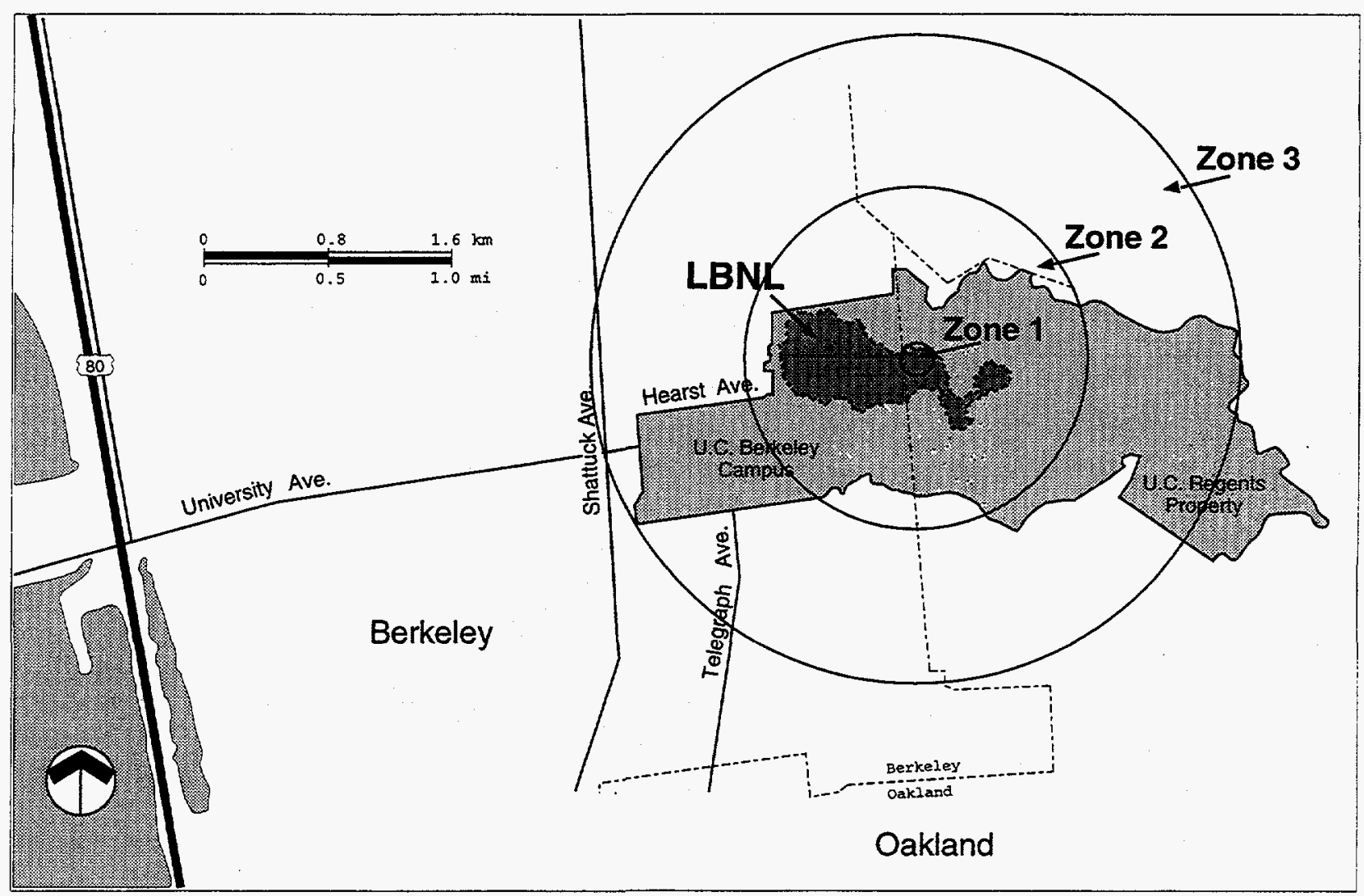

Figure 1-3. Map showing NTLF risk assessment zones.

\subsection{How might someone be exposed to tritium from LBNL?}

The risk assessment considered three zones in which people might be exposed to tritium from LBNL, from the zone of highest likely exposure (Zone 1) to the zone encompassing the UC Berkeley campus (Zone 3). With the center at the northeast corner of Building 75 (NTLF), the borders of the three zones are concentric circles with radii of 100, 1100, and 2100 meters, respectively (Figure 1-3).

Zone 1 includes the natural bowl that surrounds the NTLF building (Building 75) and its ventilation stack, including everything within 100 meters of the northeast corner of Building 75. People who work in this area (assuming 200 adults with 20 nursing infants) are at the most risk of exposure to tritium, by breathing tritiated water vapor and absorbing it through their skin.

Zone 2 covers the rest of entire LBNL site and the surrounding UC property occupied by the Lawrence Hall of Science, Samuel Silver Space Sciences Laboratory, Mathematical Sciences Research Institute, and Botanical Gardens. Also included are single family residences uphill from the NTLF along Grizzly Peak Boulevard. Workers and residents in this area (assuming 10,000 adults and 1,000 nursing infants) are at 
lesser risk of exposure to tritium, by breathing tritiated water vapor or absorbing it through the skin or, possibly, in the case of residents, ingesting tritium that has been taken up by home-grown fruits and vegetables.

Zone 3 includes the UC Berkeley campus and adjacent areas of Berkeley beyond Zone 2 . People who live, work, study, or otherwise spend time in this area (assuming 100,000 adults and 10,000 nursing infants) could be exposed to tritium dispersed by wind from the NTLF stack or washed by rain from the air near the NTLF into surface-water runoff and carried down into Strawberry Creek.

\subsection{Is tritium hazardous to human health? What do we know?}

The fact that tritium emits very low-energy radiation, is diluted throughout the body, and is eliminated fairly quickly from the body makes tritium one of the least hazardous radioactive materials. Again, tritium is a potential health risk only if it is taken inside the body.

The only studies that show radiation effects on human health are studies of individuals exposed to high dose levels (e.g., from the atomic bombings of Hiroshima and Nagasaki) -- well above those associated with background radiation, which is orders of magnitude higher than tritium from the NTLF. There are no human studies that demonstrate a link between exposure to low-level radiation and health effects. Nonetheless, it is assumed that low-dose radiation does affect health. The health risk estimates in this risk assessment are extrapolated from effects observed only at high dose levels.

There is evidence from experiments with animals and cell cultures that exposure to very high levels of radiation from HTO results in mutations and cell disruptions that can lead to health effects associated with radiation, including cancer. Both leukemia and non-leukemia soft-tissue carcinomas are associated with high levels of HTO exposure. Based both on the Japanese case and experimental evidence, this risk assessment assumes that the likelihood of an individual suffering a cancer as a result of exposure to tritium depends upon the magnitude of the dose of tritium radiation and the time period over which the dose is received.

Risk estimates for low doses of low linear-energy-transfer radiation, such as those for NTLF tritium releases, are based on linear extrapolation from selected populations exposed to relatively high dose rates-that is, greater than 100 millisieverts (mSv) for very short time periods (that is, seconds or minutes). ${ }^{2}$ When dose levels are much lower and permit natural repair of radiation damage, they could result in a much smaller biological effect per unit dose. Dose levels for uncontrolled areas near the

\footnotetext{
${ }^{2}$ See Section 1.10 for definitions of sievert and millisievert.
} 
NTLF are several orders of magnitude below these small doses and are estimated to be no greater than $0.005 \mathrm{mSv}$.

To date there is no direct experimental evidence that HTO or other tritium exposure causes genetic defects (genetic damage that results in observable defects that are capable of being carried on to succeeding generations) or noninheritable developmental effects in animals [Straume, 1993]. However, based on the genetic effects and noninheritable developmental effects identified in the Japanese case, it is possible that tritium exposure has this potential. As with cancers, it is assumed that the risk of birth defects from exposure to tritium is proportional to the relative magnitude of the dose and the time period over which that dose is received.

\subsection{How much radiation are workers exposed to from the NTLF?}

LBNL monitors the level of internal radiation to employees by taking and analyzing urine samples from employees working near the NTLF and elsewhere. Dose equivalent is measured in units known as sieverts (Sv) and "millisieverts" (mSv; $1000 \mathrm{mSv}=1 \mathrm{~Sv}$ ). One sievert is equal to $100 \mathrm{rem}$. These units represent the energy of the absorbed radiation and how much damage the particular kind of radiation can produce. The allowable workplace dose from tritium radiation for a one-year period is $50 \mathrm{mSv}$ under federal regulations. The International Commission on Radiological Protection (ICRP) has recommended a reduction in the allowable annual workplace dose to $20 \mathrm{mSv}$. The average annual dose from tritium for LBNL employees who work in the NTLF, based on measurements of tritium in urine, is calculated to be $0.55 \mathrm{mSv}$. This is about 36 times lower than the annual workplace dose recommended by the International Commission. For other LBNL workers who work in Zone 1, the average annual dose from tritium, based on the 1995 measurements of tritium in urine, is calculated to be $0.0025 \mathrm{mSv}$. For LBNL workers further away from the NTLF, the dose is less. Recent results of urine analysis from five individuals working in the Lawrence Hall of Science did not show any tritium above the detection limit.

For comparison's sake, it has been estimated that the average dose of radiation over the course of one year for an individual living anywhere in the U.S. is approximately $3.6 \mathrm{mSv}$ from all natural sources of radiation [NRC, 1990]. Radon, a natural radioactive gas produced when uranium or radium decays, produces about $2 \mathrm{mSv}$, or about 56 percent of this natural radiation. Other natural sources include radioactive products created by cosmic rays, such as carbon-14, and radioactive elements, such as uranium [NRC, 1990]. In Alameda County, the contribution of radon to the total annual background radiation dose is lower-about $1 \mathrm{mSv}$ [Price and Nero, 1996]. It follows that in Alameda County the average annual background radiation dose is on the order of $2.6 \mathrm{mSv}$, or about 72 percent of the national average. 


\subsection{What are the estimated risks due to tritium exposure?}

This risk assessment calculates the probability that a health effect will occur in a group of people exposed to NTLF tritium and the probability that a particular individual in the group will suffer a health effect. Most of these probabilities are small. One way to evaluate them is to compare the magnitude of the risk between groups. Another way is to compare the risk associated with exposure to NTLF tritium with the risk associated with exposure to background radiation from natural sources.

Table 1-1 presents the estimated risks of incurring a fatal cancer, as well as of cancer incidence, due to exposure to background radiation from all natural sources in Berkeley and the U.S. This gives a baseline against which to measure the added risk incurred by workers and community members exposed to LBNL tritium, which is given in Table 1-2. These results are the subject of Sections 1.13 through 1.17.

Table 1-1

Estimated Health Risks in the Berkeley Area and in the US [in Brackets] Due to Background Radiation From Natural Sources

\begin{tabular}{|l|c|c|}
\hline \multirow{2}{*}{ Health Effect } & \multicolumn{2}{|c|}{$\begin{array}{c}\text { Berkeley Area Estimated Risk Levels } \\
\text { [U.S. Estimated Risk Levels] }\end{array}$} \\
\cline { 2 - 3 } & $\begin{array}{c}\text { Population Risk } \\
\text { (incidence per year per million } \\
\text { population) }\end{array}$ & $\begin{array}{c}\text { Individual Risk } \\
\text { (lifetime risk, chances per } \\
\text { million) }\end{array}$ \\
\hline $\begin{array}{l}\text { Cancer incidence(a) } \\
\text { Cancer mortality }\end{array}$ & $160[220]$ & $11,000[15,000]$ \\
$\begin{array}{l}\text { Severe hereditary effects } \\
\text { including genetic defects } \\
\text { developmental defects }^{(c)}\end{array}$ & $130[180]$ & $9,000[13,000]$ \\
\hline \hline
\end{tabular}

Notes to Table 1-1:

(a) In this study we develop risk factors for cancer mortality; to estimate cancer incidence from cancer mortality, we use the ratio $6 / 5$, which is the incidence/mortality ratio recommended by the International Commission on Radiological Protection (ICRP) in 1991.

(b) Genetic damage that results in one or more observable defects that are capable of being carried on to succeeding generations.

(c) Effects on the formation or development of a fetus that result in one or more observed defects that are not passed on to succeeding generations.

(d) Based on a risk factor of 0.013 severe hereditary effects per Sv (ICRP, 1991). 
Table 1-2

Estimated Health Risks Due to NTLF Tritium Releases

\begin{tabular}{|c|c|c|}
\hline \multirow{2}{*}{ Health Effect } & \multicolumn{2}{|c|}{ Estimated Risk Levels } \\
\hline & $\begin{array}{l}\text { Population Risk } \\
\text { (incidence per year in the } \\
\text { exposed population) }\end{array}$ & $\begin{array}{l}\text { Individual Risk } \\
\text { (lifetime risk, chances per } \\
\text { million) }\end{array}$ \\
\hline \multicolumn{3}{|c|}{ Zone 1 (assumes 220 people at risk) } \\
\hline Cancer incidence ${ }^{(a)}$ & 0.0004 & 60 \\
\hline Cancer mortality & 0.0003 & 50 \\
\hline Genetic defects $(\mathrm{b})$ & 0.0000009 & 0.09 \\
\hline Developmental effects (c) & 0.00002 & 2 \\
\hline \multicolumn{3}{|c|}{ Zone 2 (assumes 11,000 people at risk) } \\
\hline Cancer incidence $(a)$ & 0.001 & 6 \\
\hline Cancer mortality & 0.0009 & 5 \\
\hline Genetic defects $(b)$ & 0.000003 & 0.005 \\
\hline Developmental effects $(c)$ & 0.00006 & 0.1 \\
\hline \multicolumn{3}{|c|}{ Zone 3 (assumes 110,000 people at risk) } \\
\hline Cancer incidence $(a)$ & 0.002 & 0.9 \\
\hline Cancer mortality & 0.001 & 0.7 \\
\hline Genetic defects $(\mathrm{b})$ & 0.000004 & 0.0008 \\
\hline Developmental effects (c) & 0.0001 & 0.02 \\
\hline
\end{tabular}

Notes to Table 1-2:

(a) In this study we develop risk factors for cancer mortality; to estimate cancer incidence from cancer mortality, we use the ratio $6 / 5$, which is the incidence/mortality ratio recommended by the ICRP (1991).

(b) Genetic damage that results in one or more observable defects that are capable of being carried on to succeeding generations.

(c) Effects on the formation or development of a fetus that result in one or more observed defects that are not passed on to succeeding generations. 


\subsection{What is the likelihood that a worker or community member will suffer a health effect as a result of exposure to background natural radiation?}

The risk estimates in the tables are presented in two ways, as individual risk and population risk. Individual risk quantifies the increased likelihood that one person, in a lifetime, would suffer the particular health effect. Table 1-1 shows that every person in the U.S. has an increased risk of 15,000 chances in a million (1.5 percent) of incurring cancer in his or her lifetime due to exposure to the current concentration of background radiation from natural sources in the environment. Individuals in the Berkeley area have an increased risk of 11,000 chances in a million (1.1 percent) of incurring cancer in their lifetimes.

Population risk quantifies the occurrence of the health effect to be expected per year for a given population size. The population risk is based on the collective dose among a number of individuals instead of the dose to one individual. The population risk is determined by multiplying a representative annual average dose for each group of individuals at risk (infants, workers, residents, etc.) by the number people in that group and by a risk factor for a particular health outcome (cancer mortality, genetic defects, or developmental effects). In Table 1-1, the value of 160 for population risk means that for every million people exposed to background radiation in the Berkeley area, it is estimated that there will be 160 cancers each year resulting from exposure to background natural radiation.

\subsection{What are the risks from LBNL tritium to workers near the NTLF?}

Compared to a person not exposed to NTLF tritium, an individual worker in Zone 1 is predicted to have an increased likelihood of 60 more chances out of a million or $(0.006$ percent) in his or her lifetime to incur cancer as a result of exposure to NTLF tritium (see Table 1-2). This risk is less than 1 percent of the risk from background radiation of 11,000 chances in one million.

An additional risk not shown on Table 1-2 is that a child born to a woman who works in Zone 1 during pregnancy and while nursing the child has an estimated increased cancer risk of eight chances in a million over a child born to a mother who works elsewhere. This estimated risk assumes transfer of tritium from the pregnant mother to the fetus and subsequently to the child throughout two years during which the child consumes only the mother's milk. This scenario is hypothetical and has no basis of measurement data. It is used to make the risk assessment conservative and health protective. 
Assuming a population of 200 people working in Zone 1 with an assumed 20 nursing infants, the likely increased cancer incidence is far less than 1 per year $(0.0004$ estimated case per year).

\subsection{What are the risks from LBNL tritium exposure to other LBNL workers and nearby facilities and residences?}

An individual who works or resides in Zone 2 has a risk estimated to be six chances out of one million of incurring a cancer as a result of exposure to NTLF tritium (see Table 1-2). This risk is about 0.05 percent of the risk from background radiation of 11,000 chances in one million.

A conservative estimate of increased incidence of cancer for the population of 11,000 people who work or reside in Zone 2 is far less than 1 per year $(0.001$ estimated case per year).

\subsection{Does LBNL tritium make it risky to live in Berkeley, or to wade or swim in Strawberry Creek or relax along its banks?}

For Zone 3, the risk assessment considered two possible means of exposure to NTLF tritium: (1) Tritiated water carried by the wind to the population on or near the UC Berkeley campus and to Berkeley Hills residents living beyond Zone 2, and (2) tritiated rain water washed down Strawberry Creek. People could inhale tritiated water that evaporates into the air around Strawberry Creek, or absorb tritiated water when wading or swimming in the creek. Tritiated water is only present in the creek for short time periods, when rain washes tritium from the air around the NTLF into surfacewater runoff that is carried down the creek. However, the risk assessment assumed that everyone in the exposed population wades or swims in the creek for two hours, 30 times per year, and that tritiated water is present on a year-round basis.

An individual who spends time in Zone 3 has an added risk estimated to be 0.9 chances out of one million to incur a cancer as a result of exposure to NTLF tritium (see Table 1-2). This risk is about 0.008 percent of the risk from background radiation of 11,000 chances in one million.

For an assumed population of 110,000 people in Zone 3, the increased cancer incidence is far less than 1 per year ( 0.001 estimated case per year). 


\subsection{Is it more likely that this study overstates or understates risk?}

As indicated in Section 1.10, this risk assessment assumes that low-dose radiation does affect health. The health risk estimates here are extrapolated from effects observed only at high-dose levels. At lower dose exposures, health effects may occur at lower rates or may not occur at all. In the health physics community it has been observed that radiation damage from chronic low doses can be repaired naturally. Such chronic doses are believed to result in a smaller biological effect than is estimated from linear models that extrapolate from high-dose effects.

Every risk assessment makes assumptions in order to estimate future concentrations and exposures for the time periods over which risk is evaluated. For example, the emissions from the NTLF used to calculate tritium concentrations in all three zones is 100 curies (Ci) per year, which is slightly less than the average release from the NTLF since 1970 (138 Ci per year). The effects are discussed in Appendix D. In 1995 LBNL made permanent changes in NTLF operation, and the emissions in 1995 were $50 \mathrm{Ci}$ [Thorson, 1996]. Future emissions are expected to stay at or below this level. Other assumptions of this study may result in an overestimate of risk, as follows:

- Individual risk for Zones 2 and 3 is calculated for residential exposure; i.e., an average exposure of 12 to 24 hours per day for 70 years.

- Estimated populations at risk (220 in Zone 1; 11,000 in Zone 2; 110,000 people on or near the UC Berkeley campus in Zone 3) are assumed to be in these areas every working day for 40 years for working populations, and every day of the year for 70 years for residential populations. It is likely that these numbers include people who are present in these zones for much less time.

- It is assumed that half of the population are women, that each of these women bears two children, and nurses each child for two years.

- Tritium content in garden produce in Zones 2 and 3 has been measured, and so far tritium is found below the detection level. However, because the uptake is theoretically possible, the risk assessment assumes that all 4,000 residents in Zone 2 and all 100,000 adults in Zone 3 eat tritium-contaminated garden produce on a regular basis, even though only a few of that population are residents with gardens.

- It is assumed that all 110,000 people of Zone 3 are in the $90^{\circ}$ sector with the highest estimated tritiated water concentrations in air.

- The risk assessment assumes that all 100,000 adults in Zone 3 wade in Strawberry Creek for two hours on a 30 days per year basis.

- The risk values are based on model estimates of tritium levels. Appendix F describes the dose based on urinalysis for workers over a four-month period 
in 1995. These data were not available when this risk assessment was initially conducted. The estimated dose are greater than that from urinalysis.

These assumptions cause the risk assessment to overestimate risk. It should be noted that in the areas of highest potential exposure to NTLF tritium, LBNL does not rely on assumptions. NTLF staff exposure is measured each week and stack emissions are monitored continuously. LBNL has always maintained exposures well below the regulatory levels. Any increase of emissions will be detected immediately and corrective action will be taken to avoid increasing risk to workers and the public.

LBNL's environmental monitoring and oversight activities continue to assure that emissions from the NTLF stack and tritium levels detected in the environment stay below required levels. For example, in 1995, a tritium alarm was added that allowed off-hours monitoring by the LBNL Fire Department. Two significant engineering changes during 1995 included the addition of redundant valving on vacuum pumps close to the tritium source, and the replacement of the existing silica gel traps with broader traps which give the same flow, but have a higher HTO trapping efficiency. These and other engineering improvements have markedly diminished HTO releases from the NTLF, especially during the latter half of 1996. It is expected that the benefits of these changes will be realized in the future. Releases of tritium in 1996 have been at the same low rate measured in the last half of 1995.

\subsection{Does LBNL tritium pose a significant risk to workers and the community?}

To answer this question, let us first have a look at the comparison of people's estimated dose from NTLF tritium with those regulatory limits in Table 1-3

Table 1-3

Comparison of Estimated Does from NTLF with Regulatory Limits

\begin{tabular}{|l|c|c|c|}
\hline & \multicolumn{3}{|c|}{ Tritium Exposure Does (mSv/year) } \\
\cline { 2 - 4 } & from NTLF & $\begin{array}{c}\text { Federal \& } \\
\text { State Limits }\end{array}$ & ICRP Limits \\
\hline Zone 1 & $0.024^{\text {(a) }}$ & $0.1^{\text {(b) }}$ & $1^{(c)}$ \\
\hline Zone 2 Workers & 0.0013 & $0.1^{(b)}$ & $1^{(c)}$ \\
\hline Zone 2 Residents & 0.0014 & $0.1^{(b)}$ & $1^{(c)}$ \\
\hline Zone 3 & 0.0002 & $0.1^{(b)}$ & $1^{(c)}$ \\
\hline
\end{tabular}

Notes to Table 1-3:

(a) The dose based on the 1995 urine analysis is about 10 times less than this estimated value.

(b) For inhalation only. (c) For all pathways 
We may find that the exposures to tritium from the NTLF are generally several orders of magnitude lower than the regulatory limits. Using this table and the following comparison with risks due to background radiation, one may figure out how insignificant the added risk from NTLF is.

The estimated added lifetime cancer risk of 60 chances per million resulting from NTLF tritium for workers near the NTLF is very small-less than 1 percent of the risk of 11,000 chances per million resulting from background radiation. By contrast, background radiation in California can differ by as much as 30 percent from one region to another. The increased risks are much smaller-and no greater than 0.1 percent of background-for individuals who work elsewhere at LBNL, who live or work near the LBNL facility, or who use the UC Berkeley campus area.

There is no way to compare these risks directly with the value of the research conducted at the facility. This is an evaluation that the community and LBNL workers must make. The risk assessment conclusions suggest that the community and workers are supporting an important effort by accepting a relatively low level of added risk.

\subsection{How reliable is this risk assessment?}

To examine the validity and reliability of the results of this risk assessment, we have compared the exposure concentrations used in the risk assessment model (as input data) with available measured values. The ratios of input exposure concentrations to measured data are given in Table 1-4. Details of all numbers are given in Appendix F. In general, the used values are greater than the corresponding measured values. In other words, the input data are generally conservative in the direction of producing larger risk.

Table 1-4

Ratio of Input Data to Measured Data

\begin{tabular}{|l|c|c|c|}
\hline \multirow{2}{*}{} & \multicolumn{3}{|c|}{ Ratio of Input Data to Measured Data } \\
\cline { 2 - 4 } & Zone 1 & Zone 2 & Zone 3 \\
\hline Air concentrations & 4.0 & 1.2 & - \\
\hline Rain water & 5.5 & 6.5 & - \\
\hline Surface water & 5.8 & 3.2 & 1.1 \\
\hline Soil and sediments & 4.0 & 3.0 & - \\
\hline Ground water & 2.1 & 4.8 & - \\
\hline Vegetation (free water) & 0.84 & 1.1 & - \\
\hline Body water levels & 9.8 & 1.4 & - \\
\hline \hline
\end{tabular}


The output (calculated risk) in Zone 2 of the model used for the risk assessment was also compared with that given by an independent EPA-approved model, CAP88-PC. The agreement between the two results is very good. Due to the inherent assumptions used in the CAP88-PC model, it is not appropriate for Zone 1 because of the proximity to the source and the complexity of the terrain, and Zone 3 because its non-realistic dose calculation for ingestion.

\subsection{Organization of the rest of this report}

Section $1 \mathrm{~A}$ is a summary of how this version of the risk assessment was revised to address the comments received on the October 1995 draft version.

The remainder of this report consists of three chapters and nine appendices, followed by a glossary and references. Chapter 2 contains information about the nature of radiation and about the use of tritium at LBNL. Chapter 3 is an overview of the way in which the risk assessment was conducted. Chapter 4 is an in-depth discussion of the risk assessment calculations. Appendix A explains the compartment model used for much of the risk assessment to estimate the distribution of tritiated water in the environment. Appendix $B$ explains how numbers were derived for use in exposure calculations. Appendix $C$ gives the values used for environmental parameters. Appendix D explains how the effects of higher NTLF emissions from 1982 through 1989 were accounted for in the risk assessment. Appendix E provides a brief review of the EPA CAP88 computer model that was also used to assess tritium concentrations. Appendix E also lists computer-generated values from CAP88. Appendix F is a summary of how the input data used in the risk assessment compare to measured values of tritium found in the LBNL environment and by urine analysis from LBNL employees. These data were obtained in 1995 and were not available when this risk assessment was drafted in 1994-95. Appendix $G$ is a conversion table that gives US unit equivalents to the SI units used in this report. Appendix $\mathrm{H}$ contains comments from regulatory agencies on the draft of this risk assessment issued in October of 1995. Appendix I contains LBNL's 1993 fact sheet, "Questions and Answers About Tritium." Copies of the reviewers' letters regarding the final draft of the report are given in Appendix J. 


\section{Chapter 1 Annex}

\section{Response to Review Comments}

The draft version of this risk assessment was reviewed by the California Department of Health Services; the U.S. Department of Health Services-Agency for Toxic Substances and Disease Registry; and the U.S. Environmental Protection Agency Region 9. Copies of their comments are contained in Appendix $\mathrm{H}$ of this report. Our responses to their comments are given in this Annex. Page references are to the draft version.

\section{A.1 Radiological Health Branch, California Department of Health Services}

\section{Comment 1}

(1) The dose and risk estimates in Tables 1-2, 4-12, 4-13 and 4-14 are confusing and not demonstrated by Step-by-Step calculations in the report. Risk values in Table 1-2 do not match those in Table 4-12. References for cancer models should be footnoted with Tables. Cancer incidence estimates should be listed along with cancer mortality. The footnote on page 3-1 seems to be out of place.

Response

We have added Section 4.7.6, including a table (4-15) that gives step-by-step calculations. This section summarizes how the environmental concentrations convert to human exposure, dose, and risk. The table is cross-referenced to risk-assessment sections, equations and data used to make the transition from one stage of the calculation to the next. 
Some risk values in Table 1-2 of the draft risk assessment were based on urine data and not on the model predictions used in Table 4-12. Since the model has been compared and reconciled with the urine data, we now use the somewhat higher risk levels predicted by the model in both tables.

Cancer incidence as well as risk levels are now included in the report. The footnote on page 3-1 has been removed.

\section{Comment 2}

(2) Comparison of annual exposures and associated risks to consensus standards is not consistent throughout the report.

Response

The report has been revised so that comparison to DOE regulations is provided consistently throughout the report.

\section{Comment 3}

(3) The atmospheric exposure pathway is only considered for Zones 1 and 2, but not Zone 3 west of Building 75. Since predominant winds are in the easterly direction airborne monitoring east of Building 75 would provide useful data for pathway analysis and dose assessment.

\section{Response}

We have added consideration of the air dispersion from NTLF to Zone 3 in Section 4.7.1.5 of the revised risk assessment.

In 1995 LBNL set up a network of eight sampling locations for collecting air samples for atmospheric tritium analysis, three onsite and five offsite. These locations are identified in Figure 4-1 of the 1995 LBNL Site Environmental Report [Thorson, 1996]. None of the current off-site sampling locations are due east of LBNL. However, rainwater is collected at six locations on site and analyzed for tritium. One of the rain water sampling locations is due east of the NTLF. Rain water sampling locations are identified in Figure 5-1 of the 1995 LBNL Site Environmental Report [Thorson, 1996]. Air and rain water sampling locations are selected to monitor those areas where predominant winds and residential and working populations coincide. The land east of LBNL belongs to the Regents of the University of California and is mostly open space. A discussion and analysis of the measurements obtained from the air and rain water tritium sampling network has been included in Appendix $F$ of the revised risk assessment. 


\section{Comment 4}

(4) It is not clear how the transfer of rain water and runoff to the upper watershed of Strawberry Creek is used in the risk assessment.

\section{Response}

To make this clear, we have added text to the beginning of Section 4.7.1.5, where this transfer is used to characterize tritium concentrations in Zone 3:

\section{Comment 5}

(5) Since the Agreement-in-Principle with DOE is terminated, the reference regarding Department of Health Services (DHS) oversight in section 1.16 should be clarified.

Response

Since the issue of oversight is not relevant to the risk assessment, and since the Agreement-in-Principle with DOE is terminated, we have elected to delete the paragraph describing the oversight role of DHS.

\section{Comment 6}

(6) No conclusion is made in Appendix D regarding the legacy of past elevated HTO emissions.

\section{Response}

We have revised Appendix $\mathrm{D}$ and added a conclusion section discussing the difference between the assumed release rate of $100 \mathrm{Ci} / \mathrm{y}$ and the average long-term release rate from the period 1970 to the present.

\section{Comment 7}

(7) It may be necessary to address the dose/response assessment to accidental releases. Response

Section 3.3 has been added to Chapter 3 to address the issue of accidents. 


\section{Comment 8}

(8) There is no discussion or comparison of the results in Appendix F (Appendix $E$ in final) and the results in Tables 1-2, 4-12, 4-13, and 4-14.

\section{Response}

We have added a section to Chapter 1 that compares the results in Appendix $\mathrm{E}$ (the old Appendix F) to the results in Zone 2, and discusses issues in the other two zones.

\section{A.2 Agency for Toxic Substances and Disease Registry}

\section{Comment 1}

(1) On page 1-8, 3rd paragraph, it would be prudent to describe what is meant by "high levels of radiation from HTO."

\section{Response}

In order to define what we mean by "high levels of radiation," we have added material to the paragraph in question.

\section{Comment 2}

(2) On page 1-8, 4th paragraph, the conclusion that there is no experimental evidence in animals for HTO genetic effects is questionable. The reference on this issued should be checked and verified.

\section{Response}

The reference for this statement is "Tritium Risk Assessment," by T. Straume (1993). This paper is included in the list of references.

\section{Comment 3}

(3) Section 1.10. Clarify the discussion on workplace exposure to distinguish internal and external doses.

Response

We have clarified the discussion here to indicate that all tritium exposures are internal exposures. 


\section{Comment 4}

(4) Table 1-1, in preparing this table, the authors should review the United Nations UNSCEAR 1993 report for genetic effects and developmental effects that can be passed to successive generations (severe and heritable genetic effects).

\section{Response}

The UNSCEAR 1993 report uses the 1990 (ICRP-60) recommendations for heritable genetic effects and developmental effects. In these recommendations, the rate of heritable genetic effects within an exposed population is 0.013 per Sv. Using this factor, a calculated severe hereditary effect is added to the table.

\section{Comment 5}

(5) Page 4-5, the numbers here suggest a weighting factor [RBE] for tritium that is at the high end. Provide the public with some information here about what this means. Also, use microsieverts consistently throughout this paragraph instead of switching between sieverts and microsieverts.

\section{Response}

We have added a sentence to make clear the RBE that is implied here and have made sure that microsieverts are used consistently in this paragraph.

\section{Comment 6}

(6) Page 4-11, Section 4.5. Consider adding the pica (dirt-eating) child as an exposure scenario to this section.

Response

We did not and will not consider the dirt-eating child as an exposure scenario because, whatever one may take into consideration (air, soil, surface water or vegetation), what actually matters when it comes to tritium measurement is the equivalent water intake. The dirt-eating child may consume one gram (maybe even as much as 10 grams) of soil a day (long-term average). Soil contains about 10 to 20 percent water by mass;

therefore, the total intake of water ingested amounts to less than one gram per day. The amount of air inhaled by this child is $10 \mathrm{~m}^{3}$ and contains about 100 grams of water. By considering inhalation, we have already taken credit for about 100 times the amount of tritium a child could possibly take in from soil. 


\section{Comment 7}

(7) Section 4.5.1, the material on dermal uptake is confusing-what is the effective permeability of the system; does $\mathrm{Ci} / \mathrm{Ck}$ incorporate the surface area available for absorption; where do equations 4-8 and 4-9 enter into equation 4-7?

\section{Response}

Sections 4.5.1 and 4.5.2 have been revised to make them less confusing.

\section{Comment 8}

(8) Page 4-19, second paragraph, update the discussion here to make clear that 10 CFR 20 limits annual worker exposure to $50 \mathrm{mSv}$ from both internal and external sources and limits annual public exposure to $1 \mathrm{mSv}$ from all exposure routes.

Response

We have updated the discussion to make this clear.

\section{Comment 9}

(9) Page 4-20, Section 4.6.4

Studies showing deleterious effects from tritium uptake were in the million Bq per liter range. These ranges may not be applicable to the concentrations around the LBNL tritium facility. You may want to consider this in the discussion of doses expected at the LBNL site.

Response

We have added a few sentences here discussing this issue.

\section{Comment 10}

(10) Section 4.7.1.1, Is the source term release fairly uniform over a one-year period or are there short periods of time that account for the majority of the tritium release?

Response

The source term is rather uniform throughout the year. The weekly measurements in tritium emission have shown that: (1) there is release every week, and (2) the week-to- 
week variation of emission is within a factor of two of the average weekly release for about $60 \%$ of the time.

\section{Comment 11}

(11) Section 4.7.2.1, is it appropriate to use the resting inhalation rates for average in inhalation rates?

\section{Response}

As the equation and discussion now make clear, we use an active or working breathing rate for 16 hours of the day and only use the resting breathing rate for an eight-hour period at night when people are assumed to be sleeping. These assumptions result in air intakes of over $20 \mathrm{~m}^{3}$ per day, which have recently been shown to be conservative by almost a factor of two, since metabolically adjusted breathing rates are more typically in the range of 10 to $15 \mathrm{~m}^{3}$ per day.

\section{A.3 US Environmental Protection Agency, Region IX Office in San Francisco}

\section{Major Concerns}

\section{Comment A}

(A) Use cancer incidence and not fatal cancers as a measure of risk.

\section{Response}

We have revised the report to include both cancer incidence and fatal cancer.

\section{Comment B}

(B) Use reasonable maximally exposed individual instead of an average individual.

\section{Response}

In the revised report we have altered the calculations to address the reasonable maximally exposed individual. 


\section{Comment C}

(C) Use concentric circles around the source instead of special partial circles.

\section{Response}

This change has been made in the revised report.

\section{Comment D}

(D) Urine samples are used in place of the model to estimate risk in Zone 1, but the authors provide little detail on how the urine analysis was carried out and converted to dose and risk.

\section{Response}

We have revised the report so that model exposures are used consistently for all three zones. Urine analysis is used for comparison purposes only (see Table F-1). In Appendix F measured air levels are compared to predicted levels, measured soil and water levels are compared to predicted levels, and predicted tritium body burdens are compared to the urine analysis results for people in Zones 1 and 2 .

\section{Minor Concerns}

\section{Comment 1}

(1) Why use world background radiation instead of background radiation for the Berkeley area?

Response

In the revised report, we compare our exposure estimates to background radiation in the Berkeley area.

\section{Comment 2}

(2) There is confusion about population dose and its significance. Authors should discuss the collective dose concept instead of multiplying the individual dose by 70 years and the population (i.e. in Table 1-1). 
Response

To address this comment, we have added text to Section 1.12 .

\section{Comment 3}

(3) The authors assume swimming in Strawberry Creek for one hour, fifteen days per year. This may be OK for an average, but is not for the maximally exposed individual.

\section{Response}

In the revised report, we assumed two hours of swimming at a time, 30 days per year.

\section{Comment 4}

(4) In Table 1-2, it is not clear how individual risk relates to population risk. This reviewer cannot determine the significance of individual risk. It is not for the maximally exposed individual.

\section{Response}

As is noted above, we have added text in Section 1.12 describing the difference between individual risk and population risk. In addition, we have added a summary table in Chapter 4 that provides a Step-by-Step review of the individual risk calculation. As is made clear below, our risk analysis as provided in the revised report does strive to estimate risk for the reasonable maximally exposed individual.

The first step of our analysis is to characterize the concentration of tritium in air, water, and soil of the proximate NTLF environment. The model reproduces the upper range of tritium concentrations that have been measured in the environment near the NTLF site. In air, tritium concentrations have been measured in the range of 10 to $100 \mathrm{~Bq} / \mathrm{m}^{3}$; in ground water and surface water runoff (hydraugers and streams) 40 to $800 \mathrm{~Bq} / \mathrm{L}$ have been measured; and in rainwater 60 to $733 \mathrm{~Bq} / \mathrm{L}$ have been observed [Schleimer and Pauer, 1991]. The reasonable upper bound tritium concentrations in each of the three exposure zones are estimated using the transport models described below. These concentrations are compared to recently measured values in Appendix F.

\section{Comment 5}

(5) Is the model described in the report one developed at LBNL or is it a standard program that is not referenced. 


\section{Response}

In order to address this comment we have added text to Section 4.7 .1 of Chapter 4 .

\section{Comment 6}

(6) In Section 4.7.1 it is stated that average tritium concentrations are used in each zone. The highest reasonable concentrations should be used.

\section{Response}

Since we have revised the assessment to determine reasonable maximum doses, the first paragraph of 4.7.1 has been revised. 



\section{Chapter 2}

\section{Radiation and Tritium Use at the NTLF}

Tritium (referred to as $T$ in this document) is the radioactive isotope of hydrogen. It is used at the NTLF for beneficial medical research. This chapter explains in general what radiation is and what its biological effects are, what tritium is, and how it is used at the NTLF.

\subsection{What Is Radiation?}

Radiation is defined as the emission and propagation of energy. ${ }^{1}$ Also, the energy emitted is called radiation. There are three major types of radiation: electromagnetic, acoustic, and particle. The types of radiation associated with radioactive elements are particle radiation and electromagnetic radiation.

Particle radiation consists of particles that have been ejected from atoms. An alpha particle is a heavy particle composed of neutrons and protons. It can be stopped by a sheet of paper and is not likely to penetrate the outer layer of our skin. A beta particle is a high-speed electron. Beta particles are more penetrating than alpha particles. Depending on the energy of the beta particle, it can go through up to two centimeters of living tissue. Beta particles from tritium are not very energetic and cannot penetrate clothing or skin; however, once tritium is inside the body even this minimal penetration energy could be enough to damage tissue.

Electromagnetic radiation includes visible light as well as unseen radiation such as radio waves, $x$ rays, and gamma radiation. Certain radioactive elements give off gamma radiation. Gamma radiation travels at the speed of light and is extremely penetrating.

Because of their ability to cause changes in the ionization (i.e., chemical bonding characteristics) of atoms and molecules, alpha, beta, and gamma radiation are called

${ }^{1}$ Material in this section is based on the book Radiation Doses, Effects, Risks (UNEP, 1985). 
ionizing radiation. Ionizing radiation (see Figure 1-2) can also cause chemical changes in cells through excitation, dissociation, and atom displacements. These chemical changes can lead to cancer, genetic defects, and developmental and reproductive effects.

An element is radioactive if its individual atoms are undergoing decay, throwing out energy and matter from their nuclei in the form of ionizing radiation, and, in the process, changing into a different element or a different isotope of the same element. This decay process goes on continuously, but at different (though specific) rates for different radioactive elements and isotopes. The decay rate of a radioactive element or isotope is expressed in terms of its half-life. A half life is the amount of time it takes for half the atoms in a quantity of an element or isotope to decay. The number of individual atomic decays that take place each second is called the activity, and is measured in becquerels or curies. A curie (Ci) is equal to $37,000,000,000$ (37 billion) becquerels (Bq).

\subsection{Tritium}

Tritium has a radioactive half life of 12.3 years. When tritium undergoes radioactive decay, it is transformed into nonradioactive helium through emission of a beta particle from its nucleus. Tritium's beta particles have a very low penetrating ability-not enough to penetrate skin. Thus, as long as it is outside the body, tritium represents little or no hazard.

However, because tritium has physical properties that are similar to hydrogen's, it acts much like hydrogen in the environment and the human body. Like hydrogen, it can be ingested, inhaled, or absorbed through the skin .

Tritium is found in the environment in three principal forms-molecular tritium $\left(\mathrm{T}_{2}\right.$ or $\mathrm{HT}$ ), tritiated water ( $\mathrm{HTO}$, as opposed to $\mathrm{H}_{2} \mathrm{O}$ ), and organically bound tritium (OBT) in which it is chemically bonded to organic molecules. Tritiated water is the most abundant chemical form of tritium in the environment.

The properties of HTO are very similar to water. Because the difference in atomic weight between $\mathrm{HTO}$ and $\mathrm{H}_{2} \mathrm{O}$ is small, they are actually more similar than tritium and hydrogen. HTO is much more readily taken up by organisms and environmental media than molecular tritium.

OBT forms when organic molecules are exposed to tritium gas or HTO. This could happen in the human body or through uptake of HTO by plants. OBT has a different metabolism than HTO and can be retained in the body for somewhat longer periods. 


\subsubsection{Sources of Environmental Tritium}

Tritium is continuously released to the environment from both natural and man-made sources. Cosmic ray reactions with molecules in the upper atmosphere are the primary natural source of tritium. The earth's crust also contributes a minor amount of tritium to the global inventory, but in recent decades human contributions have far exceeded those of natural sources. In particular, atmospheric tests of nuclear weapons in the 1950 s and 1960s produced a large portion of the tritium now in the environment. (Fortunately, this inventory will continue to decrease by $50 \%$ every 12.3 years as long as no more nuclear weapons are tested.) Tritium from underground testing is considered an unlikely source of atmospheric tritium.

Other smaller human contributions to environmental tritium include normal and accidental releases of tritium from nuclear reactors, and consumer products such as marine compasses (containing an activity of about $0.5 \mathrm{Ci}$ ), luminous dials on watches, and self-illuminated exit signs (containing an activity of about $20 \mathrm{Ci}$ ) in buildings.

The combined global inventory of natural and human tritium emissions is about 50 times greater than tritium levels from natural sources alone. The resulting estimated average concentration of tritiated water in the earth's waters is $0.00000027 \mathrm{Ci} / \mathrm{m}^{3}$ (or $10 \mathrm{~Bq} / \mathrm{L})$.

\subsubsection{Health Effects of Tritium}

According to Straume [1993] few studies are available on tritium-induced health injury in humans. Health-risk estimates for tritium are therefore based on the large number of experiments with animals and cell cultures. These experiments show that exposure to tritiated water results in mutations and cell disruptions that can lead to the health effects possible for ionizing radiation-cancer, heritable genetic effects, and reproductive and developmental effects.

These health risks are associated with exposures to tritium through inhalation, ingestion of HTO or OBT, or absorption of HTO through the skin. The health effects of ionizing radiation are proportional to the energy carried by the radiation and delivered to living cells.

\subsubsection{How People Come in Contact with Tritium}

Because the energy of electrons emitted during the decay of the tritium nucleus is insufficient to penetrate skin, this report does not address external radiation exposure, but only internal dose routes. The following exposure pathways were considered: 
- Tritiated water vapor entering the body through respiration

- Tritium ingested with water during swimming or wading, home-grown foods, or breast-milk (in the case of infants) and absorbed into the body through the gastro-intestinal tract

- Tritium from tritiated water vapor in air taken through the skin

- Tritium from tritiated water in surface water taken through the skin during activities that involve dermal contact with the contaminated water, i.e., washing, swimming, and wading in surface water

- Tritium transferred from the body water of pregnant women to the developing fetus

\subsubsection{Potential Risks}

When tritiated water enters the body it acts just like normal water, spreading throughout the body and delivering a uniform radiation dose to all soft tissues. Using the modeling techniques discussed in Chapter 4, we determined that it takes about 10 days for half the intake or uptake of tritiated water to be discharged out of the body. This period is called the biological half life. For tritium that is ingested as OBT (e.g., from garden vegetables grown by residents of Zone 2), the biological half-life is on the order of 48 days.

\subsection{Tritium Use at the NTLF}

The NTLF is the only facility at LBNL that uses tritium in significant quantities, and accounts for almost all airborne tritium releases from LBNL. The NTLF occupies Building 75 on the LBNL site (see Figure 1-1).

\subsubsection{Tritium Labeling}

Biomedical researchers use tritium labeling to investigate administration, distribution, metabolism, and excretion characteristics of new pharmaceuticals, among many other applications. These investigations are carried out on cell systems, not animal or human subjects. More than 250 users have visited the NTLF since 1982 to label almost 500 compounds.

Tritium labeling is unique, as well as cost effective and precise, in its ability to reveal individual steps in chemical reactions as well as their yields. The tritium labeling process replaces hydrogen atoms with tritium atoms in the molecule to be studied. The labeled molecules are radioactive and therefore readily identified and traced. 
The NTLF provides important public health benefits. In addition to its tritium labeling operations, the NTLF is a research facility. Collaborative research projects initiated over the past three years have shown new ways to use tritium labeling to study cell metabolism and biomolecular structure and function. NTLF staff members are active in publishing articles and reports on these and other subjects and in presenting their work at scientific conferences.

\subsubsection{Tritium Releases at the NTLF}

Like hydrogen, the tritium molecule's small size allows it to diffuse easily through all kinds of materials. This makes it difficult for a system to be fully resistant to tritium leakage. NTLF design and operations provide multiple layers of defense to restrict the release of tritium to the environment. From 1970 to 1995 tritium releases from the NTLF averaged $138 \mathrm{Ci} / \mathrm{yr}$. In 1990 an emissions reduction plan was implemented that has substantially reduced annual emissions (see Figure 2-1 and Appendix I).

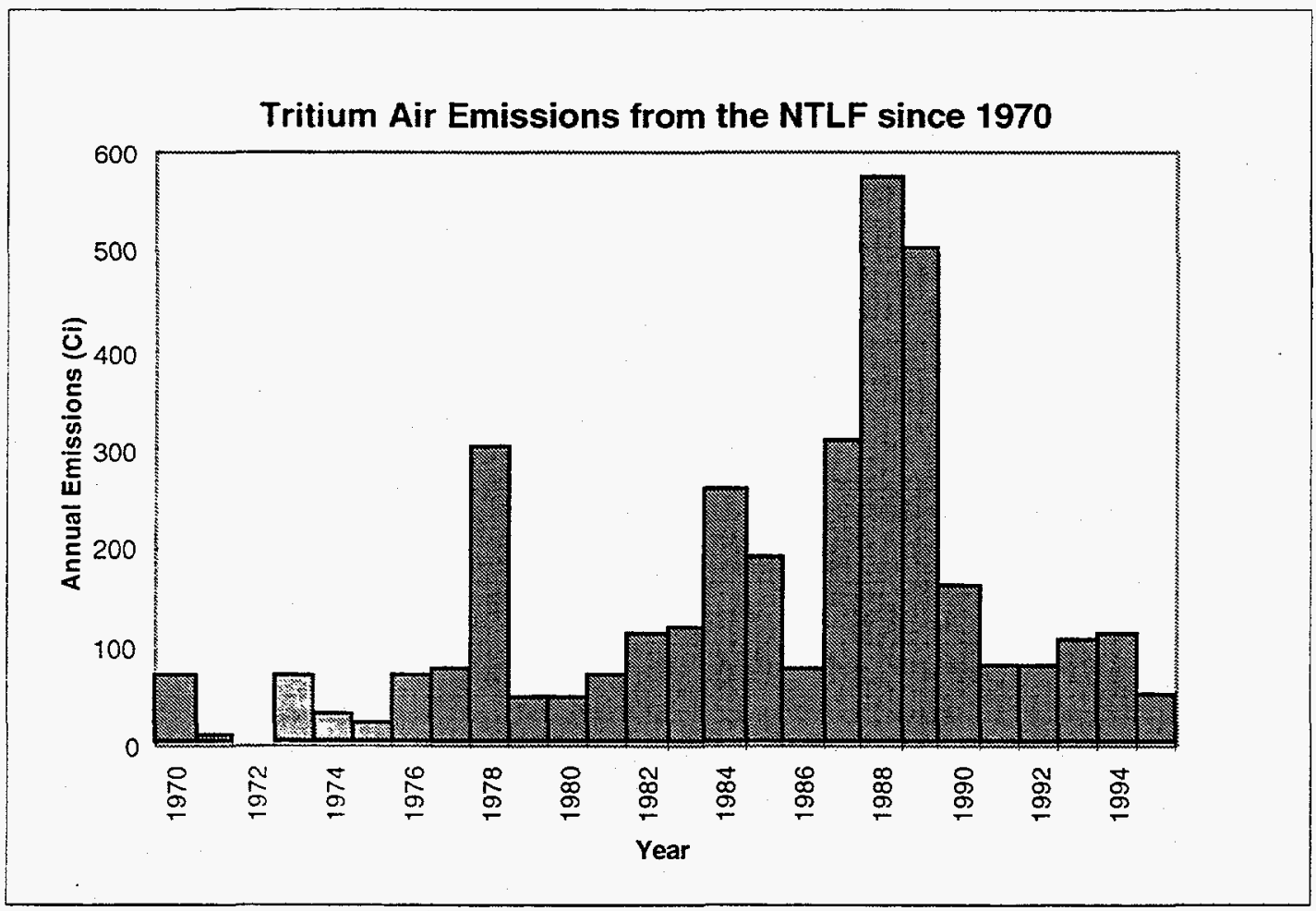

Figure 2-1. Annual releases of HTO from the NTLF. 



\section{Chapter 3}

\section{How the Risk Assessment Was Done}

This chapter looks at the methods and assumptions behind the tritium risk assessment. Please see chapter 4 for more detailed information, equations that show how the risk assessment was carried out, summaries of the data used in the analysis, and a description of the models and methods used to quantify both risks and uncertainties.

\subsection{General Approach}

In each of the three defined zones risk levels for three effects (fatal cancers, heritable genetic effects, and reproductive and developmental effects) were estimated on the basis of a continuous tritium release of 100 curies per year. To find the risk levels associated with larger or smaller releases, multiply this report's risk levels by the ratio of the larger or smaller release (in curies) to the assumed 100 curie release for the year of assessment. Health impacts of accidental releases are beyond the scope of this report.

\subsection{Computer Modeling Used in the Risk Assessment}

The risk assessment used computer models to simulate tritium releases from the NTLF for both current and past levels. These models simulate the system and process that account for the known or inferred properties of tritium exposure and health risk. The primary goal of the models was to determine how tritium could spread out from the point of release, and, specifically, how tritium will: 
- Remain or spread within the envelope of air to which it is released.

- Be transported to other parts of the environment by natural events such as wind dispersion, evaporation, precipitation.

- Be physically transformed by radioactive decay.

There are two risk assessment calculations provided in this report. In the main body of the text we provide a risk assessment based on a mass-balance box model, and in Appendix E we provide the results of a risk assessment carried out using the U.S. EPA CAP88 model. These two assessments came up with very similar results in Zone 2 . In Zone 1 the EPA model predicts lower risks and was not used in this Zone. The estimates of risk in Zone 3 are based primarily on the concentrations from the CAP88 model in Appendix E combined with the uptake dose model developed for Zone 2.

The models characterize the contamination of air, surface water, soils, and plants adjacent to the NTLF. Estimates of corresponding doses and risks to human populations are based on these contamination levels. The models were validated by comparing model predictions of tritium levels in air, water and soil with corresponding field data obtained in 1995.

The model used to characterize the spread of tritium includes two major componentsair and soil. Water and vegetation as exposure media are assumed to be in equilibrium with air and/or soil. This "two-compartment" structure was applied in two of the exposure zones (zones 1 and 2). The air compartment is represented by a box that receives the NTLF air emissions as well as emissions from soil and vegetation that have retained tritium from previous emissions. Losses from air include deposition to soil, wind-driven convective losses, and radioactive decay. The soil compartment represents the surface layer of soil that receives tritium as deposition from air. Losses from soil include diffusion to air, diffusion and infiltration to deeper soil layers, runoff to surface water, and radioactive decay. Landscape, climate and hydrology parameters used in the analysis are derived from site-specific information. Figure 3-1 illustrates the compartment model. 


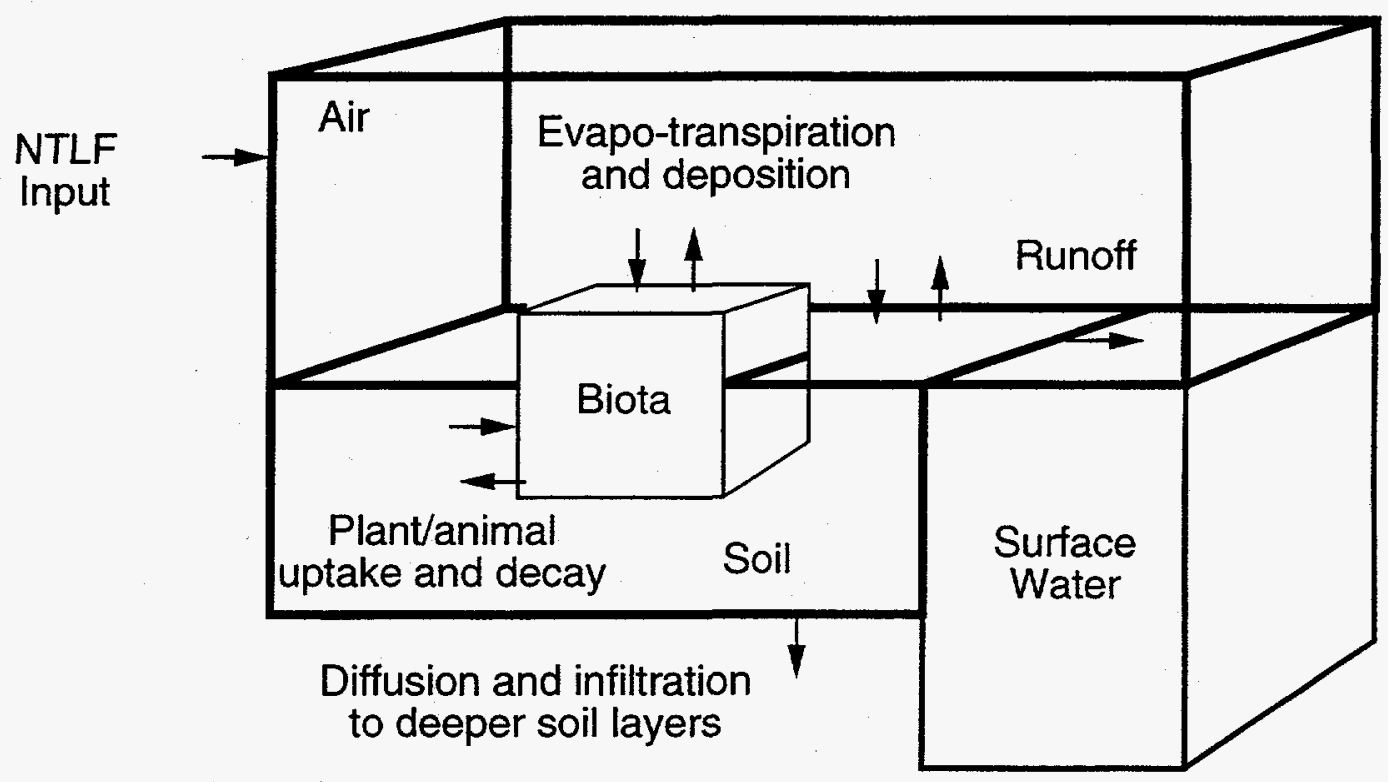

Figure 3-1. The two-compartment model.

To determine ranges of human exposure and the doses for adults, infants, and fetuses in the exposed populations, the concentrations of tritium in environmental media (air, food and surface water) were combined with the rates at which people come in contact with these media through inhalation, ingestion, and absorption. These doses were combined with risk factors for cancer mortality, genetic defects, and reproductive and developmental effects to estimate population and individual risks for the three zones. Figure 3-2 illustrates the process of tritium dispersion used to assess risks. 


\section{Tritium in Environmental Media}
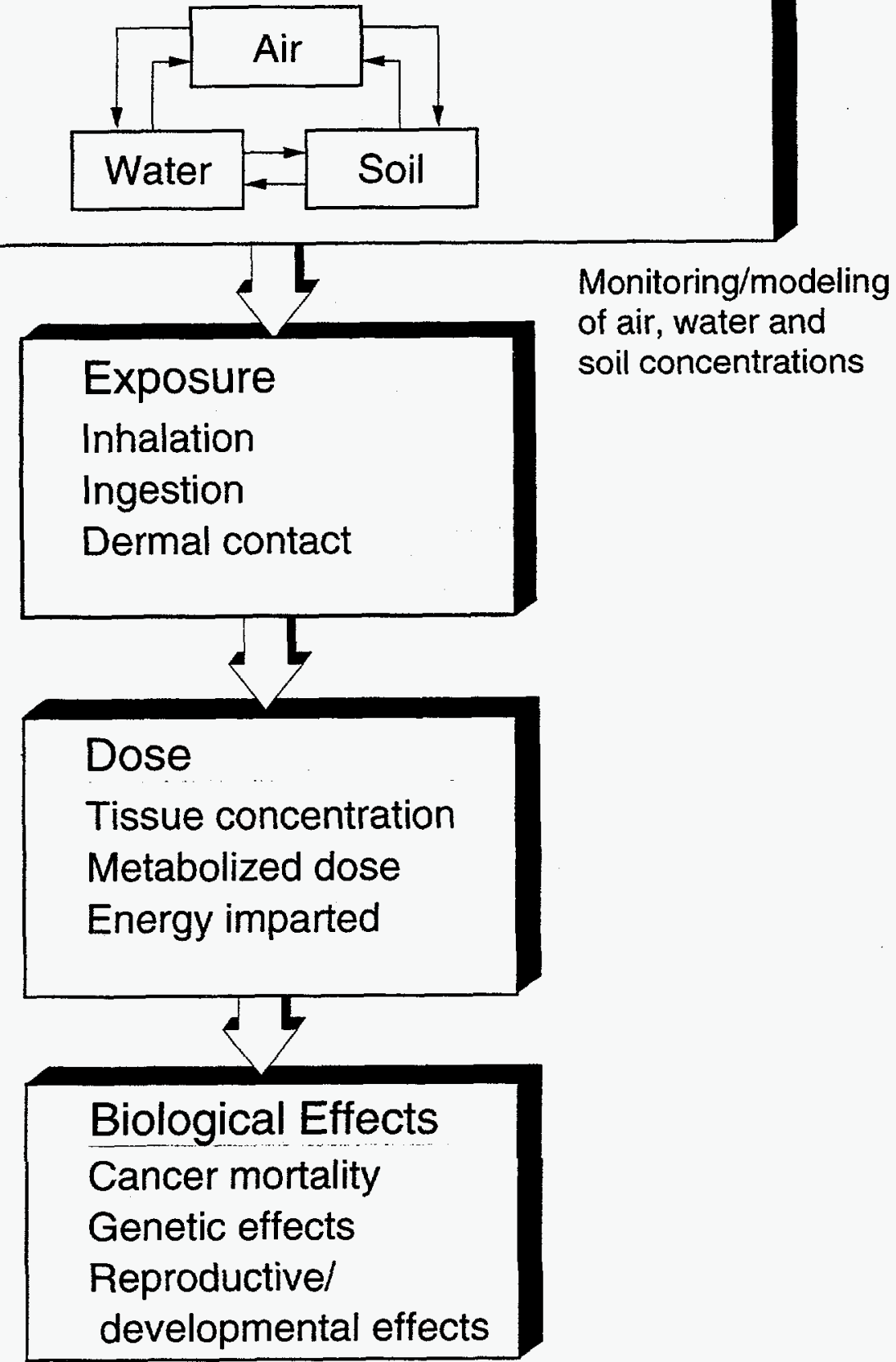

Figure 3-2. Risk assessment framework. 


\subsection{Accidents}

As is noted previously, accidental releases are beyond the scope of this report.

However, this statement refers to large and catastrophic accidents. Monitored stack emissions, which are used to define the source term for the risk assessment, include both routine (normal) releases and small accident (off-normal) events, and thus small accidents are implicitly included in the risk assessment. Even though this risk assessment does not explicitly deal with accidental releases, health impacts from such accidents can be estimated by using information in the risk assessment. Risk levels associated with releases larger than $100 \mathrm{Ci} / \mathrm{y}$ can be found by multiplying this report's risk levels by the ratio of the larger release rate (averaged over the same time period) to the $100 \mathrm{Ci} / \mathrm{y}$ release rate. For example, one accidental release of $5,000 \mathrm{Ci}$ over a 70 -year period would effectively increase the estimated risk associated with the continuous release of $100 \mathrm{Ci} / \mathrm{y}$ by a factor of 1.7 . 



\section{Chapter 4}

\section{Technical Details}

This chapter, together with the appendices, describes the steps of the risk assessment, the data used in the analysis, and the models and methods used to quantify risk and uncertainties.

\subsection{Overview of the Risk Assessment Process}

The models used in this risk assessment address the spread of tritium releases from the NTLF, contact with human populations, metabolism within the human body, and potential health impacts. The primary goal of these models is to clarify how tritium

- Remains or spreads within the envelope of air to which it is released

- Is transported to another compartment by cross-media transfer that involves dispersion or advection (i.e., volatilization, precipitation, etc.)

- Is physically transformed by radioactive decay

The models' parameters were verified by matching calculated tritium concentrations with the tritium concentrations measured in air and surface runoff in the vicinity of the NTLF and in Berkeley. Using site-specific data and the calibrated parameters, the models determine the tritium concentrations in air, surface water, soils, and plants adjacent to the NTLF. These contamination levels provided the basis for estimating the corresponding doses as well as the risks to people in the three zones. 


\subsection{Tritium Properties and Sources}

A tritium atom has two neutrons, while the common hydrogen (protium) atom has none. Tritium's atomic weight is 3 . Deuterium, with one neutron, has an atomic weight of 2 , and protium's atomic weight is 1 (see Figure 4-1). Tritium decays to helium through beta decay - the emission of a beta particle from its nucleus:

$$
{ }^{3} \mathrm{H} \rightarrow{ }^{3} \mathrm{He}+\mathrm{e}-
$$

Tritium's radioactivity per unit mass makes it a good tracer and label. A count of nuclear decays per unit time from a known mass or volume allows specific activity (analog of concentration) to be calculated. Because nuclear disintegrations are easily monitored, any molecules that have incorporated tritium are easily differentiated from non-labeled forms. Therefore, tritium has great utility for experiments in which the transport or fate of particular chemicals must be identified. Tritium can be incorporated, via substitution for protium, into any molecule or compound that contains hydrogen.

Tritium represents little or no external dose hazard, because the maximum energy of its beta particles is insufficient for skin penetration. The measured and calculated maximum penetration depth of tritium's beta particles in $\mathrm{H}_{2} \mathrm{O}$ is 6 micrometers $(\mu \mathrm{m})$. Considering that the nonliving outer skin layer (stratum corneum) is 10 to $100 \mu \mathrm{m}$ thick, the epidermis is $100-200 \mu \mathrm{m}$ thick, and the dermis is $1000-3000 \mu \mathrm{m}$ thick, the penetration

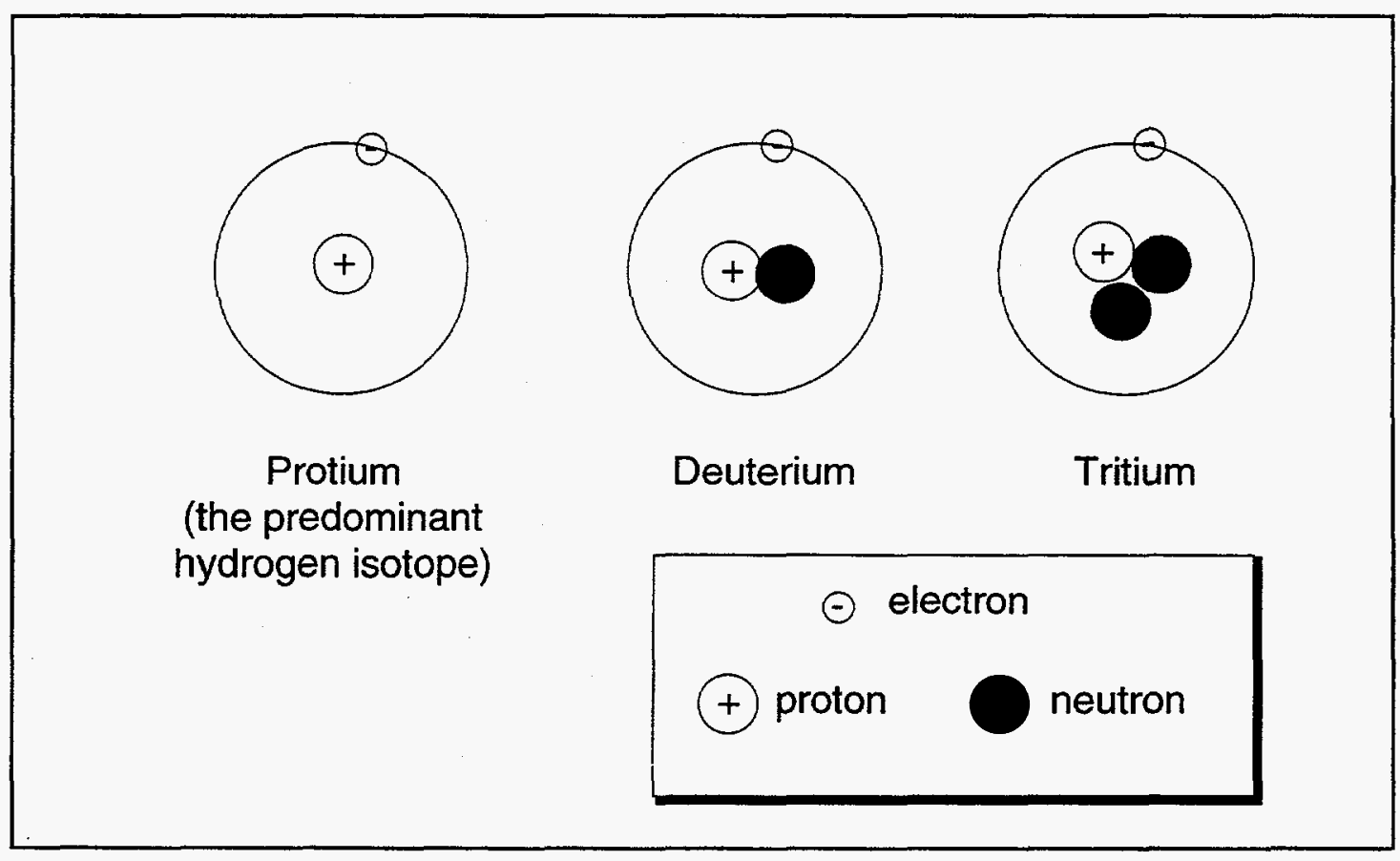

Figure 4-1. The three isotopes of hydrogen and their atomic structures. 
of tritium's beta particles through skin is not a big concern. However, once ingested, tritium's minimal penetration depth could be sufficient to inflict deleterious effects.

The radioactive half life of tritium is 12.3 years. The radiological units commonly used to characterize exposure, dose, dose equivalent and radiation protection standards for tritium are listed in Table 4-1.

Table 4-1

Common Radiological Units

\begin{tabular}{|c|c|c|c|}
\hline Unit or quantity & Symbol & Brief description & Comment \\
\hline Becquerel & $\mathrm{Bq}$ & $\begin{array}{l}1 \text { nuclear disintegration per } \\
\text { second }\end{array}$ & SI unit of radioactivity \\
\hline Curie & $\mathrm{Ci}$ & $\begin{array}{l}3.7 \times 10^{10} \text { nuclear } \\
\text { disintegrations per second }\end{array}$ & $\begin{array}{l}\text { Older unit of radioactivity often still } \\
\text { used in the US (a) }\end{array}$ \\
\hline Roentgen & $\mathbf{R}$ & $\begin{array}{l}2.58 \times 10^{10} \text { coulombs per } \mathrm{kg} \\
\text { (photons in air) }\end{array}$ & Special unit of exposure \\
\hline Gray & Gy & 1 joule $/ \mathrm{kg}$ & SI unit of radiation dose \\
\hline Rad & rad & $100 \mathrm{erg} / \mathrm{g}(=0.01 \mathrm{~Gy})$ & $\begin{array}{l}\text { Older unit of radiation dose often } \\
\text { still used in the US (a) }\end{array}$ \\
\hline Dose equivalent & $\mathrm{H}$ & Dose $\times$ RBE & Used in radiation protection \\
\hline Quality factor & RBE & $\begin{array}{l}\text { Relative Biological } \\
\text { Effectiveness of radiation }\end{array}$ & Used in radiation protection \\
\hline Sievert & Sv & Gy $x$ RBE & Sl unit of dose equivalent \\
\hline Rem & rem & $\operatorname{rad} \times \mathrm{RBE}$ & $\begin{array}{l}\text { Older unit of dose equivalent often } \\
\text { still used in the US (a) }\end{array}$ \\
\hline
\end{tabular}

Footnote to Table 4-1:

(a) While all scientific papers employ the SI units, official US regulatory values for dose exposure are given in rems, and the current US unit of radioactivity remains the curie.

\subsubsection{Physical and Chemical Properties of Tritium}

Tritium is found in the environment in three principal forms-molecular tritium $\left(\mathrm{T}_{2}\right.$ or $\mathrm{HT}$ ), tritiated water (HTO), and organically bound tritium (OBT). Tritiated water is the most abundant chemical form of tritium in the environment. HTO's properties are very similar to those of water. Because the difference in atomic weight is relatively small, the physical properties of $\mathrm{HTO}$ and $\mathrm{H}_{2} \mathrm{O}$ are more similar than those of tritium and hydrogen. HTO is taken up by organisms and environmental media far more readily than molecular tritium. HTO is the principal form of tritium released from the NTLF. 
A small fraction of tritium is incorporated into organic molecules exposed to tritium gas and HTO. This organically bound tritium (OBT) has a different metabolism than HTO. Following exposure to HTO, tritium may be converted to OBT and retained in the body for a longer period [Murphy, 1984]. Table 4-2 gives the physical and chemical characteristics of tritium that are relevant for a dose and risk assessment.

Table 4-2

Physical and Chemical Characteristics of Tritium

\begin{tabular}{|l|c|l|}
\hline \multicolumn{1}{|c|}{ Property } & Value & \multicolumn{1}{c|}{ Reference } \\
\hline Radioactive half life $\left(\mathrm{T}_{1 / 2}\right)$ & $12.35 \mathrm{y}$ & NCRP [1985] \\
\hline Decay constant $\left(=0.693 \mathrm{~T}_{1 / 2}\right)$ & $\begin{array}{c}5.6 \times 10^{-2} \mathrm{y}^{-1} \\
1.780 \times 10^{-9} \mathrm{~S}^{-1}\end{array}$ & NCRP [1985] \\
\hline Average beta decay energy & $5.685 \mathrm{keV}$ & NCRP [1985] \\
\hline Maximum beta decay energy & $18.6 \mathrm{keV}$ & NCRP [1985] \\
\hline Average track length (water) & $0.56 \mu \mathrm{m}$ & $\begin{array}{l}\text { Okada and Momoshima } \\
{[1993]}\end{array}$ \\
\hline Maximum track length (water) & $6.0 \mu \mathrm{m}$ & $\begin{array}{l}\text { Okada and Momoshima } \\
{[1993]}\end{array}$ \\
\hline $\begin{array}{l}\text { Maximum track length (air) } \\
\text { Radioactivity for } 1 \mathrm{~g} \text { of } \mathrm{T}_{2} \text { (gas) }\end{array}$ & $\begin{array}{c}5 \mathrm{~mm} \\
\text { Okada and Momoshima }\end{array}$ \\
\hline $\begin{array}{l}\text { [1993] } \\
=0.118 \text { Bq HTO per L (water) } \\
=3.2 \text { pCi HTO per L (water) }\end{array}$ & $\begin{array}{c}3.59 \times 10^{14} \mathrm{~Bq} \\
9.7 \times 10^{3} \mathrm{Ci}\end{array}$ & $\begin{array}{l}\text { Okada and Momoshima } \\
{[1993]}\end{array}$ \\
\hline \hline
\end{tabular}

\subsubsection{Sources of Tritium Release in the Environment}

The major natural source of tritium is cosmic ray reactions in the upper atmosphere. A minor portion of the annual natural tritium production comes from the earth's crust, a result of neutron capture reactions by ${ }^{6} \mathrm{Li}$ in rocks. The steady-state global inventory of tritium from all natural sources is estimated to be in the range of 1 to $1.3 \times 10^{18} \mathrm{~Bq}$ [Okada and Momoshima, 1993]. Based on a 12.3 year half-life, this inventory corresponds to an annual production of $0.062 \times 10^{18} \mathrm{~Bq} / \mathrm{y}$. Measurements taken before open-air nuclear testing began (before 1950) indicate that HTO in natural waters in the U.S. ranged from 0.14-7.9 Bq/L for Chicago rain water, $0.16-0.21 \mathrm{~Bq} / \mathrm{L}$ for Lake Michigan water, and 0.30-0.77 Bq/L for the Mississippi [Okada and Momoshima, 1993]. 
Anthropogenic sources of tritium in recent decades have far exceeded natural sources. Atmospheric nuclear weapons tests in the 1950s and 1960s are estimated to have produced from 185 to $240 \times 10^{18} \mathrm{~Bq}$ of tritium [Okada and Momoshima, 1993]. It is estimated that, in the 1990's, the legacy of the nuclear weapons test of the 1950's and $1960^{\prime} \mathrm{s}$ is an additional $52 \times 10^{18} \mathrm{~Bq}$ of tritium in the current global inventory [Okada and Momoshima, 1993].

Normal releases of tritium from nuclear facilities are estimated to produce $0.02 \times 10^{18}$ $\mathrm{Bq} / \mathrm{y}$ and off-normal releases an additional $0.001 \times 10^{18} \mathrm{~Bq} / \mathrm{y}$ with a resultant steadystate buildup of $0.4 \times 10^{18} \mathrm{~Bq}$ globally [Okada and Momoshima, 1993]. Based on total previous levels of production, the legacy of luminous products (such as watch dials) is estimated to currently release $0.4 \times 10^{18} \mathrm{~Bq} / \mathrm{y}$ with a resultant steady-state build up of $7.4 \times 10^{18} \mathrm{~Bq}$ globally [Okada and Momoshima, 1993]. However, the luminous-dial source is expected to decrease in time.

The combined natural and anthropogenic emissions of tritium result in a current global inventory of approximately $53 \times 10^{18} \mathrm{~Bq}$, which is about 50 times greater than tritium levels due to natural sources alone. However, much of this tritium is deposited in the deep ocean where it is unavailable to the circulating waters of the Earth. Okada and Momoshima [1993] estimate that current levels of tritium in surface, ground and rain water are in the range 0.1 to $8 \mathrm{~Bq} / \mathrm{L}$. Based on these concentrations they estimate that current tritium levels in humans are $1.7 \mathrm{~Bq} / \mathrm{kg}$ and result in an annual dose of $0.05 \mu \mathrm{Gy}$ per year (or $0.09 \mu \mathrm{Sv}$ per year assuming that the relative biological effectiveness (RBE) is on the order of 1.8). The RBE, the estimate of tissue damage of tritium beta emissions relative to gamma rays, is used to convert tissue doses in $\mu$ Gy to gamma-equivalent doses in $\mu \mathrm{Sv}$, and is discussed further in Section 4.6. The United Nations Scientific Committee on the Effects of Atomic Radiation reports a global average dose of $0.01 \mu \mathrm{Gy}$ per year for the human population [UNSCEAR, 1993]. Picking the middle value in this range, $0.03 \mu \mathrm{Gy}$ per year, and again assuming that the RBE of tritium is on the order of 1.8 , we find that this is about forty thousand times lower than the average background radiation dose of $2400 \mu \mathrm{Sv}$ reported by UNSCEAR [1993]. The $2400 \mu \mathrm{Sv}$ background value reported by UNSCEAR is attributable to all natural sources of radioactivitycosmic rays, terrestrial gamma rays, natural radionuclides in the body, and radon and its decay products. Based on the risk factor of 0.04 fatal cancers per Sv recommended by UNSCEAR [1993] for low-dose exposures to working populations, the $2400 \mu \mathrm{Sv}$ total background dose per year corresponds to a population risk of 100 fatal cancers per million people per year and an individual risk of 7 in a thousand per lifetime. In contrast, a $0.03 \mu \mathrm{Gy}$ tritium background dose per year combined with the risk factors derived below (in Section 4.6.4) corresponds to a population risk of 0.003 fatal cancers per million people per year and an individual risk on the order of 2 in ten million per lifetime.

The NTLF currently releases on the order of $3.7 \times 10^{12} \mathrm{~Bq} / \mathrm{y}(100 \mathrm{Ci} / \mathrm{y})$ of tritiated water. This number is typical of annual releases since 1990 and is lower than during the period 1982 to 1990. 


\subsection{Tritium Releases from the NTLF}

The NTLF is designed and operated so that multiple layers of defense restrict the release of tritium to the environment.

Tritium comes to the NTLF facility chemically bound to a uranium bed contained in a sealed metal cylinder. At the NTLF the cylinders are attached to a closed system inside a ventilated glove box. The cylinders are heated to release the chemically-bound tritium from the uranium. All formation reactions take place in the closed system within the glove box.

Two main components of this system are designed to trap or recirculate tritium to prevent its release to the environment:

- The glove-box ventilation system, tritium recovery system, and silica-gel traps, and

- The reaction manifold and the secondary uranium bed.

Tritium can enter the ambient air compartment from the NTLF via three major pathways (see Figure 4-2):

- Tritium in air drawn through the glove-box ventilation system. Directed through silica-gel traps, after which booster blowers direct it into the main stack trunk-line. The box-air would be contaminated mainly by fugitive losses through gaskets as well as some diffusional losses through the steel tubing.

- Tritium in the reaction manifold that fails to sorb out in the secondary U-bed. Directed through an HTO recovery system. The gaseous residual from this process is then sent through silica-gel traps and onward to a tributary pipe that ultimately joins the main stack trunk-line. This tritium is most likely in the form of HTO.

- Off-gases passing through the chemistry lab hoods (i.e., laboratory air) as well as any off-gases from the pump-shed (including pumps, copper oxide furnaces and storage tank). These are directed into the main stack trunk-line.

All postulated releases from the NTLF go to the air compartment as HTO. When tritium is released to the environment-whether into air, water, or soil-it spreads rapidly. 


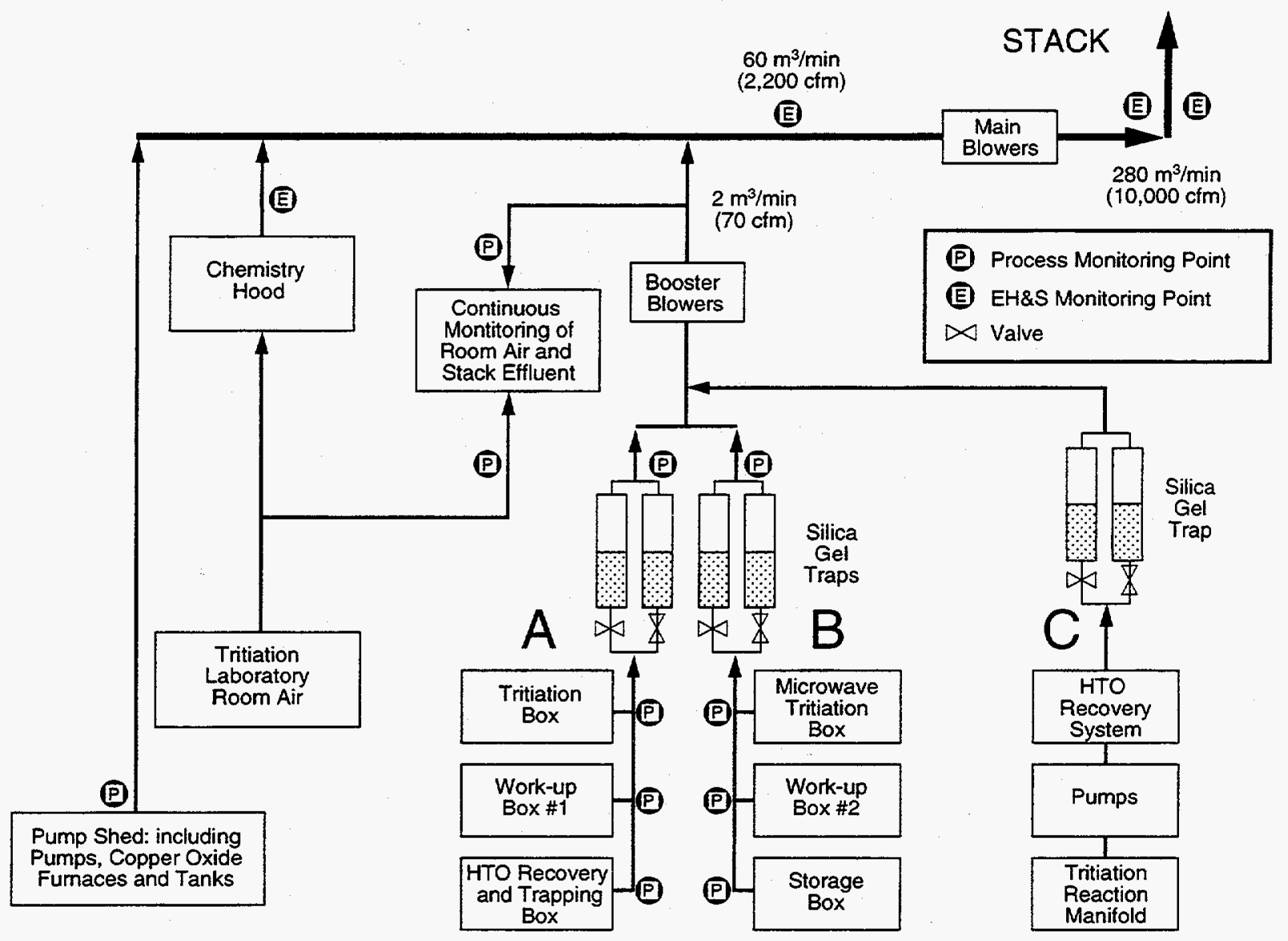

Figure 4-2. NTLF exhaust schematic.

\subsection{Environmental Distribution of Tritium Releases from the NTLF}

The predominant influences on the relative distribution of $\mathrm{HTO}$ in the environment are [Murphy, 1993]:

- The hydrogen cycling processes interacting between the various media (compartments) of the release environment

- The water content of these media

The two influences suggest the importance of understanding the water budget of the release site. The environmental cycling of tritium follows quite closely that of natural hydrogen as it occurs in gas, water, and organic molecules. Perhaps because of hydrogen abundance, no sequestering processes (bioaccumulation) in biota have evolved for hydrogen (or tritium), and thus there is no mechanistic reason to expect biomagnification, which is a metabolically mediated buildup in biological tissues. 
However, because hydrogen can bind to organic molecules, we might expect some accumulation as a result of OBT.

A review of the field study literature relating to the fate and transport of $\mathrm{HTO}$ in the environment provided some insight into the distribution of HTO subsequent to a continuous atmospheric release, and proved helpful in developing a customized HTO fate and transport model. The sections that follow look at major components of this model. Appendix A contains details of the model structure and the rationale for the model components.

\subsubsection{Model Structure}

For Zones 1 and 2, we used a two-compartment model to estimate the steady-state distribution of HTO between air and soil as a result of a constant HTO emission to the atmosphere. This is an idealization, constructed to obtain an approximate HTO distribution that is consistent with HTO affinities, site-specific characteristics, and observed environmental parameters (e.g., precipitation, runoff, and infiltration). See Appendix $C$ for an account of site-specific characteristics.

Using the principle of mass conservation for each compartment, the model provides an algorithm for predicting the steady-state HTO concentrations in the soil and air compartments. The overall model structure is illustrated in Figure 4-3. The premises of this modeling approach are as follows:

- HTO will distribute primarily in the aqueous phase of each compartment

- OBT in any compartment can be accounted for by increasing the effective residence time

- Water-phase tritium activities in each compartment will be equal under equilibrium conditions.

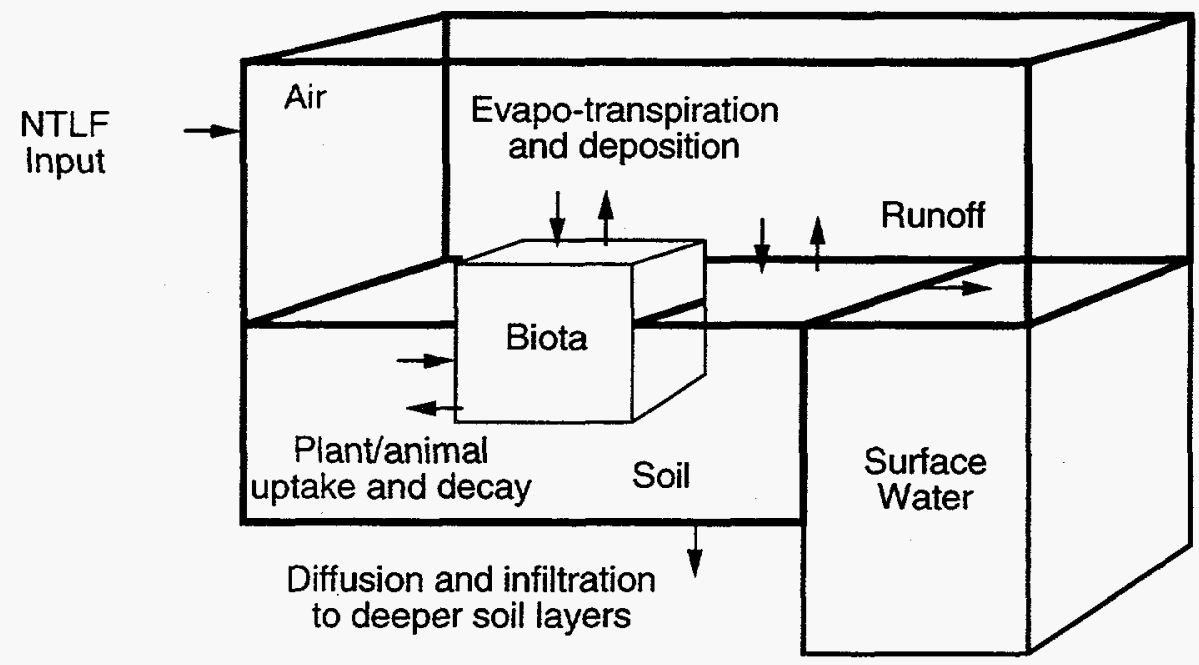

Figure 4-3. Compartment model for assessing the environmental fate of tritiated water emissions from the NTLF. 


\subsubsection{Steady State Mass Balance Equations}

The steady-state equations describing gains and losses in the two compartments were solved for the steady-state inventory in each compartment. Table 4-3, gives the gains and losses considered for each compartment. Equations 4-1 and 4-2 express gains and losses for the air and soil compartments, respectively.

$$
S+T_{s a} N_{s}=L_{a} N_{a} \quad \text { (air) }
$$

and

$$
T_{a s} N_{a}=L_{s} N_{s} \quad \text { (surface soil) }
$$

In equations 4-1 and 4-2, an $N$ represents a compartment's HTO inventory (note that a compartment's bulk and water phase inventories are equivalent) and the $T_{i j}$ (where $i$ and $j=s$ or $a$ ) are transfer rate constants, in units of day ${ }^{-1}$, representing the fraction per unit time of the inventory in compartment $i$ that is transferred to the inventory in compartment $j$. Here the total compartment activity in $\mathrm{Bq}$ is used to represent inventory (activities in $\mathrm{Bq}$ are proportional to molar inventories). The compartment abbreviations are $a$ for air, and $s$ for surface soil. The product of an $N$ term and a $T$ term is the rate of change of inventory in $\mathrm{Bq} / \mathrm{d} . L_{i} N_{i}$ represents all losses from compartment $i$, in $\mathrm{Bq} / \mathrm{d}$. The term $S$ in Equation 4-1 represents the rate of $H T O$ input (i.e., the NTLF's HTO emission rate) into the air compartment, in Bq/d. Transfer rate constants are functions of landscape characteristics and environmental mass transfer rates. Details on the derivation of transfer rate constants are provided in Appendix A.

Table 4-3

\begin{tabular}{|c|c|c|}
\hline Compartment & Gains & Losses \\
\hline $\begin{array}{l}\text { (1) Air } \\
\text { (both gas and vapor } \\
\text { phases- particulate } \\
\text { phase ignored) }\end{array}$ & $\begin{array}{l}\text { Evapotranspiration from } \\
\text { Biota and soil } \\
\text { - HTO load carried in with } \\
\text { outside air (negligible for } \\
\text { occupational volume) } \\
\text { - NTLF HTO release }\end{array}$ & $\begin{array}{l}\text { - Precipitation scavenging } \\
\text { - Radioactive decay } \\
\text { - Loss to "outside" air via } \\
\text { advective flushing }\end{array}$ \\
\hline (2) Soil & $\begin{array}{l}\text { - Diffusion from air (ignored) } \\
\text { - Washout (scavenged portion) } \\
\text { from precipitation } \\
\text { - Loading in runoff entering } \\
\text { from outside the 'unit world' } \\
\text { (neglected since we calculate } \\
\text { added risk) }\end{array}$ & $\begin{array}{ll}\text { - } & \text { Diffusion to air (included in } \\
\text { evapotranspiration) } \\
\text { - } \\
\text { Diffusion to deeper soil } \\
\text { (lumped in with advection) } \\
\text { - } & \text { Advection to deeper soil } \\
\text { - } & \text { Loss carried away in runoff } \\
\text { - } & \text { Radioactive decay }\end{array}$ \\
\hline
\end{tabular}

Summary of HTO Exchange and Loss Between Air and Soil 


\subsubsection{Calculating $L_{a}$}

For the air compartment, $L_{a}$ is the sum of all loss-rate constants from the air compartment.

$$
L_{a}=T_{a s}+T_{a o}+\lambda,
$$

where $T_{a s}$, in day ${ }^{-1}$ units, is the rate constant for advection and diffusion losses to soil and accounts for rain-water washout from air to ground-surface soil, $T_{a 0}$ is the rate constant, in day ${ }^{-1}$ units, for convective dispersion losses in air and $\lambda$, in day ${ }^{-1}$ units, is the rate constant for losses due to radioactive decay.

\subsubsection{Calculating $L_{s}$}

The soil compartment represents the surface layer of soil, where losses include diffusion to air, diffusion and infiltration to deeper soil layers, runoff to surface water, and radioactive decay. The mass balance that defines the inventory, $N_{S}$, in Bq of $\mathrm{HTO}$, is described by Equation 4-2. $L_{s}$ is the sum of all loss-rate constants from the soil compartment.

$$
L_{s}=T_{s a}+T_{\text {recharge }}+T_{\text {runoff }}+\lambda,
$$

where $T_{s a}$ is the soil-to-air transfer rate (primarily representing evapotranspiration processes), and $T_{\text {recharge }}$ and $T_{\text {runoff }}$ are the rate constants for recharge losses to ground water and runoff losses to outside of the landscape unit, respectively. All the rate constants are in day ${ }^{-1}$ units. These loss-rate constants are derived in Appendix A.

\subsubsection{Solutions for the Tritium Inventories}

By solving Equations 4-1 and 4-2 simultaneously we obtain:

$$
\begin{gathered}
N_{s}=\frac{S}{\frac{L_{s} L_{a}}{T_{a s}}-T_{\mathrm{sa}}} \\
N_{a}=\frac{S}{L_{a}-T_{s a} \frac{T_{a s}}{L_{s}}}
\end{gathered}
$$

These solutions are used later to estimate tritium risk to human health. The rate constants used in the equations were selected to ensure that the model reproduces the available measured concentrations of tritium in the air and water from the NTLF site. 


\subsubsection{Air Dispersion Model for Zone 3}

For Zone 3 we used the CAP88-PC microcomputer radionuclide dispersion and doseassessment code supplied and approved by US/EPA. This model is able to calculate doses and risks to individuals at various distances from the tritium source. For the point of maximum off-site exposure, the dose represents the cumulative exposure from all significant exposure pathways (inhalation, ingestion, air immersion, and surface exposure). The methods and parameters used to calculate the dose are very conservative. In this risk assessment, however, we only use the tritium concentration in air calculated by CAP88 as input data in our model for risk calculations.

\subsection{Human Contact with Tritium Releases}

For releases of tritium from the NTLF, pathways leading to internal exposures of tritium include:

- HTO vapor entering the body through respiration

- Tritium in water, breast milk, or foods ingested and absorbed through the gastro-intestinal tract

- HTO vapor in air taken up through the skin

- HTO in water taken up through the skin during dermal contact with the contaminated water; e.g., while swimming and wading.

\subsubsection{Intake and Uptake}

When environmental concentrations of tritium are constant over an exposure duration, $\mathrm{ED}$, the population-averaged intake (for ingestion or inhalation routes) or uptake (for dermal contact) is the average daily exposure rate $\left(A E D_{i j k}\right)$, in $\mathrm{Bq} / \mathrm{kg}$-d, and is given by

$$
A E D_{i j k}=\left[\frac{C_{i}}{C_{k}}\right] \times\left[\frac{I U_{i j}}{B W}\right] \times \frac{E F \times E D}{A T} \times C_{k} .
$$

In this expression $\left[C_{i} / C_{k}\right]$ is the intermedia transfer ratio, which expresses the ratio of tritium concentration in the exposure medium (i.e., personal air, tap water, milk, soil, etc.) to the tritium concentration in an environmental medium $k$ (ambient air, soil, surface water, groundwater, etc.). For inhalation and dermal uptake of tritium from ambient air when the environmental and exposure medium are the same, the ratio $\left[C_{i} / C_{k}\right]$ is unity; similarly, for ingestion and dermal uptake from water, the ratio $\left[C_{i} / C_{k}\right]$ is also unity; but for ingestion uptake of vegetation, where the environmental medium is air and the exposure medium is vegetation, the ratio $\left[C_{i} / C_{k}\right]$ is equivalent to the plant/air concentration ratio. 
$\left[\Omega_{i j} / B W\right]$ is the intake or uptake factor per unit body weight associated with the exposure medium $i$ and route $j$. For exposure through inhalation or ingestion, $\left[M U_{i j} / B W\right]$ is the daily intake rate for the exposure medium per unit body weight; for example, $\mathrm{m}^{3}$ (air) $/ \mathrm{kg}$-d, L(milk) $/ \mathrm{kg}$-d, or $\mathrm{kg}$ (soil) $/ \mathrm{kg}$-d. For uptake through the dermal route, $\left[I U_{i j} / B W\right]$ is the uptake factor per unit body weight and per unit initial concentration in the applied medium, [L(water) $/ \mathrm{kg}-\mathrm{d}$ or $\mathrm{m}^{3}($ air $) / \mathrm{kg}-\mathrm{d}$ ]. To illustrate this further, we note that the uptake factor, $\left[I U_{i j} / B W\right]$, for dermal contact with water is obtained by multiplying the effective tritium permeability from water, $\mathrm{L} / \mathrm{m}^{2} / \mathrm{d}$, by the exposed skin surface area, $\mathrm{m}^{2}$, divided by body weight of the exposed individual and that for dermal contact with air, $\left[I U_{i j} / B W\right]$ is obtained by multiplying the effective tritium permeability from air, $\mathrm{m}^{3} / \mathrm{m}^{2} / \mathrm{d}$, by the exposed skin surface area, $\mathrm{m}^{2}$, divided by body weight of the exposed individual. Specific development of these factors $\left[I U_{i j} / B W\right]$ is described below in Section 4.5.2.4 and explicitly represented in Equations 4-8 and 4-9.

$E F$ is the exposure frequency for the exposed individual, in days per year. $E D$ is the exposure duration for the exposed population, in years. $A T$ is the averaging time for the exposed population, in days; and $C_{k}$ is the tritium concentration in environmental medium $k$.

\subsubsection{Exposure Factors}

In constructing dose models one needs to define the characteristics of individuals in various age/sex categories and the characteristics of the microenvironments in which they live or from which they obtain air, water and food. This section defines the types of anatomical and activity data needed to carry out the dose assessment and provides representative values for these parameters. Appendix B describes how these data were obtained and evaluated. An arithmetic mean value and a coefficient of variation $(\mathrm{CV})-$ the arithmetic standard deviation divided by the arithmetic mean-are defined for all exposure factors used in this assessment.

\subsubsection{Exposure Duration and Averaging Time}

In the basic exposure model, the exposure duration (ED) is the amount of time, in years, that the exposed population is assumed to be in contact with a specified environmental contaminant. The averaging time (AT) is the period, in days, over which exposure is averaged. The estimates of risk given in section 4.7 are based on population exposures and the committed dose in a defined population on an annual basis. Thus, for this risk assessment ED and AT represent the same period of time and the ratio $E D / A T$ in Equation $4-7$ is [ $1 \mathrm{y}] /[365 \mathrm{~d}]$. 


\subsubsection{Anatomical Properties, Inhalation, and Ingestion}

The arithmetic-mean and $\mathrm{CV}$ of body weight and body surface area for three age groups-infant, child, and adult is given in Appendix B. The body weight for infants is needed for estimating exposures to tritium in breast milk. Appendix B also contains an evaluation of available data on population breathing rates, ingestion of water during recreational activities, ingestion of breast-milk by infants, and ingestion of home-grown fruits, vegetables and grains. The descriptions, parameter symbols, and values prepared for these inputs are summarized in Table 4-4.

Table 4-4

Values of Human Anatomical and Intake Properties

Used in the Exposure Calculations. (a)

\begin{tabular}{|c|c|c|c|c|c|c|c|}
\hline \multirow{2}{*}{$\begin{array}{l}\text { Parameter, symbol } \\
\text { Body weight of infants } \\
\text { age } 0 \text { to } 1 \mathrm{y}, \mathrm{BW}\end{array}$} & \multicolumn{2}{|c|}{ Child(b) } & \multicolumn{2}{|c|}{ Adult(b) } & \multicolumn{2}{|c|}{ Combined (b) } & \multirow{2}{*}{$\begin{array}{r}\text { Units } \\
\mathrm{kg}\end{array}$} \\
\hline & 7.2 & $(0.3)$ & - & - & - & - & \\
\hline Body weight, BW & 29 & $(0.24)$ & 71 & $(0.2)$ & 62 & $(0.2)$ & $\mathrm{kg}$ \\
\hline Surface area, $S A_{b}$ & 0.032 & $(0.09)$ & 0.024 & $(0.06)$ & 0.026 & $(0.07)$ & $\mathrm{m}^{2} / \mathrm{kg}$ \\
\hline $\begin{array}{l}\text { Working breathing rate, } \\
\mathrm{BR}_{\mathrm{W}}\end{array}$ & - & - & 0.030 & $(0.3)$ & - & - & $m^{3} / \mathrm{kg}-\mathrm{h}$ \\
\hline Active breathing rate, $\mathrm{BR}_{\mathrm{a}}$ & 0.023 & $(0.3)$ & 0.018 & $(0.3)$ & 0.019 & $(0.3)$ & $\mathrm{m}^{3} / \mathrm{kg}-\mathrm{h}$ \\
\hline $\begin{array}{l}\text { Resting breathing rate, } \\
\text { BR }_{r}\end{array}$ & 0.008 & $(0.3)$ & 0.006 & $(0.2)$ & 0.0064 & $(0.2)$ & $m^{3} / \mathrm{kg}-\mathrm{h}$ \\
\hline Breast milk intake, $I_{b m}(c)$ & 0.11 & (1) & - & & - & & $\mathrm{kg} / \mathrm{kg}-\mathrm{d}$ \\
\hline $\begin{array}{l}\text { Water intake during } \\
\text { recreation, I } I_{f \mid r}\end{array}$ & 0.0007 & (1) & 0.0007 & (1) & 0.0007 & (1) & L/kg-h \\
\hline $\begin{array}{l}\text { Ingestion of homegrown } \\
\text { exposed produce, lep }\end{array}$ & 0.0016 & $(0.7)$ & 0.00078 & $(0.7)$ & 0.00096 & $(0.7)$ & $\mathrm{kg} / \mathrm{kg}-\mathrm{d}$ \\
\hline $\begin{array}{l}\text { Ingestion of homegrown } \\
\text { unexposed produce, Iup }\end{array}$ & 0.00095 & $(0.7)$ & 0.00053 & $(0.7)$ & 0.00062 & $(0.7)$ & $\mathrm{kg} / \mathrm{kg}-\mathrm{d}$ \\
\hline
\end{tabular}

Footnotes to Table 4-4:

(a) Listed are the arithmetic-mean value and (in parentheses) the estimated CV. Body weights are from Najjar and Roland [1987], breathing rates are from ICRP [1975], tap water intakes are from Yang and Nelson [1986] and Ershow and Cantor [1989], and food intakes are from Yang and Nelson [1986].

(b) The child category covers ages 0 to 15, the adult category covers ages 16 to 70 , the combined category is used to represent lifetime equivalent exposure and is obtained by multiplying the child category by $15 / 70$, the adult category by $55 / 70$, and then summing these products.

(c) Breast milk intakes are from Butte et al. [1984] and Whitehead and Paul [1981]. 


\subsubsection{Activity Patterns and Exposure Times}

Activity patterns define the frequency and duration that could expose individuals to tritium-contaminated media-air, water, soil. For occupational exposures the exposure time per day is typically 8 to 10 hours and the exposure frequency (EF) is 200 to 300 days per year (assuming 50 working weeks per year and from 4 to 6 working days per week). For non-occupational exposures, the U.S. EPA [1989a] reports the average time spent at home indoors as 8 to $16 \mathrm{~h} / \mathrm{d}$ and the time spent at home outdoors as $0.3 \mathrm{~h} / \mathrm{d}$, with an estimated $\mathrm{CV}$ in both cases of 0.14 .

For estimating possible doses from water recreation activities in creeks running down from the Berkeley Hills, we assume every adult in Zone 3 wades 2 hours per day for 30 days annually (the U.S. EPA [1992a] reports that for recreational swimming, the time spent swimming ranges from $0.5 \mathrm{~h} / \mathrm{d}$ to $1 \mathrm{~h} / \mathrm{d}$ and the frequency ranges from $5 \mathrm{~d} / \mathrm{y}$ to $150 \mathrm{~d} / \mathrm{y}$, see Table 4-5).

\section{Table 4-5}

Values and Units of Exposure Parameters Used to Characterize Activity Patterns.

\begin{tabular}{|l|c|c|c|c|}
\hline \multicolumn{1}{|c|}{ Activity pattern } & $\begin{array}{c}\text { Value } \\
\text { used }\end{array}$ & $\begin{array}{c}\text { Likely } \\
\text { range }\end{array}$ & Units & Reference \\
\hline Exposure time at work, $\mathrm{ET}_{\mathrm{W}}$ & 9 & 8 to 10 & $\mathrm{~h} /$ day & This report \\
\hline Exposure frequency at work, $\mathrm{EF}_{\mathrm{w}}$ & 250 & 200 to 300 & day/y & This report \\
\hline Exposure time, at home indoors, $\mathrm{ET}_{\mathrm{h}}$ & 12 & 8 to 16 & $\mathrm{~h} /$ day & U.S. EPA [1989a] \\
\hline Exposure time, at home outdoors, $\mathrm{ET}_{\mathrm{o}}$ & 0.3 & 0.02 to 0.4 & $\mathrm{~h} / \mathrm{day}$ & U.S. EPA [1989a] \\
\hline Exposure frequency at home, $\mathrm{EF}_{\mathrm{h}}$ & 365 & $\mathrm{n} / \mathrm{a}$ & day/y & This report \\
\hline Exposure time in surface water, $\mathrm{ET}_{\mathrm{sw}}$ & 2 & 0.5 to 1 & $\mathrm{~h} / \mathrm{d}$ & U.S. EPA [1992a] \\
\hline Exposure frequency to surface water, $\mathrm{EF}_{\mathrm{sw}}$ & 30 & 5 to 150 & day/y & U.S. EPA [1992a] \\
\hline \hline
\end{tabular}

\subsubsection{Dermal Uptake from Air}

For individuals who are at rest during the time of exposure, the amount of tritium entering the body by dermal uptake is approximately equal to that by inhalation [Hill and Johnson, 1993, Pinsom and Langham, 1980]. For an individual at rest, the ratio of inhalation intake per unit body weight $(\mathrm{Bq} / \mathrm{kg}-\mathrm{h})$ to air concentration $\left(\mathrm{Bq} / \mathrm{m}^{3}\right)$ is 0.0064 $\mathrm{m}^{3} / \mathrm{kg}-\mathrm{h}$, as defined in Table 4-4. For dermal uptake of tritium from air, the ratio of dermal uptake to air concentration is equal to the product of the effective skin permeability $(\mathrm{m} / \mathrm{h})$ and the mass-specific surface area of the body: 


$$
\begin{gathered}
\frac{\text { inhalation intake rate }}{C_{\text {air }}}=0.0064 \mathrm{~m}^{3} / \mathrm{kg}-\mathrm{h} \\
\frac{\text { dermal uptake rate }}{C_{\text {air }}}=K_{p}^{\text {air }}(\mathrm{m} / \mathrm{h}) \times S A_{b}\left(\mathrm{~m}^{2} / \mathrm{kg}\right)
\end{gathered}
$$

where $K_{p}^{a i r}$ is the effective permeability of tritium in air through human skin and $S A_{b}$ is the ratio of body surface area to body weight as given in Table 4-4. By equating (4-8) and (4-9) we found that $K_{p}^{a l r}$ is on the order of $0.25 \mathrm{~m} / \mathrm{h}$, which is somewhat high but not inconsistent with permeabilities that have been measured for organic vapors (EPA, 1992).

\subsubsection{Dermal Uptake from Water}

Dermal uptake of tritium from water pertains to recreational scenarios, such as wading and swimming in creeks. As with air, the dermal uptake of tritium from water is based on the measured ratio of uptake to concentration. The permeability of water on skin has been measured at $1.5 \times 10^{-5} \mathrm{~m} / \mathrm{h}(\mathrm{EPA}, 1992)$. Since the diffusion coefficients of $\mathrm{HTO}$ in air and water are essentially the same as $\mathrm{H}_{2} \mathrm{O}$ [NCRP, 1985], this value is assumed to be appropriate for HTO.

\subsection{The Relation Between Tritium Exposure, Radiological Dose and Health Effects}

This section looks at how exposures to tritium are linked to potential health impacts within the exposed population. First, a review of the potential health effects associated with tritium establishes the relation between tissue concentration and radiological dose. To establish the appropriate relation between exposure and dose, we next look at metabolism and dosimetry, followed by regulatory standards that have been established to limit exposure and dose. A derivation of the risk factors used to estimate the incidence of health impacts within the exposed population concludes the section.

\subsubsection{Health Risks Associated with Tritium}

To quantify the likely magnitude of health risks associated with exposures to tritium, it is necessary to address tritium metabolism and dose in terms of radiation biology and radiation protection methods.

Each decay of a tritium atom releases energy that is carried by the resulting beta particle. The rate of decay is expressed as the product of the number of atoms $N$ and the decay constant, which is equal to 0.693 divided by the half-life, $T_{1 / 2}$, 


$$
\text { decays per unit time }=N \times 0.693 / T_{1 / 2} \text {. }
$$

The energy release rate by these decays is equal to the rate of decay times the average beta decay energy $E_{\beta}$ (in joule/decay). Furthermore, the energy absorption rate is equal to the energy release rate divided by the tissue mass, $M_{t}$.

$$
\text { energy absorption rate }=\frac{E_{\beta} \times N \times 0.693}{T_{1 / 2} \times M_{t}} \text {. }
$$

The unit for energy absorption in living tissues is the gray (Gy). One Gy represents one joule of energy deposited per kilogram $(\mathrm{kg})$ of tissue.

Because few studies are available on tritium-induced health injury in humans, healthrisk estimates for tritium must be based on the large number of experiments with animals and cell cultures [Straume, 1993]. These experiments show that exposure to tritiated water results in mutations and cell disruptions that can lead to cancer, heritable genetic defects, and reproductive and developmental effects [Straume, 1993]. These effects are qualitatively similar to the injuries caused by low linear-energy-transfer (LET) radiations produced by cesium- 137 and cobalt -60 , such as $x$-rays and gammarays, for which a significant amount of human data is available. The quantitative difference between tritium beta emissions and a standard low-LET radiation is expressed by the relative biological effectiveness (RBE). The RBE for tritium ranges from 1 to 3 [Straume, 1993]. This means that although the health effects of the beta doses from tritium are believed to be qualitatively similar to health effects of gamma rays, the beta rays are believed to be more potent per unit energy deposition than gamma rays. However, there have been no human experiments that demonstrate the validity of these conclusions for the weak beta energy of tritium decay. As has been noted by UNSCEAR [1993] there is some likelihood that no health effects would occur at low doses and low dose rates.

\subsubsection{Tritium Metabolism and Dosimetry}

There is general consensus that the current understanding of the metabolism of HTO is sufficient for radiation protection purposes [Hill and Johnson, 1993]. When it enters the body, HTO quickly reaches equilibrium with hydrogen in the body and imparts a uniform dose to all soft tissues. The ICRP [1978] recommends the assumption that internalized HTO is completely absorbed and mixed rapidly with total body water so that the concentration in all body waters-blood, urine, sweat, sputum, insensible perspiration, and exhaled water vapor-is the same. However, following HTO exposures, a small fraction of tritium will eventually be incorporated into organic molecules as OBT and will have a different metabolic rate than total body water tritium. Because there is no preferential distribution of OBT to any specific body tissue, it can be assumed that both HTO and OBT are uniformly distributed throughout the body, once taken in through some exposure route. 
Human studies indicate that, generally, tritium retention can be characterized by a three-component exponential function. These three components have biological halflives of 6 to 12 days, 10 to 34 days, and 130 to 550 days, with respective median values of 9, 22, and 340 days [Hill and Johnson, 1993]. The first biological half-life is for the body water metabolism of hydrogen and reflects the turnover of water within the pool of body water. The second half-life appears to be related to tritium involved in carbontritium bonds, and the last is for tritium incorporated into organic molecules having very slow turnover rates [Hill and Johnson, 1993].

Tritium can also enter the body as OBT through food products. The fate of OBT after ingestion depends primarily on the human body's hydrogen metabolism. Usually, direct uptake and metabolism of OBT has been ignored in models of tritium dosimetry. However, recent reports based on more advanced environmental tritium models indicate that ingestion doses from OBT in food could be higher than doses from equivalent quantities of tritium ingested or inhaled as HTO [Etnier et al., 1984]. To properly assess combined exposures to HTO and OBT, we describe the retention of tritium following exposure with a model that accounts for intake of both. Following the recommendation of Hill and Johnson [1993], we use the four-compartment model proposed by Etnier et al. [1984] to describe tritium retention. One compartment is used to represent the retention of tritium in body water and the other three compartments are used to represent the retention of tritium in different types of organic molecules. This model is illustrated in Figure 4-4.

The $\lambda$ parameters in this model represent rate constants for the transfer of tritium among compartments. These parameters are measured by studying the retention and loss of tritium in human and animal subjects. Some of these parameters can be determined directly from curves of tritium retention in the body. For example, in Figure $4-4, \lambda_{w o}$ is equal to $0.693 / T_{1 / 2}^{w}, \lambda_{k w}$ is equal to $0.693 / T_{1 / 2}^{l}$, and $\lambda_{n f}$ is equal to $0.693 / T_{1 / 2}^{n}$; where $T_{1 / 2}^{i t}, T_{1 / 2}^{l}$, and $T_{1 / 2}^{n}$ are the biological half-lives that reflect, respectively, the turnover of hydrogen within the pool of body water, labile tritium involved in non-water bonds, and tritium incorporated into organic molecules that have very slow turnover rates. Other $\lambda$ parameters are derived from steady-state distributions of tritium activity. Etnier et al. [1984] report the following values (with units of day ${ }^{-1}$ ): $\lambda_{u t}$ is equal to $0.0005463, \lambda_{u f}$ is equal to $0.00416, \lambda_{f w}$ is equal to 1.5472 , and $\lambda_{f n}$ is equal to 0.10328 .

Under steady-state conditions, these parameters can be used to assess the body burden associated with a continuous input of tritium as HTO or OBT by estimating the effective tritium half life, $T_{1 / 2}^{t t}$, for a given intake. When HTO is ingested, based on the ranges of compartment half-lives discussed above, the model in Figure 4-4 gives an estimated mean value of $T_{1 / 2}^{\text {tlt }}$ equal to 15 days with a CV of 0.2 . When OBT is ingested into either the labile or fast fat compartment, the model in Figure 4-4 gives an estimated mean 


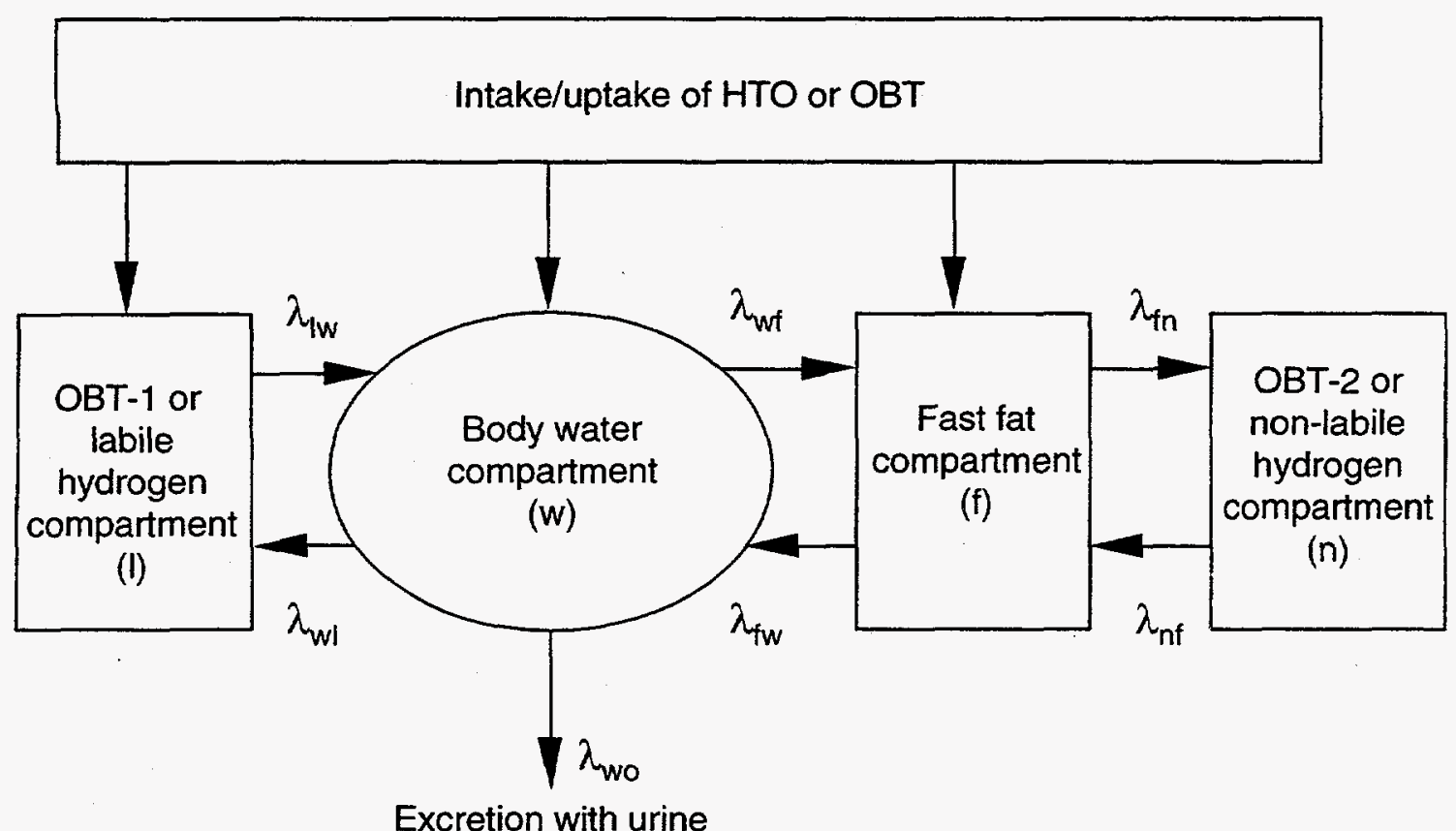

Figure 4-4. Four-compartment model for tritium metabolism, applied to the intake or uptake of HTO and OBT. The four compartments are body water (w); rapid-turnover OBT, which contains labile tritium (l); fast-fat, with rapid turnover of non-labile OBT (f); and slowturnover, with slow turnover of non-labile OBT $(n)$. The $\lambda$ parameters are rate constants for tritium transfer among compartments and relate to the half-lives in these compartments.

value of $T_{1 / 2}^{t l t}$ equal to 48 days with a $C V$ of 0.3 . Based on the appropriate effective halflife $T_{1 / 2}^{\text {tlt }}$, the total amount of tritium retained in the body, $Q_{\text {total }}$ in $\mathrm{Bq}$, is calculated from

$$
Q_{\text {total }}(B q)=\frac{I U \times T_{1 / 2}^{t l t}}{0.693}
$$

From this steady state inventory and the body weight, BW (in $\mathrm{kg}$ ), we calculate the total body burden (in Bq/ $\mathrm{kg}$ ) and the corresponding dose rate in Gy per year as

$$
\text { burden }(B q / k g)=\frac{I U \times T_{1 / 2}^{t t i}}{0.693 \times B W}
$$




$$
\begin{aligned}
\text { dose rate }(G y / y)= & \text { burden } \times 5.685 \frac{\mathrm{keV}}{\text { dist }} \times 3.15 \times 10^{7} \frac{\mathrm{sec}}{\text { year }} \\
& \times 1.6 \times 10^{-16} \frac{\mathrm{Joule}}{\mathrm{keV}} \\
& =\text { burden } \times 2.865 \times 10^{-8}
\end{aligned}
$$

where dist means disintegration.

\subsubsection{Regulatory Guidance Relevant to Tritium}

International, federal, and state agencies have all set standards for controlling human exposures to tritium in both occupational and nonoccupational settings.

For radiation protection in occupational settings, the ICRP [1978] has recommended the use of both an annual limit on intake (ALI) and a derived air concentration (DAC) for HTO. The DAC is the air concentration that would result in the ALI through inhalation and dermal routes for exposure times and exposure frequencies typical in the work environment (2000 hours of exposure per year and $3750 \mathrm{~m}^{3}$ of air as a annual breathing volume). The 1978 recommendation of the ICRP is that the ALI for HTO be 3 billion Bq $(0.08 \mathrm{Ci})$ and that the corresponding DAC be $800,000 \mathrm{~Bq} / \mathrm{m}^{3}\left(22 \mu \mathrm{Ci} / \mathrm{m}^{3}\right)$. This number corresponds to a committed annual effective dose of $0.05 \mathrm{~Sv}(5 \mathrm{rem})$ to workers. Based on the risk factor of 0.04 fatal cancers per Sv recommended for low-dose exposures to working populations by the United Nations Scientific Committee on the Effects of Atomic Radiation [UNSCEAR, 1993], 0.05 Sv corresponds to an annual fatal cancer risk of 0.002 for the working population exposed to this level. Recently, the ICRP [1991] has recommended the reduction of the committed annual effective dose limit for workers from $0.05 \mathrm{~Sv}$ to $0.02 \mathrm{~Sv}$. With this recommendation, the ALI and DAC for HTO become 1 billion $\mathrm{Bq}$ and $300,000 \mathrm{~Bq} / \mathrm{m}^{3}$, respectively. These new values correspond to a fatal cancer risk of 0.0008 per year of exposure at the $0.02 \mathrm{~Sv}$ limit.

Currently, the Code of Federal Regulations (CFR) of the United States (10 CFR-835, 1994) follows the 1978 ICRP guidelines and specifies that exposure at U.S. Department of Energy (DOE) facilities not exceed a committed annual effective dose of $0.05 \mathrm{~Sv}$ to workers. Based on this standard, the CFR recommends the same ALI and DAC for tritium as those recommended by the ICRP in 1978. In addition, the CFR specifies that the dose limit for worker during pregnancy is $0.005 \mathrm{~Sv}(0.5 \mathrm{rem})$, that any minor exposed to radiation or radioactive material during direct on-site access at a DOE site or facility shall not receive in excess of $0.001 \mathrm{~Sv}(0.1 \mathrm{rem})$ total effective dose equivalent annually, and that any member of the public exposed to radiation or radioactive material during direct on-site access at a DOE site or facility shall not receive in excess of $0.001 \mathrm{~Sv}(0.1 \mathrm{rem})$, annually. To guarantee compliance with these latter guidelines, a limit of roughly $16,000 \mathrm{~Bq} / \mathrm{m}^{3}$ for HTO-in-air concentrations is required. $10 \mathrm{CFR} 20$ limits annual worker exposure to $0.05 \mathrm{~Sv}$ from both internal and external sources and limits annual public exposure to $0.001 \mathrm{~Sv}$ from all exposure routes. 
The CFR also specifies maximum contaminant levels in air (40 CFR-61, 1993) and water (40 CFR-141, 1994) for beta particles released from man-made radionuclides to unrestricted areas. For emissions to air, the CFR specifies that emissions of radionuclides to the ambient air from Department of Energy facilities should not exceed those amounts that would cause any member of the public to receive in any year an effective dose equivalent of $0.0001 \mathrm{~Sv}(0.01 \mathrm{rem})$. Based on scaling the DAC for working environments from a risk of 0.05 to $0.0001 \mathrm{~Sv}$ and adjusting for an annual exposure time of $8,760 \mathrm{~h}$ (i.e., $24 \mathrm{~h} / \mathrm{d}$ for $365 \mathrm{~d} / \mathrm{y}$ ) versus 2,000, we estimate that the ambient concentration limit corresponding to continuous exposure for a member of the public is on the order of $365 \mathrm{~Bq} / \mathrm{m}^{3}\left(10,000 \mathrm{pCi} / \mathrm{m}^{3}\right)$. The maximum contaminant levels for tritium in water is specified in the CFR as $740 \mathrm{~Bq} / \mathrm{L}(20,000 \mathrm{pCi} / \mathrm{L})$. The State of California uses federal standards for tritium concentration limits in air and water [California Environmental Regulations Section 64443. Man-Made Radioactivity, 1993].

\subsubsection{Risk Factors: The Relation Between Radiological Dose and Health Effects}

Detrimental effects of toxic chemicals on humans, animals, and plants can be classified as stochastic or nonstochastic effects [ICRP, 1977]. Stochastic effects are those for which the probability of an effect occurring, rather than the severity of effect, is proportional to dose without threshold. Nonstochastic effects are those for which the severity of effect is a function of dose and for which a threshold may exist. For example, the human health effects of carcinogens and many types of genetic effects are assumed to be stochastic. In contrast, the effects of neurotoxins, such as lead and mercury, are assumed to be nonstochastic. The detrimental effects of body burdens of tritiated water are stochastic. This section identifies risk factors that can be used to estimate the likely occurrence of these effects in exposed populations.

Together with previous studies, a large number of radiobiological studies conducted over the past decade indicate that tritium in body water produces the same portfolio of radiogenic effects as that observed following whole-body exposure to penetrating ionizing radiations such as $x$-rays and gamma rays [Straume and Carsten, 1993], including cancer, heritable genetic defects, and reproductive and developmental effects. Nevertheless, it has been observed and reported that the beta rays produced by tritium have greater biological effectiveness (i.e., damage potential) than $\mathrm{x}$-rays or gamma rays of the same energy [Straume and Carsten, 1993].

We have shown that an annual dose equivalent from tritium exposure can be calculated from tritium concentration in body water by converting this body-water concentration to an estimate of equivalent whole-body energy deposition in Gy. Based on the average dose in Gy for a population, we derive the risk factors to predict the potential incidence of detrimental effects. However, studies showing deleterious effects from tritium uptake were in the million-Bq-per-liter range. These ranges may not be applicable to the concentrations around the LBNL tritium facility. 


\subsubsection{The Risk Factor for Cancer, $\mathbf{R}_{\text {HTO }}^{\text {can }}$}

Exposures to tritiated water appear to induce DNA changes, indicating that HTO might be an initiator of cancer. In addition, there is evidence that HTO can cause transformations in mutant stem cells and thus enhance later stages of the progression from normal to cancer cells, thus indicating that HTO might also be considered a promoter of cancer. Types of cancers associated with HTO dose include leukemia and nonleukemia (primarily soft-tissue carcinomas) [Straume, 1993].

Straume [1993] has developed a stochastic dose-response model of fatal cancer risk for HTO doses that is based on the dose-response data for human cancer and a modification for the biological effectiveness of HTO relative to gamma rays. This model expresses the probability of cancer per Gy of dose and is illustrated in Figure 4-5. In this model the risk factor for cancer incidence within a population has respective median and mean values of 0.080 and 0.089 fatal cancers per Gy of dose. According to Straume [1993], the full range of this distribution is from 0.018 to 0.580 , and the CV is approximately 1.3. The International Commission on Radiological Protection [ICRP, 1990] recommends a risk factor of 0.05 per $\mathrm{Sv}$ for fatal cancers in populations that include adults (of all ages) and children. Thus, the risk factor of 0.089 per Gy used here has an implicit relative biological effectiveness (RBE) of 1.8. However, Straume's [1993] data for RBE used to construct his risk factor suggests that the RBE he used was actually 2.3. This discrepancy suggests that Straume's model differs somewhat from the ICRP [1990] approach.

The factor 0.089 is the risk factor for fatal cancer. In order to determine the total number or incidence of cancers, we multiply the number of fatal cancers by 1.2. This ratio is used by the ICRP in their stochastic dose-response model. This ratio implies that for every 5 fatal cancers predicted to result from radiation exposure, there will be on average a likelihood of 1 nonfatal cancer in addition to five fatal cancers. 


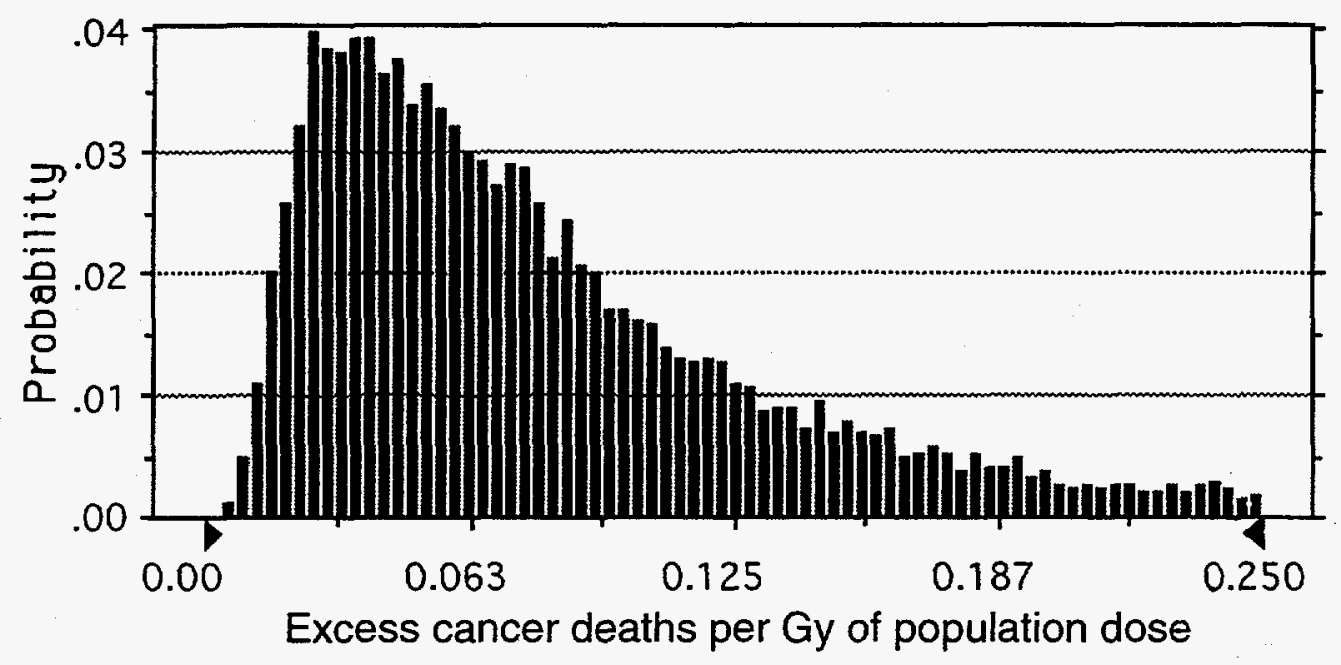

Figure 4-5. The stochastic cancer risk factor for population doses of tritiated water as derived from the model of Straume [1993].

\subsubsection{The Risk Factor for Heritable Genetic Effects, $\mathbf{R}_{\text {HTO }}^{\text {gen }}$}

To estimate genetic risk to humans from low-level HTO exposures, we use a model developed by Straume [1993], who has used ranges and distributions of gamma-rayinduced risks to construct a stochastic-dose response function for the number of heritable genetic defects expected per Gy of population dose. The distribution of defects per unit dose obtained from this model is shown in Figure 4-6. This distribution has respective median and mean values of 0.006 and 0.0066 defects per live-born Gy of population dose in the first generation. The range of this distribution is from 0.0014 to 0.033 , and the CV is approximately 1.3 . 


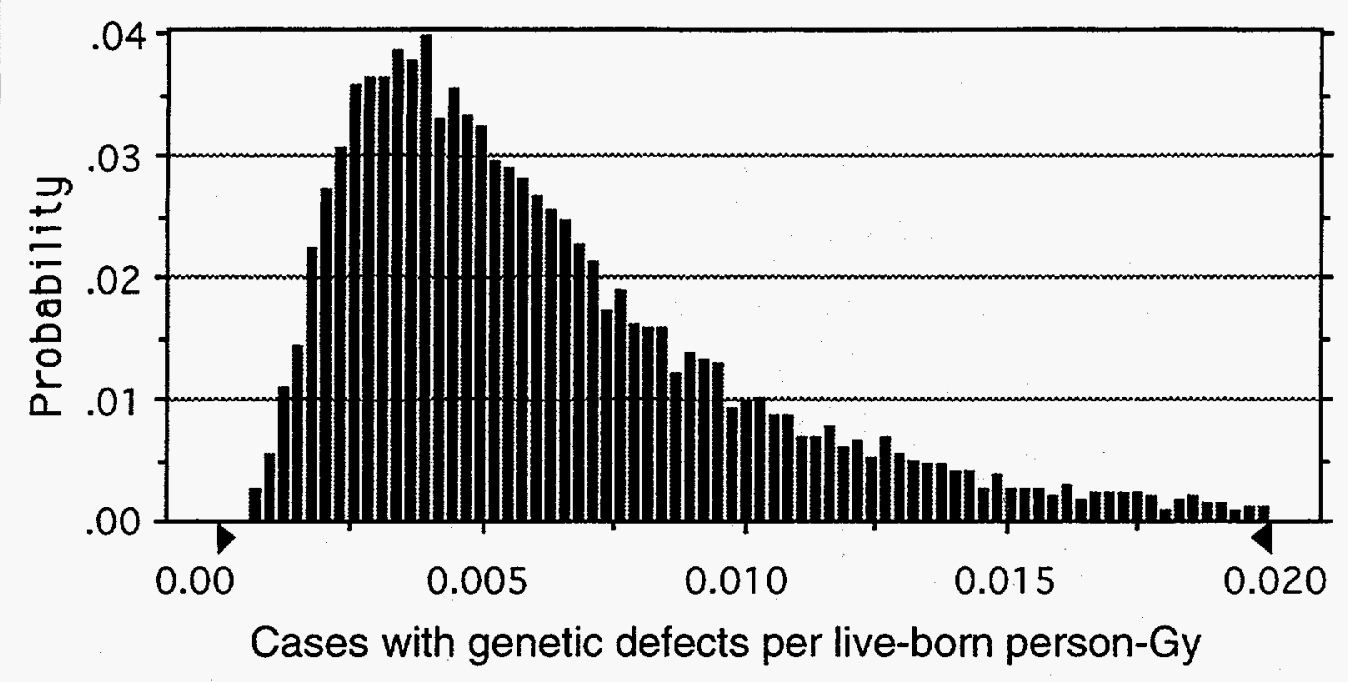

Figure 4-6. The stochastic distribution of the genetic risk factor expressed as the number of heritable defects per live-born Gy of population dose in the fetus.

\subsubsection{The Risk Factor for Developmental and Reproductive Effects, $\mathbf{R}_{\mathrm{HTO}}^{\text {rep }}$}

To estimate reproductive and developmental risk in humans from low-level HTO exposure, we use the model of Straume [1993] who has used ranges and distributions of gamma-ray-induced risks to construct a range of likely values for the dose-response function for HTO doses. From these data we developed a stochastic-dose response function for the number of reproductive and developmental effects expected per Gy of dose to the live-born infant. The probability density function of this model is shown in Figure 4-7. This distribution has respective median and mean values of 0.15 and 0.17 defects per live-born Gy of population dose. The range of this distribution is from 0 to 0.4 , and the $C V$ is approximately 0.45 . 


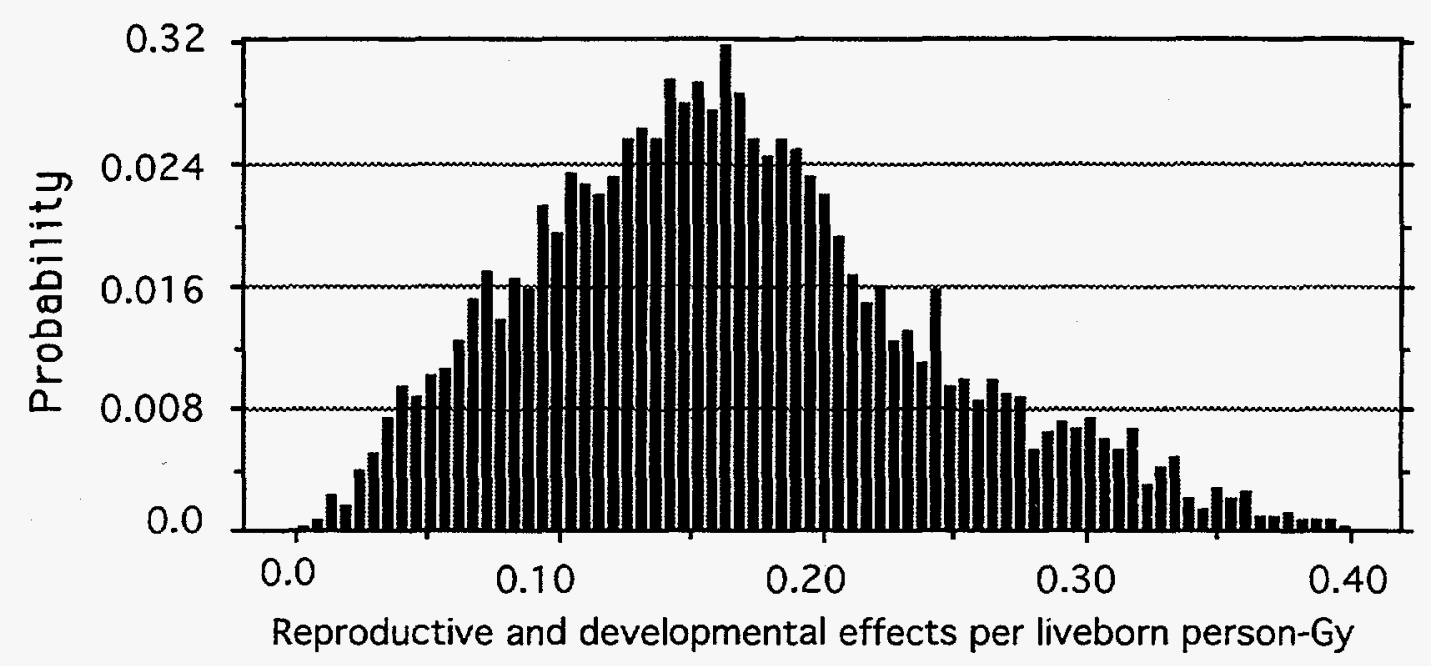

Figure 4-7. The distribution of reproductive and developmental effects associated with population doses of tritiated water expressed per average dose in Gy within that population. This model is based on recommendations of Straume [1993].

\subsection{Estimated Health Risks for Tritium Releases from the NTLF}

In this section, we quantify the potential health risks to the populations in and near the NTLF facility. The purpose of this assessment is to determine how tritium doses and potential health effects might be distributed among the occupational and nonoccupational populations of LBNL, the University of California (UC), and the cities of Berkeley and Oakland.

Three geographic zones and associated populations are defined in order to carry out this analysis (see Figure 4-8). Zone 1 includes the natural bowl that surrounds the NTLF facility and its tritium release stack. The population potentially at risk within this zone is the working population and its off-spring. Zone 2 includes the entire LBNL site; the UC property occupied by the Lawrence Hall of Science, the Samuel Silver Space Sciences Laboratory, the Mathematical Sciences Research Institute, and the Botanical Garden; and some single-family residences along the ridge above the LBNL site. Zone 3 includes the main UC Berkeley campus and areas of the city of Berkeley beyond Zone 2 and within $2 \mathrm{~km}$ of the NTLF. 


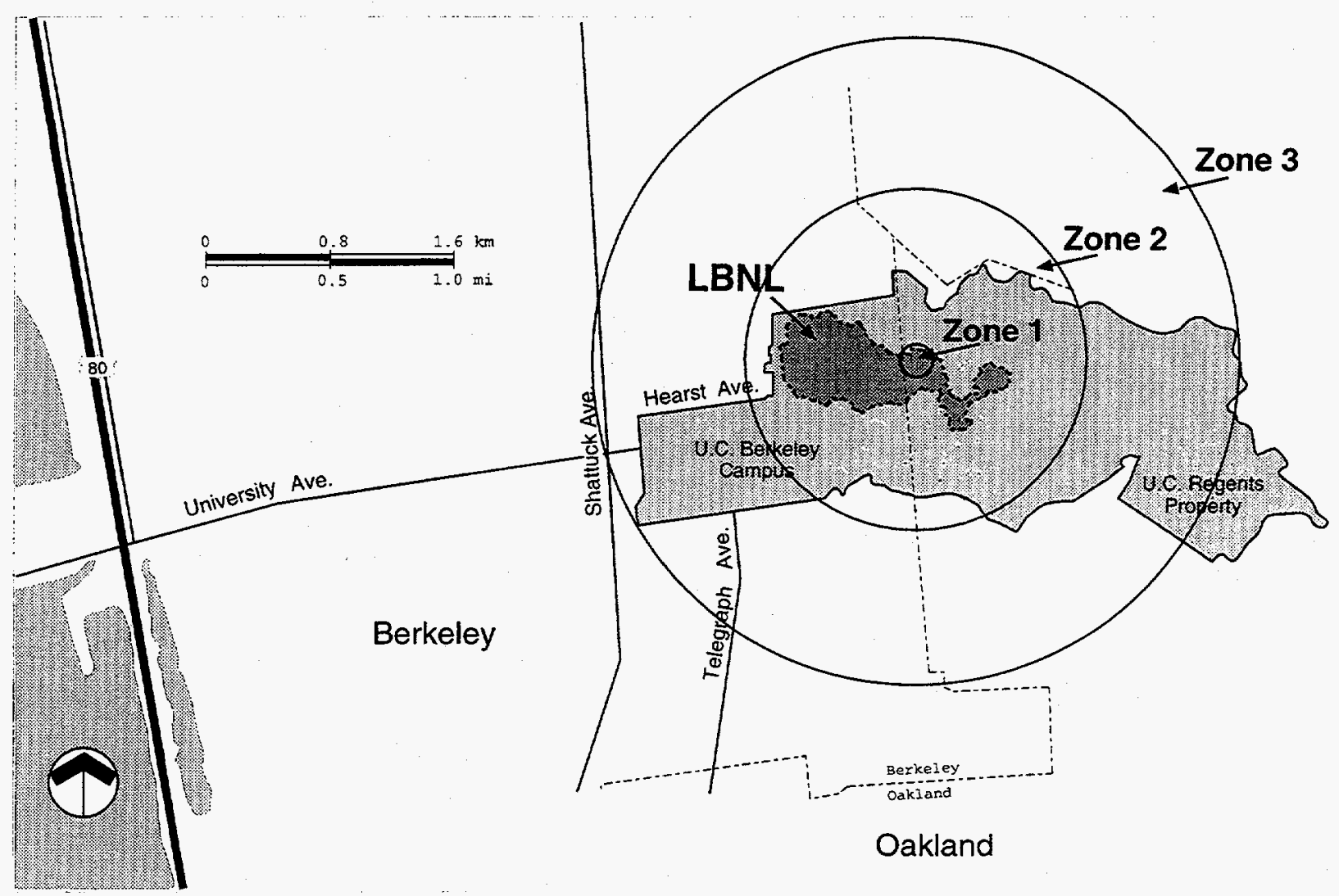

Figure 4-8. Geographical areas of tritium release, zones 1, 2, and 3.

\subsubsection{Tritium Concentrations in Air, Water, and Soil of the NTLF Environment}

The first step of our analysis is to characterize the concentrations of tritium in air, water, and soil of the proximate NTLF environment. The model reproduces the upper range of tritium concentrations that have been measured in the environment near the NTLF site. In air, tritium concentrations have been measured in the range of 10 to $100 \mathrm{~Bq} / \mathrm{m}^{3}$; in ground water and surface water runoff (hydraugers and streams) 40 to $800 \mathrm{~Bq} / \mathrm{L}$ have been measured; and in rainwater 60 to $733 \mathrm{~Bq} / \mathrm{L}$ have been observed [Schleimer and Pauer, 1991]. The reasonable upper bound tritium concentrations in each of the three exposure zones are estimated using the transport models described above and in Appendix A. These concentrations are compared to recently measured values in Appendix F.

Landscape, climate and hydrology parameters used in the analysis are derived from site-specific information. These parameters are summarized in Table 4-6. The references and methods used to obtain these values are described in detail in Appendix 
C. The model used to determine tritium concentrations in Zones 1 and 2 is a sitespecific model, which is described in Appendix A. It is based on the CalTOX model, which is a standard model used by the California Department of Toxic Substances Control for assessing risks at toxic substances release sites [McKone, 1993]. In Zone 3, we use the EPA radionuclide air dispersion model CAP88 to determine tritium concentration in air. As is discussed in Chapter 1 of this report, the site-specific model and the CAP88 model give close dose and risk estimates in Zone 2. The CAP88 model is not appropriate in Zone 1, because of the proximity to the source and because of the complex terrain. For application in Zone 3, we note that the CAP88 model calculates ingestion doses by pooling all vegetation within $80 \mathrm{~km}$ of the tritium source and assuming this vegetation provides some fraction of the food consumed by any individual in this area. Since this algorithm is not realistic, based on what is known about food distribution patterns in this area, we decided to use only the calculated air concentration from CAP88 in combination with the dose models developed for Zone 2 to estimate the exposure, dose and risk in Zone 3.

Table 4-6

Landscape properties for the NTLF Environment.

\begin{tabular}{|l|c|c|c|l|}
\hline \multicolumn{1}{|c|}{ Parameter description } & Symbol & $\begin{array}{c}\text { Mean } \\
\text { value }\end{array}$ & CV & \multicolumn{1}{|c|}{ Reference(s) } \\
\hline Yearly average wind speed, $\mathrm{m} / \mathrm{s}$ & $\mathrm{v}_{\mathrm{W}}$ & 2 & 0.3 & Thorson [1996] \\
\hline Yearly average temperature, ${ }^{\circ} \mathrm{C}$ & $T$ & 12.5 & 0.2 & $\begin{array}{l}\text { Merry [1991] } \\
\text { NOAA [1974] }\end{array}$ \\
\hline Yearly average relative humidity, \% & $R H$ & 79 & 0.04 & $\begin{array}{l}\text { Merry [1991] } \\
\text { NOAA, [1974] }\end{array}$ \\
\hline Soil compartment depth, $\mathrm{m}$ & $d_{\mathrm{S}}$ & 2.5 & 0.5 & $\begin{array}{l}\text { Thibodeaux, [1994] } \\
\text { Murphy [1993] }\end{array}$ \\
\hline $\begin{array}{l}\text { Volumetric moisture content of soil, } \\
\text { L(water)/L(soil) }\end{array}$ & $\sigma_{\mathrm{S}}$ & 0.3 & 0.1 & $\begin{array}{l}\text { van der Leeden et al. } \\
{[1991]}\end{array}$ \\
\hline Annual average precipitation, $\mathrm{m} / \mathrm{y}$ & rain & 0.64 & 1.0 & $\begin{array}{l}\text { Merry [1991] } \\
\text { NOAA [1974] }\end{array}$ \\
\hline $\begin{array}{l}\text { Annual average evapotranspiration, } \\
\mathrm{m} / \mathrm{y}\end{array}$ & evapotrans & 0.45 & 0.14 & $\begin{array}{l}\text { van der Leeden et al. } \\
{[1991]}\end{array}$ \\
\hline Annual average runoff, $\mathrm{m} / \mathrm{y}$ & runoff & 0.13 & 0.26 & $\begin{array}{l}\text { van der Leeden et al. } \\
\text { [1991] }\end{array}$ \\
\hline Infiltration to ground water, $\mathrm{m} / \mathrm{y}$ & recharge & 0.06 & 0.26 & This report \\
\hline Scavenging efficiency & Aq & 0.4 & 0.2 & Murphy [1993] \\
\hline \hline
\end{tabular}




\subsubsection{Source Term}

The NTLF currently releases tritium at a rate of approximately $100 \mathrm{Ci} / \mathrm{y}$ (3.7 trillion $\mathrm{Bq} / \mathrm{y})$. This has been typical since 1990. This value is lower than during the period 1982 to 1990, but higher than current releases by about a factor of 2 or more. According to the 1990 LBNL Site Environmental report, essentially all of LBNL's tritium emissions originate from the NTLF [LBNL Site Report, 1990]. The total inventory of tritium that is attached to the uranium beds (U-beds) is roughly $10,000 \mathrm{Ci}$-the U-beds are designed with a stoichiometric capacity for $25,000 \mathrm{Ci}$ of tritium, and thus are always underutilized. The release of the entire inventory, even in the case of an extreme event, is unlikely. It is even less likely that it would persist for an extended period (i.e., more than a few days). Note that a catastrophic accident would be a one-time release and certainly would not persist.

\subsubsection{Source Area and Mixing Height of the Atmosphere Near the NTLF}

The NTLF stack is located on the slope west of Building 75 (Figure 4-9). Its surrounding area is in a natural bowl or amphitheater. We used this bowl to characterize the initial mixing volume of the stack release. To be conservative, we used $15 \mathrm{~m}$ as the mixing height for Zone 1, which may lead to an overestimate of the tritium concentration in air.

\subsubsection{Predicted Concentrations in the Vicinity of the NTLF, Zone 1}

The total volume of air for characterizing exposure in Zone 1 is estimated to be 471,000 $\mathrm{m}^{3}$ and the volume of soil compartment in this zone is estimated to be $78,540 \mathrm{~m}^{3}$. Based on these volumes, the landscape properties defined in Table 4-6, and the model equations in Appendix A, the estimated tritium turnover rates for the air and soil compartments in Zone 1 are shown in Table 4-7.

Table 4-7

Tritium Turnover Rates for the Air and Soil Compartments in Zone 1

\begin{tabular}{|c|l|l|}
\hline Compartment & \multicolumn{1}{|c|}{ Turnover Rate } \\
\hline \multirow{4}{*}{ Air } & Turnover rate from air to soil, $T_{\text {as }}$ & 0.76 per day \\
\cline { 2 - 3 } & Turnover rate out of the air volume by wind, $T_{\text {ao }}$ & 224 per day \\
\cline { 2 - 3 } & Effective environmental residence of tritium in air, $1 / \mathrm{L}_{a}$ & 0.0044 day \\
\hline \multirow{3}{*}{ Soil } & Turnover rate from soil to air, $\mathrm{T}_{\text {sa }}$ & 0.0016 per day \\
\cline { 2 - 3 } & Turnover rate out of the soil by leaching, $\mathrm{T}_{\text {so }}$ & 0.0007 per day \\
\cline { 2 - 3 } & Effective environmental half-life of tritium in soil, $1 / \mathrm{L}_{\mathrm{S}}$ & 400 days \\
\hline \hline
\end{tabular}


Table 4-8 lists the air, soil, and runoff water concentrations of tritium predicted for Zone 1 based on these turnover rates used in Equations 4-5 and 4-6 under the assumption that there are continuous tritium releases of $100 \mathrm{Ci} / \mathrm{y}$. The predicted concentrations are even below the regulatory standards for the ambient (i.e., nonoccupational) environment, $365 \mathrm{~Bq} / \mathrm{m} 3$ in air and $740 \mathrm{~Bq} / \mathrm{L}$ in water, as discussed in Section 4.6.3.

Table 4-8

Tritium Concentrations and Inventories in Zone 1, Corresponding to a Release of $100 \mathrm{Ci} /$ year

\begin{tabular}{|l|c|c|}
\hline Compartment & $\begin{array}{c}\text { Tritium concentration } \\
\left(\mathrm{Bq} / \mathrm{m}^{3}\right)\end{array}$ & $\begin{array}{c}\text { Tritium inventory } \\
(\mathrm{Bq})\end{array}$ \\
\hline Air & 96 & $4.5 \times 10^{7}$ \\
\hline Soil & $1.8 \times 10^{5}$ & $1.4 \times 10^{10}$ \\
\hline Runoff water & $5.8 \times 10^{5}(580 \mathrm{~Bq} / \mathrm{L})$ & $\mathrm{N} / \mathrm{a}$ \\
\hline \hline
\end{tabular}

\subsubsection{Predicted Concentrations in Zone 2}

Zone 2 has a larger radius, and we used $25 \mathrm{~m}$ as the mixing height for estimating the tritium concentrations in Zone 2 . With a radius of $1100 \mathrm{~m}$, the total volume of air for characterizing exposure in Zone 2 is estimated to be $9.5 \times 10^{7} \mathrm{~m}^{3}$ and the volume of soil in this zone is estimated to be $9.5 \times 10^{6} \mathrm{~m}^{3}$. Based on these volumes, the landscape properties defined in Table 4-6, and the model equations in Appendix A, we estimated the tritium turnover rates given in Table 4-9 for the air and soil compartments in Zone 2. 


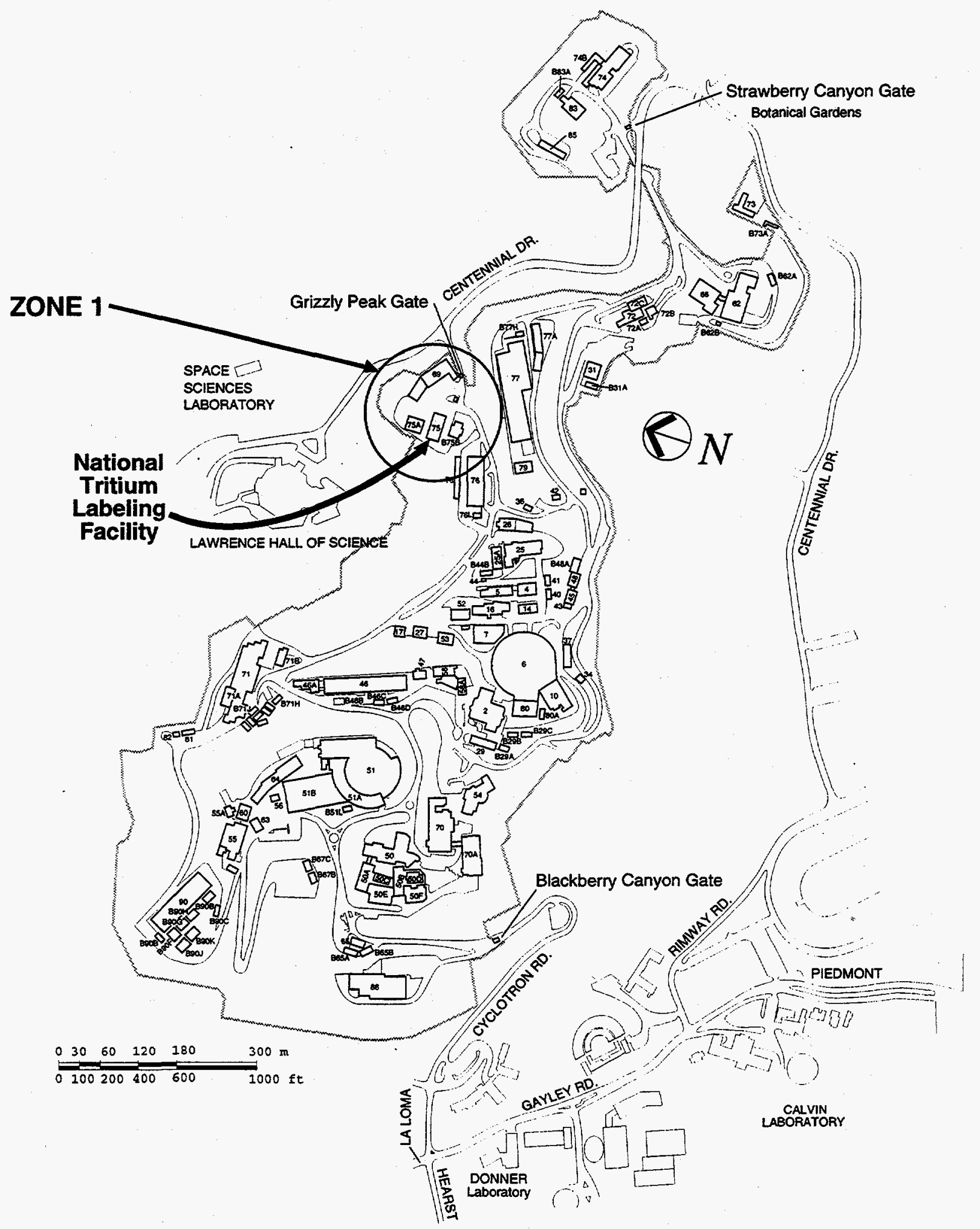

XBD 9505-01902.EPS

Figure 4-9. Location map. The NTLF is located in Building 75 on the LBNL site. 
Table 4-9

Tritium Turnover Rates for the Air and Soil Compartments in Zone 2

\begin{tabular}{|c|l|l|}
\hline Compartment & \multicolumn{1}{|c|}{ Turnover Rate } \\
\hline \multirow{4}{*}{ Air } & Turnover rate from air to soil, $T_{\text {as }}$ & 0.69 per day \\
\cline { 2 - 3 } & Turnover rate out of the air volume by wind, $T_{a}$ & 20 per day \\
\cline { 2 - 3 } & Effective environmental residence of tritium in air, $1 / L_{a}$ & 0.047 day \\
\hline \multirow{3}{*}{ Soil } & Turnover rate from soil to air, $T_{\text {sa }}$ & 0.0016 per day \\
\cline { 2 - 3 } & Turnover rate out of the soil by leaching, $T_{\text {so }}$ & 0.0007 per day \\
\cline { 2 - 3 } & Effective environmental half-life of tritium in soil, $1 / L_{s}$ & 400 days \\
\hline \hline
\end{tabular}

Table 4-10 lists the concentrations of tritium in air, soil, runoff water, vegetation HTO, and vegetation OBT predicted for Zone 2 using releases of $100 \mathrm{Ci} / \mathrm{y}$. The $\mathrm{HTO}$ levels in vegetation were derived by assuming that vegetation water is a mix of $75 \%$ atmospheric water and 25\% soil water [Murphy, 1993; Anspaugh et al., 1973]. The OBT levels in vegetation were derived by assuming that the OBT compartment contains about $3 \%$ of the hydrogen in fresh-plant material such as vegetables [Diabate and Strack, 1993]. We assume that the OBT level in fresh vegetables is 0.03 times HTO levels in plant water. For releases of $100 \mathrm{Ci} / \mathrm{y}$ the predicted concentrations are below the regulatory standards for the ambient (i.e., nonoccupational) environment, $365 \mathrm{~Bq} / \mathrm{m}^{3}$ in air and 740 $\mathrm{Bq} / \mathrm{L}$ in water, as discussed in Section 4.6.3.

\subsubsection{Predicted Concentrations in Zone 3}

In Zone 3, air concentrations are obtained using CAP88 (see Appendix F) with an Table 4-10

Tritium Concentrations and Inventories in Zone 2, Assuming a Release of $100 \mathrm{Ci} /$ Year

\begin{tabular}{|l|c|c|}
\hline \multicolumn{1}{|c|}{ Compartment } & Tritium concentration, $\mathbf{B q} / \mathrm{m}^{\mathbf{3}}$ & Tritium inventory, Bq \\
\hline Air & 5.2 & $4.9 \times 10^{8}$ \\
\hline Soil & $1.5 \times 10^{4}$ & $1.4 \times 10^{11}$ \\
\hline Runoff water & $4.8 \times 10^{4}(48 \mathrm{~Bq} / \mathrm{L})$ & $\mathrm{n} / \mathrm{a}$ \\
\hline Vegetation (HTO levels) & $110 \mathrm{~Bq} / \mathrm{kg}$ (fresh mass) & $\mathrm{n} / \mathrm{a}$ \\
\hline Vegetation (OBT levels) & $3 \mathrm{~Bq} / \mathrm{kg}$ (fresh mass) & $\mathrm{n} / \mathrm{a}$ \\
\hline \hline
\end{tabular}


adjustment to account for tritium added by the runoff in Strawberry Creek. Since Zone 3 represents the region from one to two kilometers from the NTLF and beyond, we use the highest $90^{\circ}$ sector yearly average tritium concentration produced by CAP88 at a distance of $1.5 \mathrm{~km}$ from the NTLF. This sector is the northwest sector with an estimated annual concentration of $0.35 \mathrm{~Bq} / \mathrm{m}^{3}$ associated with a $100 \mathrm{Ci} / \mathrm{y}$ release rate. This is where there is a rather high frequency of wind blowing from NTLF. As discussed below, we add to this concentration an amount used to account for evaporation of tritiated water from Strawberry Creek.

From measurements taken from air, rain water, soil, and surface water near the NTLF [Thorson, 1996], rain water appears to be washing tritium out of the air and into surface soil and the interstitial water of the soil. Some of the tritium in the soil water moves as runoff in the Chicken Creek Basin from which it is carried into Strawberry Creek and down toward the Berkeley Campus. This transfer by rainwater and runoff is used to assess tritium doses to those who come in contact with the lower portion of Strawberry Creek on the UC Berkeley Campus. This section illustrates how we estimated tritium concentrations in water and air associated with the segment of Strawberry Creek that flows through the Berkeley Campus.

Only a small fraction of the water flowing down Strawberry Creek (into Zone 3) originates from Zone 1 (bowl area). Assuming most of the stream flow stems from runoff, this fraction can be estimated as:

$$
F_{S, b w l}=A_{b w l} / A_{S, C t c h m t}
$$

where $F_{S, b w l}$ is the fraction of Strawberry Creek flow originating from the "bowl area," $\mathrm{A}_{\mathrm{bwl}}$ is the area of the Zone 1 and As,Ctchmt is the total area of the Strawberry-Creek catchment. This fraction is estimated to be roughly

$$
F_{S, b w l}=0.01
$$

Based on the fraction derived in Equation 4-16, we estimate that the tritium concentration in Strawberry Creek is on the order of $1 \%$ of the tritium water concentration in Zone 1. Based on the mass-balance model for water evaporation (Equation 4-17) in the area of the UC Campus, we estimate that evaporation from Strawberry Creek could contribute no more than about $0.01 \%$ to the total water inventory in air above the campus.

This analysis was carried out as follows. We assumed that the flow path of Strawberry Creek through the UC Berkeley campus and city is on the order of $2000 \mathrm{~m}$ (1.3 mile) and that it has an average width of 1 meter and depth of 0.5 meter. For evaporation of water from fast-moving water bodies, Southworth [1979] has shown that the rate of water evaporation is limited by the rate of mass transfer of saturated vapor in the air above the water. Furthermore, he has shown that this evaporation rate depends on the wind speed over the water, the water flow velocity, and the difference between the saturated 
and average relative vapor concentrations in air. This evaporation rate is given as follows:

evaporation rate $(\mathrm{m} / \mathrm{d})=0.00316 \times 86400 \mathrm{~s} / \mathrm{d} \times\left(v_{\mathrm{w}}+\right.$ current $\left._{\mathrm{w}}\right) \times\left[\varnothing_{\mathrm{a}}(100 \%)-\emptyset_{\mathrm{a}}\right]$

where $v_{\mathrm{w}}$ is the yearly average wind speed ( $3 \mathrm{~m} / \mathrm{s}$ from Table 4-6), current $\mathrm{w}_{\mathrm{w}}$ is the flow rate of the stream $\left(1 \mathrm{~m} / \mathrm{s}\right.$ assumed), $\varnothing_{\mathrm{a}}(100 \%)$ is the volumetric water content of the air at saturation and $\varnothing_{\mathrm{a}}$ is the volumetric water content of the air at the average relative humidity. Using Equations A-2 and A-3 in Appendix A with an assumed daytime temperature of $293 \mathrm{~K}$ and a yearly average daytime relative humidity of $70 \%$, we obtain $\varnothing_{\mathrm{a}}(100 \%)=1.7 \times 10^{-5}, \varnothing_{\mathrm{a}}=1.2 \times 10^{-5}$ and an evaporation rate of $0.005 \mathrm{~m} / \mathrm{d}$. Based on the stream dimensions already given, this amounts to a total mass evaporation of $10 \mathrm{~m}^{3}$ per day into the surrounding volume. Based on the box model already described, assume the residence time of this air mass to be 0.02 day, then the water coming from Strawberry Creek is on the order of $10^{-6}$ of the water in this air volume. The uncertainty is estimated to be 5 times higher or lower, and most likely lower. Table 4-11 gives the estimated Zone 3 tritium inventories and concentrations in air and surface water.

Table 4-11

Tritium Concentrations and Inventories in Zone 3, Assuming a Release of $100 \mathrm{Ci} / \mathrm{Y}$

\begin{tabular}{|l|c|c|}
\hline Compartment & Tritium concentration, Bq/m & Tritium inventory, Bq \\
\hline Air & 0.35 & $\mathrm{n} / \mathrm{a}$ \\
\hline Surface water (Strawberry Creek) & $1.1 \times 10^{4}(11 \mathrm{~Bq} / \mathrm{L})$ & $\mathrm{n} / \mathrm{a}$ \\
\hline \hline
\end{tabular}

\subsubsection{Generic Calculations of Intake, Uptake, Body Burdens, and Dose}

This section presents the mathematical expressions used to estimate the inhalation, dermal uptake, and ingestion exposures in each of the three zones.

\subsubsection{Average Intake by Inhalation}

The average intake of tritium in $\mathrm{Bq} / \mathrm{d}$ per $\mathrm{kg}$ body weight by inhalation in a working population is calculated using the yearly average tritium concentration of the air in each zone, $C_{a i r}\left(Z_{i}\right) \mathrm{Bq} / \mathrm{m}^{3}$; the working inhalation rate per unit body weight, $B R_{w} \mathrm{~m}^{3} / \mathrm{kg}-\mathrm{h}$; the exposure time at work, $E T_{w} \mathrm{~h} / \mathrm{d}$; and the exposure frequency at work, $E F_{w}$ days $/ \mathrm{y}$. 


$$
\operatorname{Intake}(\text { inh })=\frac{B R_{w} \times E T_{w} \times E F_{w}}{365 d / y} \times C_{\text {air }}\left(Z_{i}\right) \quad(\mathrm{Bq} / \mathrm{kg}-\mathrm{d})
$$

The average intake of tritium in $\mathrm{Bq} / \mathrm{d}$ per $\mathrm{kg}$ body weight by inhalation in a nonoccupational population is calculated using the yearly average tritium concentration of the air of each zone, $C_{a i r}\left(Z_{i}\right) \mathrm{Bq} / \mathrm{m}^{3}$; the active and resting inhalation rates per unit body weight, $B R_{a}$ and $B R_{r}$ in $\mathrm{m}^{3} / \mathrm{kg}$-h; the exposure time at home, $E T_{h} \mathrm{~h} / \mathrm{d}$; the exposure frequency at home, $E F_{h}$ days/y; and the assumed resting time at home, 8 hours.

$$
\text { Intake }(\text { inh })=\frac{\left(B R_{r} \times 8+B R_{a} \times E T_{h}\right) \times E F_{h}}{365 d / y} \times C_{a i r}\left(Z_{i}\right) \quad(B q / \mathrm{kg}-\mathrm{d})
$$

Values used for the parameters in these expressions are discussed in Section 4.5 and Appendix B.

\subsubsection{Average Dermal Uptake}

The average uptake of tritium in $\mathrm{Bq} / \mathrm{d}$ per $\mathrm{kg}$ body weight by dermal uptake in the working population is calculated using the yearly average tritium concentration of the air in each zone, $C_{a i r}\left(Z_{i}\right)$, in $\mathrm{Bq} / \mathrm{m}^{3}$; the surface area per unit body weight, $S A_{b}$, in $\mathrm{m}^{2} / \mathrm{kg}$; the exposure time at work, $E T_{w}$, in $\mathrm{h} / \mathrm{d}$; the exposure frequency at work, $E F_{w}$, in days $/ y$; and the permeability for tritium in air through the skin, $K_{p}^{a i r}$, in $\mathrm{m} / \mathrm{h}$.

$$
\operatorname{Uptake}(\mathrm{drm})=\frac{S A_{b} \times E T_{w} \times E F_{w}}{365 d / y} \times K_{p}^{a i r} \times C_{a i r}\left(Z_{i}\right) \quad(\mathrm{Bq} / \mathrm{kg}-\mathrm{d})
$$

Equation 4-20 was also used for non-occupational exposures to air by replacing $E T_{w}$ and $E F_{w}$ with the exposure time and exposure frequency at home, $E T_{h}$ and $E F_{h}$. For recreational exposures to water, one needs to replace $E T_{w}$ and $E F_{w}$ with the exposure time and exposure frequency for recreation, $\mathrm{ET}_{\mathrm{sw}}$ and $E F_{\mathrm{sw}}$; replace the air permeability $K_{p}^{\text {arr }}$ with the water permeability $K_{p}^{\text {water }}$; and $C_{\text {air }}\left(Z_{i}\right)$ with $C_{\text {water }}\left(Z_{i}\right)$. Values used for the parameters in this expression are discussed in Section 4.5 and Appendix $B$.

\subsubsection{Average Intake by Ingestion of Homegrown Foods}

The average intake of tritium in $\mathrm{Bq} / \mathrm{d}$ per $\mathrm{kg}$ body weight by ingestion of homegrown produce is calculated using the yearly average tritium concentration of the vegetation in each zone, $C_{v e g}\left(Z_{i}\right) \mathrm{Bq} / \mathrm{kg}$ and the ingestion rates of exposed and unexposed produce, $I_{e p}$ and $I_{u p}$ (in $\mathrm{kg} / \mathrm{kg}-\mathrm{d}$ ).

$$
\text { Intake }(\text { ing })=\left(I_{e p}+I_{u p}\right) \times C_{v e g}\left(Z_{i}\right) \quad(\mathrm{Bq} / \mathrm{kg}-\mathrm{d})
$$


Values used for the parameters in this expression are discussed in Section 4.5 and Appendix B.

\subsubsection{Average Ingestion Intake of Surface Water During Recreation}

The average intake of tritium in $\mathrm{Bq} / \mathrm{d}$ per $\mathrm{kg}$ body weight by ingestion during water recreation is calculated using the yearly average tritium concentration in the water of Zone $3, C_{\text {water }}\left(Z_{i}\right)$ (in $\mathrm{Bq} / \mathrm{m}^{3}$ ); the ingestion rate during the activity, $I_{f l r}$ (in L/kg-h); the exposure time and exposure frequency for recreation, $E T_{s w}$ (in $\mathrm{h} / \mathrm{d}$ ) and $E F_{s w}$ (in $\mathrm{d} / \mathrm{y}$ ); and a conversion factor from $\mathrm{m}^{3}$ to $\mathrm{L}$.

$$
\text { Intake(ing) }=\frac{I_{f t r} \times E T_{s w} \times E F_{s w}}{365 d / y} \times 10^{-3} \mathrm{~m}^{3} / L \times C_{\text {water }}\left(Z_{i}\right) \quad(\mathrm{Bq} / \mathrm{kg}-\mathrm{d})
$$

Values used for the parameters in this expression are discussed in Section 4.5 and Appendix B.

\subsubsection{Total Body Burden of Tritiated Water}

The total body burden in $\mathrm{Bq} / \mathrm{kg}$ from all exposure routes for an average individual within the population is the sum of inhalation and ingestion intakes and dermal uptake in $\mathrm{Bq} /$ day multiplied by the removal time. The removal time is equal to the effective biological half-life, $T_{1 / 2}^{t t t}$, divided by 0.693 .

$$
\text { Burden }(\text { adult })=\frac{[\operatorname{Intake}(\text { inh })+\operatorname{Intake}(\text { ing })+\operatorname{Uptake}(\text { drm })] \times T_{1 / 2}^{\text {tlt }}}{0.693}(\mathrm{~Bq} / \mathrm{kg})
$$

As discussed above, $T_{1 / 2}^{\text {tlt }}$ is 15 days for $\mathrm{HTO}$ and 48 days for OBT.

\subsubsection{Estimated Live-Born Infant Body Burden}

The body burden of tritium in a fetus is assumed to be the same as the mother.

$$
\operatorname{Burden}(\text { fetus })=\operatorname{Burden}(\text { adult })
$$

\subsubsection{Potential Infant Intake and Body Burden through Breast Feeding}

In estimating infant exposure through breast milk, the tritium concentration in breast milk is assumed to equal the tritium burden of the mother. The infant burden is then 
equal to the breast-milk intake, $I_{b m}$ in $\mathrm{kg}$ (milk) per $\mathrm{kg}$ body weight per day, times the removal time in the infant.

$$
B u r d e n(\text { infant })=\frac{B u r d e n(a d u l t) \times I_{b m} \times T_{1 / 2}^{t l t}}{0.693}(B q / k g)
$$

\subsubsection{Total Dose, Population Risk, and Individual Risk}

The total dose in Gy associated with ingestion, inhalation, and dermal uptake is calculated from the product of body burden and a conversion factor (Equation 4-27) that translates from $\mathrm{Bq} / \mathrm{kg}$ to $\mathrm{Gy} / \mathrm{y}$, as given by Equation 4-14.

$$
\begin{gathered}
\operatorname{Dose}[\mathrm{Gy} / \mathrm{y}]=\operatorname{Burden}[\mathrm{Bq} / \mathrm{kg}] \times 2.86 \times 10^{-8}[\mathrm{~Gy} / \text { y per } \mathrm{Bq} / \mathrm{kg}] \\
\text { Factor }=2.86 \times 10^{-8}[\mathrm{~Gy} \cdot \mathrm{kg} / \mathrm{y} / \mathrm{Bq}]
\end{gathered}
$$

The population risk for cancer represents the estimated increase of fatal cancers per year due to exposures including adults and infants. The magnitude of the population for cancer risk depends on the number of exposed adults and the number of infants born to exposed adults.

$$
\begin{aligned}
& \text { Population Risk (cancer) [cancers per year ] } \\
= & {\left[\text { Dose (adult) } \times \mathrm{N}_{\text {adults }}\left(\mathrm{Z}_{\mathrm{i}}\right)+\text { Dose (infant) } \times \mathrm{N}_{\text {infants }}^{\prime}\left(\mathrm{Z}_{\mathrm{i}}\right) \times 2\right] \times R_{H T O}^{c a n} }
\end{aligned}
$$

where $N_{\text {adults }}\left(Z_{i}\right)$ is the total number of adults in the population, $N^{\prime}{ }_{\text {infants }}\left(Z_{i}\right)$ is the number of infants born per year to adults in this population, and 2 years is the time that an infant is assumed to be breast fed. The individual lifetime cancer risk for an average individual is estimated as the product of the population risk and the exposure duration divided by the number of adults in the population.

$$
\text { Individual Lifetime Risk (cancer) }=\text { Dose (adult) } \times E D \times R_{H T O}^{c a n}
$$

The population risk for genetic effects represents the estimated increased hereditary effects per year per live-born child within the exposed population. The magnitude of the population risk for heritable defects depends on the total number of live births and the exposure to the parents of a child.

$$
\begin{aligned}
& \text { Population Risk(genetic) [ genetic effects per year] } \\
& =\text { Dose }(\text { adult }) \times N_{\text {infants }}^{\prime}\left(Z_{i}\right) \times R_{H T O}^{\text {gen }}
\end{aligned}
$$

Assuming one birth per adult per lifetime, we obtain 
Individual Lifetime Risk (genetic) [genetic effects per lifetime]

$$
=\text { Dose }(\text { adult }) \times R_{H T O}^{\text {gen }}
$$

The population risk for reproductive and developmental effects represents the expected number of effects per year per live-born child within the exposed population. The magnitude of the population risk for reproductive and developmental effects depends on the total number of live births and the dose to the fetus during development.

$$
\begin{aligned}
& \quad \begin{array}{l}
\text { Population Risk }(\text { rep }- \text { dev })[\text { effects per year }] \\
=\text { Dose }(\text { adult }) \times N_{\text {irfant }}^{\prime}\left(Z_{i}\right) \times R_{H T O}^{r e p}
\end{array} \\
& \text { Individual Lifetime Risk }(\text { rep }- \text { dev })[\text { effects per live birth }] \\
& =\text { Dose }(\text { adult }) \times R_{H T O}^{r e p}
\end{aligned}
$$

\subsubsection{Estimated Doses and Risks in Zone 1}

The population at risk is taken to include the working population in this zone as well as the infants born to mothers who are part of this working population. We assume that the number of adults in this population $N_{\text {adults }}\left(Z_{1}\right)$ is 200 . We estimated the number of live-born infants per year associated with this population, $N^{\prime}$ infants $\left(Z_{1}\right)$, by assuming that half of the working population are women and that each woman bears 2 children over a twenty year period.

$$
\begin{gathered}
N_{\text {adults }}\left(Z_{1}\right)=200 \\
N_{\text {infants }}^{\prime}\left(Z_{1}\right)=\frac{N_{\text {adults }}\left(Z_{1}\right)}{2} \times \frac{2 \text { infants }}{20 \text { years }}=10 \text { infants } / y
\end{gathered}
$$

For the purposes of calculating lifetime individual risk, the exposure duration was assumed to be a working lifetime of 40 years. We estimated population risk and individual risks based on the equations in Section 4.7.2 for calculating intake, uptake, body burdens, dose, and risk, and on the tritium concentrations given in Section 4.7.1. The results for assumed releases of $100 \mathrm{Ci} / \mathrm{y}$ are in Table 4-12. 
Table 4-12.

Predicted Doses and Risks for Zone 1, with a Release Rate of $100 \mathrm{Ci}$ /year.

\begin{tabular}{|l|c|c|}
\hline \multicolumn{1}{|c|}{ Dose Group } & $\begin{array}{c}\text { Total Dose(a) } \\
\text { (Gy/year) }\end{array}$ & $\begin{array}{c}\text { Relative Dose Fractions } \\
\text { (Inhalation/lngestion/Dermal) }\end{array}$ \\
\hline Adult & $1.4 \times 10^{-5}$ & $0.82 / 0 / 0.18$ \\
\hline Nursing infant & $3.2 \times 10^{-5}$ & $0 / 1 / 0$ \\
\hline Live-born infant & $1.0 \times 10^{-5}$ & $5 \times 10^{-5}$ \\
\hline \hline Health End Point & $\begin{array}{c}\text { Population Risk per Year } \\
\text { (expected effects per year) }\end{array}$ & $\begin{array}{c}\text { Individual Risk per Lifetime } \\
\text { (probability in a lifetime) }\end{array}$ \\
\hline Fatal Cancer & $3 \times 10^{-4}$ & $6 \times 10^{-5}$ \\
\hline Cancer incidence (b) & $4 \times 10^{-4}$ & $9 \times 10^{-8}$ \\
\hline Genetic defects & $9 \times 10^{-7}$ & $2 \times 10^{-6}$ \\
\hline $\begin{array}{l}\text { Developmental and } \\
\text { reproductive effects }\end{array}$ & $2 \times 10^{-5}$ & -10 \\
\hline \hline
\end{tabular}

Notes to Table 4-12:

(a) Doses and corresponding risks are about nine times higher than doses measured by urinalysis in Zone 1 workers in 1995. This suggests that some assumptions about exposure were overly conservative.

(b) In this study we develop risk factors for cancer mortality; to estimate cancer incidence from cancer mortality, we use the ratio 6/5, which is the incidence/mortality ratio recommended by the ICRP (1991).

\subsubsection{Estimated Doses and Risks in Zone 2}

The population at risk in Zone 2 is taken to include the working population in this zone as well as the infants born to mothers who are part of this working population. The working population is assumed to be 6,000 . In addition, the population is assumed to include some 4,000 residents who occupy the single-family homes near the LBNL site. All of these residents are assumed to consume food from home gardens. For purposes of assessing tritium metabolism and dose, children over the age of two are represented as adults. We assume that half of the population are women and that each woman bears 2 children over a twenty-year period. Thus, we have

$$
\begin{aligned}
N_{\text {adults }}\left(\mathrm{Z}_{2}\right) & =6,000 \text { working adults }+4,000 \text { residents } \\
& =10,000 \text { individuals } \\
N_{\text {infants }}^{\prime}\left(Z_{2}\right) & =N_{\text {adults }}\left(Z_{2}\right) / 20 \text { years }=500 \text { infants } / y
\end{aligned}
$$

For the purposes of calculating lifetime individual risk, we only report the risk to the residential population, whose individual risk is about twice that of the occupational population. The exposure duration for the residential population is assumed to be 70 years. We estimated the population and individual risks based on the equations in Section 4.7.2 for calculating intake, uptake, body burdens, dose, and risk based on the tritium concentrations listed in Section 4.7.1. The results are listed in Table 4-13. 
Table 4-13

Predicted doses and risks for Zone 2, with a release rate of $100 \mathrm{Ci} /$ year.

\begin{tabular}{|c|c|c|}
\hline Dose Group & $\begin{array}{l}\text { Total Dose } \\
\text { (Gy/year) }\end{array}$ & $\begin{array}{l}\text { Relative Dose Fractions } \\
\text { (Inhalation/Ingestion/Dermal) }\end{array}$ \\
\hline \multicolumn{3}{|c|}{ Working Population } \\
\hline Adult & $7.3 \times 10^{-7}$ & $0.82 / 0 / 0.18$ \\
\hline Nursing infant & $1.7 \times 10^{-6}$ & $0 / 1 / 0$ \\
\hline Live-born infant & $5.4 \times 10^{-7}$ & \\
\hline \multicolumn{3}{|c|}{ Residential Population } \\
\hline Adult & $8.0 \times 10^{-7}$ & $0.53 / 0.15 / 0.32$ \\
\hline Nursing infant & $2.8 \times 10^{-6}$ & $0.19 / 0.69 / 0.12$ \\
\hline Live-born infant & $6.0 \times 10^{-7}$ & \\
\hline Health end point & $\begin{array}{l}\text { Population Risk per Year } \\
\text { (expected effects per year) }\end{array}$ & $\begin{array}{l}\text { Individual Risk per Lifetime } \\
\text { (probability in a lifetime) }\end{array}$ \\
\hline Fatal Cancer & $9 \times 10^{-4}$ & $5 \times 10^{-6}$ \\
\hline Cancer incidence & $1 \times 10^{-3}$ & $6 \times 10^{-6}$ \\
\hline Genetic defects & $3 \times 10^{-6}$ & $5 \times 10^{-9}$ \\
\hline $\begin{array}{l}\text { Developmental and } \\
\text { reproductive effects }\end{array}$ & $6 \times 10^{-5}$ & $1 \times 10^{-7}$ \\
\hline
\end{tabular}

\subsubsection{Estimated Doses and Risks in Zone 3}

We consider inhalation, ingestion, dermal uptake from air and surface water as potential exposures in Zone 3, as illustrated in Figure 4-10 and discussed in Section 4.7.1.5. For purposes of assessing tritium metabolism and dose, children over the age of 2 are represented as adults. We assume that the total number of individuals in this population, $N_{\text {adults }}\left(Z_{3}\right)$, is on the order of 100,000 . We assume that half of the population are women and that each woman bears 2 children over a twenty-year period. 


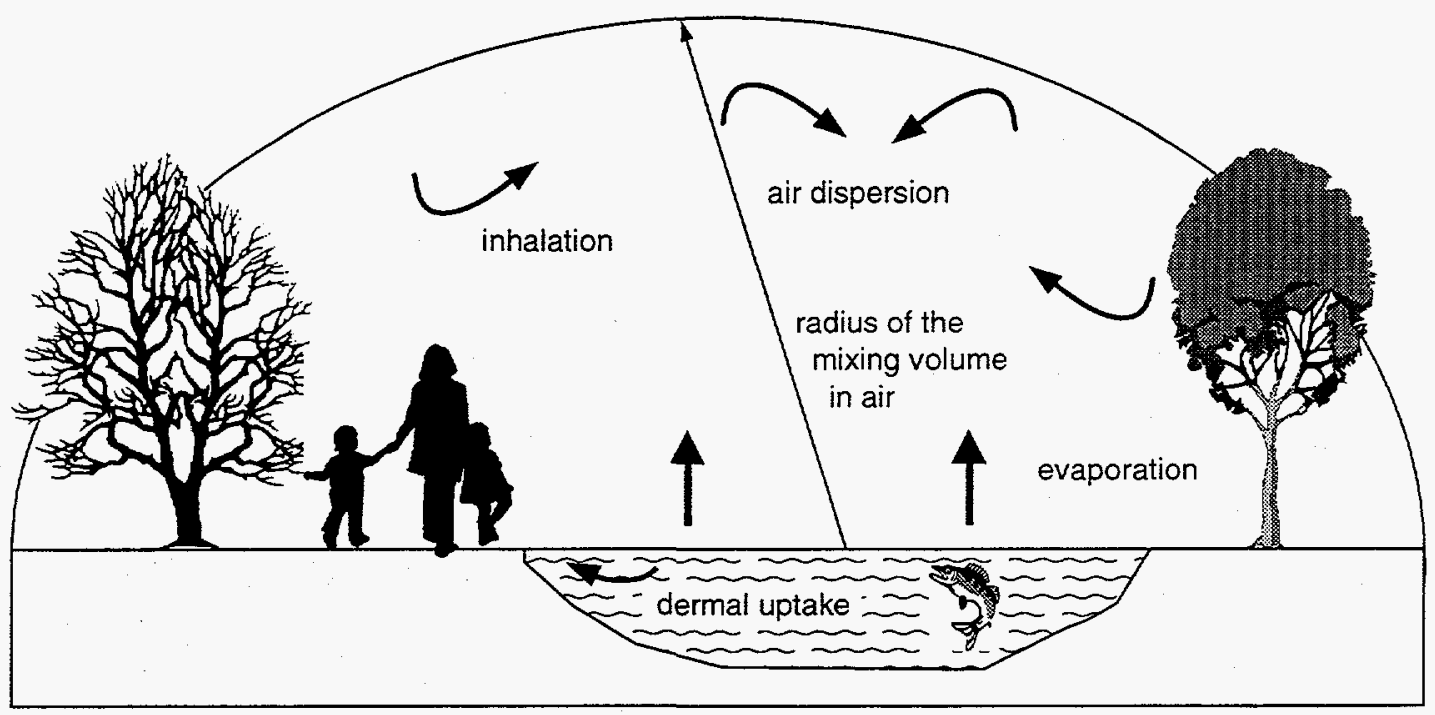

XED 9505-01896.EPS

Figure 4-10. Exposure scenarios near Strawberry Creek. This diagram illustrates dermal uptake from water as a result of wading in the creek and inhalation and dermal uptake of tritium from the air envelope surrounding the creek, which contains elevated levels of tritium as a result of tritium in the creek.

$$
\begin{gathered}
N_{\text {adults }}\left(Z_{3}\right)=100,000 \\
N_{\text {infants }}^{\prime}\left(Z_{3}\right)=\frac{N_{\text {adults }}\left(Z_{3}\right)}{2} \times \frac{2 \text { infants }}{20 \text { years }}=5,000 \text { infants } / y
\end{gathered}
$$

For the purposes of calculating lifetime individual risk, the exposure duration is assumed to be 70 years. We estimated the population and individual risks based on the equations in Section 4.7.2 for estimating intake, uptake, body burdens, dose, and risk, and based on the tritium concentrations listed in Section 4.7.1. Table 4-14 gives the results for assumed releases of $100 \mathrm{Ci} / \mathrm{y}$. 
Table 4-14

Predicted Doses and Risks for Zone 3, with a Release Rate of $100 \mathrm{Ci} /$ year.

\begin{tabular}{|l|c|c|}
\hline \multicolumn{1}{|c|}{ Dose Group } & Total Dose, Gy/year & $\begin{array}{c}\text { Relative Dose Fractions } \\
\text { (Inhalation/Ingestion/Dermal) }\end{array}$ \\
\hline Adult & $1.2 \times 10^{-7}$ & $0.64 / 0.07 / 0.29$ \\
\hline Nursing infant & $4.0 \times 10^{-7}$ & $0.17 / 0.72 / 0.11$ \\
\hline Live-born infant & $0.9 \times 10^{-7}$ & \\
\hline \hline Health end point & $\begin{array}{c}\text { Population risk per year } \\
\text { (expected effects per year) }\end{array}$ & $\begin{array}{c}\text { Individual risk per lifetime } \\
\text { (probability in a lifetime) }\end{array}$ \\
\hline Fatal Cancer & $1 \times 10^{-3}$ & $7 \times 10^{-7}$ \\
\hline Cancer incidence & $2 \times 10^{-3}$ & $9 \times 10^{-7}$ \\
\hline Genetic defects & $4 \times 10^{-6}$ & $8 \times 10^{-10}$ \\
\hline $\begin{array}{l}\text { Developmental and } \\
\text { reproductive effects }\end{array}$ & $1 \times 10^{-4}$ & $2 \times 10^{-8}$ \\
\hline \hline
\end{tabular}

\subsubsection{Step-by-Step Calculations}

Table 4-15 provides a step-by-step summary of the exposure and risk assessment calculations. It provides a summary of how the environmental concentrations converts to human exposure, dose, and risk. The table also includes cross references to sections, equations to make the transition from one stage of the calculation to the next. 
Table 4-15

\section{A Step-By-Step Summary Of The Exposure And Risk}

Assessment Calculations

\begin{tabular}{|c|c|c|c|}
\hline & Zone 1 & Zone 2 & Zone 3 \\
\hline $\begin{array}{l}\text { Air concentrations } \mathrm{Bq} / \mathrm{m}^{3} \\
\text { [values in brackets are concentration in } \\
\text { atmospheric water, } \mathrm{Bq} / \mathrm{L} \text { ] }\end{array}$ & 96 & $5.2[130]$ & $0.35[8.7]$ \\
\hline relevant equations & $4-6$ & $4-6$ & CAP88, 4-17 \\
\hline reference sections & $\begin{array}{c}4.4 .1,4.4 .2 \& \\
4.7 .1 .3\end{array}$ & $\begin{array}{c}4.4 .1,4.4 .2 \& \\
4.7 .1 .4\end{array}$ & $\begin{array}{c}\text { 4.7.1.5, } \\
\text { Appendix E }\end{array}$ \\
\hline Soil water $\mathrm{Bq} / \mathrm{L}$ & & 48 & 2 \\
\hline relevant equations & & $4-5$ & $4-5,4-15,4-16$ \\
\hline reference sections & & $\begin{array}{c}4.4 .1,4.4 .2 \& \\
4.7 .1 .4 \\
\end{array}$ & 4.7.1.5 \\
\hline Vegetation (free water) $\mathrm{Bq} / \mathrm{L}$ & & 110 & 7 \\
\hline reference sections & & 4.7.1.4 & 4.7 .1 .4 \\
\hline Vegetation (OBT) $\mathrm{Bq} / \mathrm{kg}$ & & 3 & 0.2 \\
\hline reference sections & & 4.7.1.4 & 4.7.1.4 \\
\hline Surface water $\mathrm{Bg} / \mathrm{L}$ & & & 11 \\
\hline relevant equations & & & $4-15,4-16$ \\
\hline reference sections & & & 4.7.1.5 \\
\hline Inhalation intake, $\mathrm{Bq} / \mathrm{kg} / \mathrm{d}$ & 18 & $\begin{array}{l}1.0 \text { (workers) } \\
0.7 \text { (residents) }\end{array}$ & 0.12 \\
\hline relevant equations & $4-18$ & $4-18 \& 4-19$ & $4-19$ \\
\hline reference sections & 4.7.2.1 & 4.7.2.1 & 4.7.2.1 \\
\hline Dermal intake, Bq/kg/d & 3.9 & $\begin{array}{c}0.2 \text { (workers) } \\
0.4 \text { (residents) }\end{array}$ & $\begin{array}{c}0.0546 \text { (air) } \\
0.0007 \text { (water) }\end{array}$ \\
\hline relevant equations & $4-20$ & $4-20$ & $4-20$ \\
\hline reference sections & 4.7 .2 .2 & 4.7.2.2 & 4.7.2.2 \\
\hline Ingestion intake, $\mathrm{Bg} / \mathrm{kg} / \mathrm{d}$ & none & 0.19 (residents) & 0.01 \\
\hline relevant equations & - & $4-21$ & $4-21 \& 4-22$ \\
\hline reference sections & - & 4.7 .2 .3 & $4.7 .2 .3 \& 4.7 .2 .4$ \\
\hline Body water levels, Bq/L & 468 & 28 (residents) & 4.2 \\
\hline relevant equations & $4-23$ & $4-23$ & $4-23$ \\
\hline reference sections & 4.7 .2 .5 & 4.7.2.5 & 4.7 .2 .5 \\
\hline Annual dose rate, Gy/y & $1.3 \times 10^{-5}$ & $8.0 \times 10^{-7}$ (residents) & $1.2 \times 10^{-7}$ \\
\hline relevant equations & $4-26$ & $4-26$ & $4-26$ \\
\hline reference sections & 4.7 .2 .8 & 4.7 .2 .8 & 4.7 .2 .8 \\
\hline Individual risk per lifetime & $5 \times 10^{-5}$ & $5 \times 10^{-6}$ (residents) & $7 \times 10^{-7}$ \\
\hline relevant equations & $4-29$ & $4-29$ & $4-29$ \\
\hline reference sections & 4.7.2.8 & 4.7.2.8 & 4.7 .2 .8 \\
\hline
\end{tabular}




\subsection{Summary and Discussion}

The estimated risks for tritium releases from the NTLF are quite low relative to the background incidence of the diseases considered-cancer, heritable genetic defects, and reproductive and developmental effects. The estimated cancer risk of the NTLF facility is orders of magnitude lower than the cancer incidence attributable to background radiation. Within Zone 3, the projected levels of tritium in the environment and the estimated population risk are so low that neither the levels of tritium present nor the potential health impacts could be easily detected by measuring devices or health surveys.

The highest estimated additional annual population cancer risk in Zone 1 is on the order of two cases per million population per year. This means that, if the facility continued to operate for a very long period of time with 200 people, we would have to wait on average about 2,500 years before we would see an additional cancer in this facility. In Zones 2 and 3 , the population risks are slightly higher but the sample population is much larger so that the risk per individual is much lower.

An uncertainty analysis was given to assess the reliability of these results. The uncertainty analysis was based on a tiered approach that included the following steps:

1. Variance in the input values was clearly stated. At a minimum, this is done by listing the estimation error or the experimental variance associated with the parameters when these values or their estimation equations are listed in tables. Summary and justification of the assumptions used for each aspect of the model are provided. In addition, it is stated whether these assumptions are likely to result in representative values or conservative (upper bound) estimates of risk.

2. A sensitivity analysis was used to assess how model predictions are impacted by model reliability and data precision.

3. Variance propagation methods (Monte-Carlo methods) were used to map how the overall precision of risk estimates is tied to uncertainty associated with the model inputs.

Based on the range of parameter values used as input for the predictions of risk, we assessed the precision of the model predictions by making thousands of repeated calculations of risk with all input values varied within their likely ranges. For the estimations of cancer risk in Zone 1, we found that $50 \%$ of the range of output values were within a factor of 2 of the reported risk and $95 \%$ of the output values were within a factor of 10 of the reported risk. 


\section{Appendix A}

\section{Two-Compartment Environmental Transport Model for Tritium}

The physical and chemical properties of HTO include its complete miscibility in water, the absence of any known sequestering tendencies (i.e., no preferential uptake of HTO by organisms or other components of the environment), the similarity of its properties (such as diffusion coefficient and vapor pressure) to water, and the observed uniform distribution of HTO among the aqueous phases of all interacting compartments in field studies that have approximated steady-state conditions [Murphy, 1984, 1993]. These properties imply that the fate and transport tendencies of HTO are best predicted by modeling it as having infinite affinity for the water phase of any compartment and relatively negligible affinity for other phases, such as the organic phase of biota or mineral phase of soil.

\section{A.1 General Issues}

We use a two-compartment model to estimate the steady-state distribution of tritiated water between air and soil media that would result from continuous HTO emissions to the atmosphere (air compartment) from the NTLF. Using the principle of mass conservation, the model provides an algorithm for predicting steady-state HTO-specific activities (concentrations) in the soil and air compartments.

\section{A.1.1 Tritium in Air}

On a local scale, the transfer of HTO from air to the land surface occurs mainly by precipitation with a minor role played by diffusional vapor exchange [NCRP, 1979]. On 
a global scale, the tritium concentration in air is relatively uniform and, on average higher than that in soil, so that the reverse of the local-scale case appears to hold.

The deposition of HTO from air to ground does not necessarily represent a definitive loss from the air compartment since deposited HTO can re-emerge back into the air compartment via evapotranspiration or simple evaporation. Only HTO that finds its way deep into the ground (well below the root zone) represents a true air compartment loss.

\section{A.1.2 Tritium in Soil}

When HTO enters soil, it follows the same transport processes as $\mathrm{H}_{2} \mathrm{O}$ [Murphy, 1993]. Thus, important transport mechanisms in the terrestrial environment include bulk flow (due to gradient of hydraulic head), and flow due to vapor gradient, temperature gradient, and HTO concentration gradient. The environmental half-life of tritium in soil is generally longer than in other components of the ecological system, and this relatively longer compartment half-life extends the residence time of tritium in vegetation rooted in that soil. High-water-use plants may affect the movement of a tritium pulse in soil. The observed environmental half-life of tritium in soil appears to be made up of two components-a shorter one reflecting the bulk movement of water and a longer one reflecting tritium retained in more stationary water, such as chemically bound water [Koranda and Martin, 1973].

\section{A.1.3 Tritium in Surface Waters}

Under steady-state conditions, the concentration of tritium in surface waters would be the same as that in the water-phase of the atmosphere. When the source of tritium is air and the residence-time of the surface water body is long relative to the half-life of tritium-which is the case for the oceans, the Great Lakes, San Francisco Bay, etc.-the HTO concentration in the surface water is lower than that in atmospheric water on average. However, near the top of a surface water column a steady-state concentration is likely to exist. HTO concentrations in aquatic organisms closely follow those in the water [Murphy, 1993].

\section{A.1.4 Tritium Uptake in Biota}

Plants take up HTO from water vapor in air through plant respiration and from water in soil through transpiration [Koranda and Martin, 1973]. For plants grown in tritiumfree soil, the tritium concentration in plant leaves is on the order of 0.3 to 0.7 times the tritium concentration in atmospheric water [Murphy, 1993]. Some of the tritiated water taken into plant tissues can be converted to organically-bound tritium (OBT), which has a longer residence time in plants than molecular water. Photosynthesis is the primary process by which HTO is converted to OBT in plants. However, a very low fraction of 
tritium moving through the plant is transformed to OBT. Thus, Murphy [1993] has noted that OBT in plants can be neglected as a sink for Tritium. Nevertheless, the effective residence time of tritium in plants may be affected by even small amounts of OBT.

\section{A.1.5 Why Only Two Compartments?}

As discussed in Section A.1.4, tritium activity in the terrestrial biota compartment is readily inferred once the soil and air activities are known. Thus, the activity in the biota compartment need not be predicted explicitly. Adding a biota compartment would require the quantification of inputs such as the uptake rate from soil into plants, but there is insufficient information for this quantification.

Because the current application of the model does not include estimating exposure through the food ingestion pathway, the biota concentrations are not required for our purposes. Biota need only be considered inasmuch as it affects the ultimate steady state HTO inventories in air and soil water (soil water affects runoff concentration, which will be subject to dermal contact). In addition, the fraction of land covered by surface water is minimal, allowing the surface water compartment to be neglected for the purposes of the fate and transport modeling (streams are considered in the dose assessment). Thus, a two compartment model is sufficient.

The premises of our modeling approach are that HTO will distribute itself primarily in the aqueous phase of a compartment, that non-aqueous tritium (i.e., OBT) in any compartment can be accounted for by increasing the effective residence time and that under equilibrium conditions water-phase tritium activities in each compartment will be equal.

For convenience, we call the water-phase HTO-specific activity in compartment $i$, the "aquivalence," which will be denoted $A Q_{i}$. In a closed system that is in equilibrium, the aquivalences of all compartments are the same. Similar terminology has been used in modeling the fate and transport of inorganic and organic chemical species [Mackay and Diamond, 1989; Diamond et al., 1992; McKone, 1993].

We propose here a model for a system that has achieved steady state in terms of mass exchange by balancing gains and losses. However, in terms of chemical thermodynamics the system is not assumed to be at equilibrium. The simultaneous balancing of gains and losses for both soil and air compartments allows nonequilibrium aquivalences of the two compartments to be calculated. The bulk compartment's specific activity is easily calculated once its aquivalence is quantified. Because only the aqueous phase of a compartment is allowed to hold HTO, both the total compartments inventory and water-phase inventory of tritium are the same. The bulk specific activity (i.e., inventory normalized by the aqueous as well as non-aqueous phase volumes) of compartment $i$, is calculated as a function of its volumetric water content, denoted $\varnothing_{i}$, and its aquivalence $\left(A Q_{i}\right)$ as: 


$$
C_{i}=\varnothing_{i} \times A Q_{i}
$$

where $C_{i}$ denotes compartment $i$ 's bulk specific activity, and the other terms are as defined above.

Thus, the bulk specific activities of HTO in adjacent compartments may differ even under equilibrium conditions, since the two compartments may differ in their volumetric water contents. Under equilibrium conditions compartment $i$ 's capacity for holding HTO is effectively dictated by its volumetric water content, $\varnothing_{i}$.

The volumetric fraction of water in air is calculated based on the observed relative humidity ( $\mathrm{RH}$ - expressed as the fraction of saturation) at LBNL, and the saturation vapor pressure. The saturated vapor pressure $(V P$ sat $)$ in Pascals $(\mathrm{Pa})$ is calculated as a function of temperature by using the following Antoine equation [Weast et al., 1986].

$$
\log V P_{s a t}=11.28-2319.25 / T
$$

where $T$ is the ambient absolute air temperature in kelvins. Using $V P_{\text {sat }}$, we calculate the volume fraction of water in air, $\varnothing_{a}$, as

$$
\varnothing_{a}=R H \times \frac{V P_{\text {sat }}}{R \times T} \times \frac{M W_{H 2 O}}{\rho_{H 2 O}}
$$

where $R$ is the unirersal gas constant, $8.314 \mathrm{~Pa}-\mathrm{m}^{3} / \mathrm{mol}^{-} \mathrm{K} ; M W_{H 2 O}$ is the molecular weight of water, $18 \mathrm{~g} / \mathrm{mol}$; and $\rho_{H 2 O}$ is the density of water, $10^{6} \mathrm{~g} / \mathrm{m}^{3}$.

The volumetric water fraction of the soil compartment is determined directly from field data (See Table 6).

\section{A.2 Steady State Mass Balance Equations}

The steady-state equations describing gains and losses in the two compartments are used to solve for the steady-state inventory in each compartment. Equations A-4 and A-5, which are the same as Equations 4-1 and 4-2, express gains and losses for the air and soil compartments, respectively.

$$
S+T_{\mathrm{sa}} N_{\mathrm{s}}=L_{\mathrm{a}} N_{\mathrm{a}}
$$

and

$$
T_{\text {as }} N_{\mathrm{a}}=L_{\mathrm{s}} N_{\mathrm{s}}, \quad \text { (surface soil) }
$$

where $N$ represents a compartment HTO inventory (a compartment's bulk inventory and its water-phase inventory are equivalent) and the $T_{\mathrm{ij}}(\mathrm{i}, \mathrm{j}=\mathrm{a}$ or $\mathrm{s})$ are transfer rate 
constants, with units of day ${ }^{-1}$, that express fraction per unit time of the inventory of compartment $i$ that is transferred to compartment $j$. The compartment abbreviations are $a$ for air, and $s$ for surface soil. The product of an $N$ term and a $T$ term is the rate of change of inventory in $\mathrm{Bq} / \mathrm{d}$. $L_{\mathrm{i}} N_{\mathrm{i}}$ represents all losses from compartment $i, \mathrm{~Bq} / \mathrm{d}$. The term $S$ in Equation A-4 represents the rate of HTO input (i.e., the NTLF's HTO emission rate) into the air compartment, $\mathrm{Bq} / \mathrm{d}$. Transfer-rate constants are functions of landscape characteristics and environmental mass transfer rates.

In terms of aquivalence the balance in $\mathrm{Bq} / \mathrm{d}$ is expressed as a loss from a compartment $i$ and transfer to a compartment $j$ in the form

$$
\text { loss }=\text { Area } \times v_{i j} \times \oslash_{i k} \times A Q_{i}=T_{i j} N_{i},
$$

where Area in $\mathrm{m}^{2}$ is that across which mass exchange occurs, $v_{i j}$ is the advection velocity from $i$ to $j$ at the exchange boundary, and $\emptyset_{i k}$ is the volumetric moisture content of the moving phase $k$ from $i$ to $j$, (in this analysis the moving phase is always water, e.g., recharge or runoff, and therefore $\emptyset_{\mathrm{ik}}$, is generally equal to $\emptyset_{\text {water }}$ and $A Q_{\mathrm{i}}$ represents the aquivalence of compartment $i$. Compartment inventory $N_{i}$ is calculated using Equation A-1 and the compartment volume.

$$
N_{i}=\varnothing_{i} A Q_{i} V_{i}
$$

Combining Equations A-6 and A-7 and rearranging terms yields the following for $T_{i j}$,

$$
T_{i j}=\frac{\operatorname{Area} \times v_{i j}}{V_{i}} \frac{\emptyset_{i k}}{\emptyset_{i}}=\frac{v_{i j}}{d_{i}} \frac{\emptyset_{i k}}{\emptyset_{i}},
$$

where $V_{i}$ is the compartment volume, $d_{i}$ is the compartment depth or height, and $\varnothing_{i}$ is the volumetric fraction of water in compartment, $i$. This is the general approach used in the paragraphs that follow to obtain the transfer rate constants.

\section{A.2.1 Transfer Rate Constants}

In the box model used for air, the inventory $N_{\mathrm{a}}$, in $\mathrm{Bq}$, is described by solving Equations A-4 and A-5. $L_{\mathrm{a}}$ is the sum of all loss-rate constants from the air compartment.

$$
L_{a}=T_{a s}+T_{a 0}+\lambda
$$

$L_{a} N_{a}$ is the sum of all losses from the air compartment, in $\mathrm{Bq} / \mathrm{d}$. The rate constant $T_{a s}$ accounts for rain-water washout from air to surface soil.

$$
T_{a s}=\frac{\text { rain } \times \emptyset_{\text {water }}}{\emptyset_{a} \times d_{a}},
$$


The air compartment mixing depth is analogous to the mixing height parameter used in Gaussian plume modeling. For the NTLF analysis this parameter depends on the boxmodel volume used in the analysis. For the Zone 1 risk characterization, the mixing depth is roughly $15 \mathrm{~m}$ (see Site Characteristics subsection below). In Equation A-10, $\varnothing_{\text {water }}$ describes the scavenging factor for rain drops passing through air.

The factor $T_{\mathrm{ao}}$ on a box model accounts for atmospheric dispersion that is applied to the natural bowl in which the NTLF is located. According to Benarie [1980], the long-term average pollutant concentration in a region bordered by a box model with volume $V_{a}$ and pollution source, $S$ in $\mathrm{Bq} / \mathrm{d}$, is given by

$$
C_{a i r}=N_{a} / V_{a}=\frac{c S}{A r e a \times v_{w}} \text {, }
$$

where $c$ is a unitless proportionality constant, Area is the area of the model region, and $v_{w}$ is the long-term average wind speed in $\mathrm{m} / \mathrm{d}$. This implies that the inverse of the rate constant, $T_{a 0}$, is the convective residence time and is given by the expression, $c d_{a} / \nu_{\mathrm{w}}$, where $d_{\mathrm{a}}$ is the atmospheric mixing height. Based on a model for area sources developed by Turner [1970], the constant $c$ can be estimated as $4.3 \sqrt{\text { Area }} / d_{a}$. Making the appropriate substitutions gives the following expression for the convective loss-rate constant in the air compartment:

$$
T_{a 0}=\frac{0.23 v_{w}}{\sqrt{\text { Area }}}
$$

Equation 5 describes the mass balance for the soil compartment inventory, $N_{s}$, in Bq of HTO. $L_{S}$ is the sum of soil compartment transfer-rate constants:

$$
L_{s}=T_{s a}+T_{\text {recharge }}+T_{\text {runoff }}+\lambda,
$$

where $T_{\mathrm{sa}}$ is the soil-to-air transfer rate primarily representing evapotranspiration processes, $T_{\text {recharge }}$ and $T_{\text {runoff }}$ are the rate constants for recharge losses to ground water and runoff losses to outside the unit, respectively; and $\lambda$ is the radioactive decay rate. Rate constants are in units of day ${ }^{-1}$. These loss-rate constants are given by

$$
\begin{gathered}
T_{s Q}=\frac{\text { evapotrans } \times \varnothing_{\text {water }}}{\emptyset_{s} \times d_{s}}, \\
T_{\text {recharge }}=\frac{\text { recharge } e \varnothing_{\text {vater }}}{\varnothing_{s} \times d_{s}}, \\
T_{\text {runoff }}=\frac{\text { runoff } \times \varnothing_{\text {water }}}{\varnothing_{s} \times d_{s}},
\end{gathered}
$$




$$
\text { recharge }=\text { rain }- \text { evapotrans }- \text { runoff } .
$$

The parameter recharge is the yearly average ground-water recharge at the site, in $\mathrm{m} / \mathrm{d}$; rain is the yearly average rainfall, in $\mathrm{m} / \mathrm{d}$; evapotrans is the yearly average evapotranspiration, in $\mathrm{m} / \mathrm{d}$; and runoff is the yearly average runoff; in $\mathrm{m} / \mathrm{d}$.

\section{A.2.2 Solutions for the Compartment Inventories}

Equations A-4 and A-5 represent a system of two equations, with two unknowns, and can be solved to determine the steady-state inventories, $N_{i}$, of contaminant in the soil and air compartments. This solution yields the following relationships,

$$
\begin{aligned}
& N_{s}=\frac{S}{\left[\frac{L_{s}}{T_{a s}} \times L_{a}-T_{s a}\right]} \\
& N_{a}=\frac{S}{\left[L_{a}-T_{s a} \times \frac{T_{a s}}{L_{s}}\right]}
\end{aligned}
$$

These solutions are used to determine the inventory of tritium in the air, soil, and runoff from the site. 



\section{Appendix B}

\section{Human Anatomical and Intake Factors Used in the Exposure Assessment Calculations}

In constructing dose models one needs to define the characteristics of individuals in various age/gender categories and the characteristics of the microenvironments in which they live or from which they obtain water and food. Appendix B defines the types of anatomical and activity data needed to carry out the exposure/dose assessment and explains how these data are obtained. For all factors used in this assessment, we define both an arithmetic mean value and a coefficient of variation (CV), which is the arithmetic standard deviation divided by the arithmetic mean.

\section{B.1 Body Weight}

We calculate the arithmetic-mean body weight and CV of body weight for three age groups-infant, child, and adult. The body weight for infants is needed for estimating exposures to contaminants in breast milk. Body weight for adults and children are needed to calculate lifetime-average contact rates per unit body weight and contact rates for an exposure duration of less than a full lifetime. The child age category applies to ages 0 to 15 years, but excludes breast-fed babies. General data on body-weight distributions by age and gender are available from the ICRP [1975], the U.S. EPA [1985, 1989a] and Najjar and Roland [1987]. Because it provides more details on age-specific variations, we used the Najjar and Roland [1987] data set to develop the mean value and $\mathrm{CV}$ of body weight for ages 0 to 1,0 to 15,15 to 70 , and for lifetime. These values are listed in Table B-1. 
Table B-1

Values of Human Anatomical and Intake Properties Used in the Exposure Calculations $(a)$

\begin{tabular}{|c|c|c|c|c|c|c|c|}
\hline \multirow{2}{*}{$\begin{array}{l}\text { Parameter, symbol } \\
\begin{array}{l}\text { Body weight of infants } \\
\text { age } 0 \text { to } 1 \mathrm{y}, \mathrm{BW}\end{array}\end{array}$} & \multicolumn{2}{|c|}{ Child(b) } & \multicolumn{2}{|c|}{ Adult (b) } & \multicolumn{2}{|c|}{ Combined (b) } & \multirow{2}{*}{ Units } \\
\hline & 7.2 & $(0.3)$ & - & & - & - & \\
\hline Body weight, BW & 29 & $(0.24)$ & 71 & $(0.2)$ & 62 & $(0.2)$ & $\mathrm{kg}$ \\
\hline Surface area, $S A_{b}$ & 0.032 & $(0.09)$ & 0.024 & $(0.06)$ & 0.026 & $(0.07)$ & $\mathrm{m}^{2} / \mathrm{kg}$ \\
\hline $\begin{array}{l}\text { Working breathing rate, } \\
\mathrm{BR}_{W}\end{array}$ & - & - & 0.030 & $(0.3)$ & - & - & $m^{3} / \mathrm{kg}-\mathrm{h}$ \\
\hline Active breathing rate, $B R_{a}$ & 0.023 & $(0.3)$ & 0.018 & $(0.3)$ & 0.019 & $(0.3)$ & $\mathrm{m}^{3} / \mathrm{kg}-\mathrm{h}$ \\
\hline Resting breathing rate, $\mathrm{BR}_{\mathrm{r}}$ & 0.008 & $(0.3)$ & 0.006 & $(0.2)$ & 0.0064 & $(0.2)$ & $\mathrm{m}^{3} / \mathrm{kg}-\mathrm{h}$ \\
\hline Fluid intake, $I_{f l}$ & 0.029 & $(0.2)$ & 0.020 & $(0.2)$ & 0.022 & $(0.2)$ & L/kg-d \\
\hline Breast milk intake $(\mathrm{c}), \mathrm{I}_{\mathrm{bm}}$ & 0.11 & $(1)$ & - & & - & & $\mathrm{kg} / \mathrm{kg}-\mathrm{d}$ \\
\hline $\begin{array}{l}\text { Water intake during } \\
\text { recreation, } I_{\text {flr }}\end{array}$ & 0.0007 & (1) & 0.0007 & (1) & 0.0007 & (1) & L/kg-h \\
\hline $\begin{array}{l}\text { Ingestion of homegrown } \\
\text { exposed produce, Iep }\end{array}$ & 0.0016 & $(0.7)$ & 0.00078 & $(0.7)$ & 0.00096 & $(0.7)$ & $\mathrm{kg} / \mathrm{kg}-\mathrm{d}$ \\
\hline $\begin{array}{l}\text { Ingestion of homegrown } \\
\text { unexposed produce, I }\end{array}$ & 0.00095 & $(0.7)$ & 0.00053 & $(0.7)$ & 0.00062 & $(0.7)$ & $\mathrm{kg} / \mathrm{kg}-\mathrm{d}$ \\
\hline
\end{tabular}

Notes to Table B-1:

(a) Listed are the arithmetic-mean value and (in parentheses) the estimated coefficient of variation (CV), equal to the standard deviation divided by the mean. Body weights are from Najjar and Roland [1987], breathing rates are from ICRP [1975], tap water intakes are from Yang and Nelson [1986] and Ershow and Cantor [1989] and food intakes are from Yang and Nelson [1986].

(b) The child category covers ages 0 to 15 , the adult category covers ages 16 to 70 , the combined category is used to represent lifetime equivalent exposure and is obtained by multiplying the child category by $15 / 70$, the adult category by $55 / 70$, and then summing these products.

(c) Breast-milk intakes are from Butte et al. [1984] and Whitehead and Paul [1981].

\section{B.2 Body Surface Area}

Information on the relation between human body weight and surface area has been published by the ICRP [1975] and the U.S. EPA [1989b]. The EPA [1989b] reports that surface area (SA) in $\mathrm{m}^{2}$ can be estimated as 0.1 times body weight (BW) in $\mathrm{kg}$ raised to the $2 / 3$ power. Using this formula, along with methods described in Bevington [1969], we estimate the mean value and standard deviation of surface area per unit body weight, $S A_{b}$, in $\mathrm{m}^{2} / \mathrm{kg}$ for children and adults using the formula 


$$
S A_{b}=\left[\frac{S A}{B W}\right]=0.1 \times B W^{-1 / 3} \pm\left(0.1 \frac{\sigma_{B W}}{3}\right) B W^{-4 / 3}
$$

where the second term is the standard deviation of the surface area-body weight ratio. The resulting surface-area values and CVs are given in Table B-1.

\section{B.3 Breathing Rate}

General data on breathing rates by age and gender are available from the EPA [1985, 1989a] and the ICRP [1975]. Values in Table B-1 are taken primarily from the ICRP [1975] with variances estimated by McKone and Daniels [1991]. The working breathing rate is for 8 hours of work and, when combined with 8 hours of breathing at the active rate and 8 hours at the resting rate, gives a daily equivalent intake of $30 \mathrm{~m}^{3}$ for an adult [EPA, 1989b]. Layton [1992] has derived breathing rates that are consistent with the quantities of oxygen needed to metabolize reported dietary intakes of fats, carbohydrates, and proteins. He has shown that the values in Table B-1 could be high by a factor of from $20 \%$ to $30 \%$, but this is within the CV reported here.

\section{B.4 Water Ingestion}

Tap-water intake includes all household tap water that is consumed as a beverage or used to prepare foods and beverages. Yang and Nelson [1986] have published tapwater and total-fluid intakes in $\mathrm{mL} / \mathrm{d}$ for the U.S. population by age, sex, and region of the country. Ershow and Cantor [1989] have published population-based estimates of sex-, region-, and season-averaged tap-water intakes per unit body weight by the U.S. population in $\mathrm{mL} / \mathrm{kg}-\mathrm{d}$. From these two papers, we have derived intakes of tap water in $\mathrm{L} / \mathrm{kg}-\mathrm{d}$ for children, adults, and lifetime equivalent. We also need to determine the amount of incidental ingestion that occurs during water recreation. Based on EPA [1989b] data, we use $0.0007 \mathrm{~L} / \mathrm{kg}-\mathrm{h}$ (CV equal to 1 ) as the ingestion rate of any surface water during recreational use. The mean values and CVs of tap-water intake and surface water intake are listed in Table B-1.

\section{B.5 Breast-Milk Ingestion}

Data on ingestion of breast milk by infants are available in Butte et al. [1984] and Whitehead and Paul [1981]. We calculate the breast-milk ingestion per unit body weight for infants ages 0 to 12 months as $0.11 \mathrm{~kg} / \mathrm{kg}-\mathrm{d}$ with a $C V$ of 0.2 . This $C V$ is based on other ingestion factors. 


\section{B.6 Ingestion of Homegrown Fruits, Vegetables, and Grains}

Ingestion of homegrown foods obtained from gardens in the vicinity of the NTLF are included in the risk assessment. For the food intakes included in the exposure assessment, we calculate here the arithmetic mean and standard deviation of homegrown food intakes per unit body weight for children, adults, and lifetime equivalent exposure, all on body-weight basis. We consider homegrown foods to be those produced on the land associated with a household and consumed within that household. The following food groups are considered in the exposure assessment:

- Leafy vegetables, which include exposed produce such as cabbage, cauliflower, broccoli, celery, lettuce, and spinach;

- Other exposed produce, such as apples, pears, berries, cucumber, squash, grapes, peaches, tomatoes, string beans, etc.;

- Protected produce or root crops, such as carrots, beets, turnips, potatoes, legumes, melons, citrus fruits, etc.; and

- Grains such as wheat, corn, rice, barley, millet, etc.

Total intake of foods in each of these groups is obtained from data compiled by the Nationwide Food Consumption Survey (NFCS) [USDA, 1983]. In this survey, the U.S. Department of Agriculture (USDA) used a stratified probability sample of households in the 48 conterminous states and the District of Columbia in each of four seasons from April 1977 through March 1978. The samples were designed to be representative of the United States and were classified according to geographic regions of the country, geographic divisions within each of the regions, and central city, suburban, and nonmetropolitan populations. We calculate total annual average food intakes using results compiled by Yang and Nelson [1986], who analyzed the data from the USDA survey. The variance of intake-per-body-weight ratio used to determine the $\mathrm{CV}$ is calculated under the assumption that food intake correlates with body weight to the two-thirds power. The mean and variance of body weight used in this estimate are taken from Table B-1. Listed first in Table B-1 is our estimated total annual average population intake of fruits and vegetables and of grains expressed on a body-weight and agespecific basis.

Limited data are available on the amount of home-grown food that is produced and consumed in California or in the U.S. The U.S. EPA [1989a] has compiled for U.S. households data on the fractions of consumed produce that come from home gardens. For all categories of fruits and vegetables reported in this study, the fraction that is homegrown is in the range 0.04 to 0.75 , and for the one grain listed (corn), the average fraction that is homegrown is 0.45 for the $25 \%$ of the individuals surveyed who consumed homegrown corn. From these data we estimated that the fraction of consumed fruits and vegetables that are homegrown is 0.24 with a CV of 0.7 , and that 
the fraction of consumed grains (mostly corn) that are homegrown is 0.11 also with a $\mathrm{CV}$ of 0.7 . These values represent households with home gardens and not necessarily the average of total homegrown consumption in either the U.S. or California.

According to Yang and Nelson (1986), 47\% of all consumed produce (fruits and vegetables) consists of leafy vegetables and other exposed produce, which intercept contaminants from the atmosphere. The remaining $53 \%$ of fruits and vegetables consists of protected produce or root crops, in which contaminant transfer to the edible portion is primarily by root uptake. All grain crops are assumed to be exposed primarily to air contaminants.

Based on the information provided in the previous paragraphs, we estimated the mean and $\mathrm{CV}$ of the ingestion of exposed (above-ground) and unexposed homegrown produce in households near the NTLF. Table B-1 lists our estimates of the mean average annual ingestion of both exposed and unexposed homegrown foods on a bodyweight basis for children, for adults, and for a lifetime of exposure. As is the case for other contact rates, both the mean value and the $\mathrm{CV}$ are provided. 



\section{Appendix C}

\section{Landscape, Climate and Hydrology Parameters}

The purpose of this appendix is to describe how values and ranges of inputs for the landscape, climate, and hydrology parameters used in the risk assessment model are obtained. Table C-1 lists the landscape properties for the NTLF environment derived in this appendix.

Table C-1

Landscape Properties for the NTLF Environment.

\begin{tabular}{|l|l|l|l|l|}
\hline Parameter description & Symbol & $\begin{array}{l}\text { Mean } \\
\text { value }\end{array}$ & CV & Reference(s) \\
\hline Yearly average wind speed, $\mathrm{m} / \mathrm{s}$ & $v_{W}$ & 2 & 0.3 & Thorson [1995] \\
\hline Yearly average temperature, ${ }^{\circ} \mathrm{C}$ & $T$ & 12.5 & 0.2 & Merry [1991] NOAA [1974] \\
\hline Yearly average relative humidity, \% & $R H$ & 79 & 0.04 & Merry [1991] NOAA [1974] \\
\hline Soil compartment depth, $\mathrm{m}$ & $d_{S}$ & 2.5 & 0.5 & $\begin{array}{l}\text { Thibodeaux, [1994] Murphy } \\
\text { [1993] }\end{array}$ \\
\hline $\begin{array}{l}\text { Volumetric moisture content of soil, } \\
\text { L(water)/L(soil) }\end{array}$ & $\varnothing_{S}$ & 0.3 & 0.1 & van der Leeden et al. [1991] \\
\hline Annual average precipitation, $\mathrm{m} / \mathrm{y}$ & rain & 0.64 & 1.0 & Merry [1991] NOAA [1974] \\
\hline $\begin{array}{l}\text { Annual average evapotranspiration, } \\
\text { m/y }\end{array}$ & evapotrans & 0.45 & 0.14 & van der Leeden et al. [1991] \\
\hline Annual average runoff, $\mathrm{m} / \mathrm{y}$ & runoff & 0.13 & 0.26 & van der Leeden et al. [1991] \\
\hline Infiltration to ground water, $\mathrm{m} / \mathrm{y}$ & recharge & 0.06 & 0.26 & This report \\
\hline Scavenging efficiency & AQ rain & 0.4 & 0.2 & Murphy [1993] \\
\hline \hline
\end{tabular}




\section{C.1 Wind Speed}

Winds are generally light and blow from the southeast or west-northwest (Figure 2-10 in the 1995 Site Environmental Report, [Thorson, 1996]. During 1995, wind speeds were less than 1.5 meters per second ( 3.5 miles per hour) about $40 \%$ of the time. Over $95 \%$ of the time, winds were less than 5 meters per second (11 miles per hour) [Thorson, 1996]. Predominant wind patterns have winds blowing from the southeast during nighttime hours and from a westerly direction during the daytime. Based on this data and a compilation of hourly wind data, we used a mean annual wind speed of $2 \mathrm{~m} / \mathrm{s}$ with a CV of 0.3 .

\section{C.2 Temperature}

The mean monthly temperature for San Francisco is $14^{\circ} \mathrm{C}$ and has a coefficient of variation $(\mathrm{CV})$ of 0.21 [NOAA, 1974]. The average annual temperature employed in the 1994 NESHAPS study for LBNL (derived from Oakland airport data) was $10{ }^{\circ} \mathrm{C}(283 \mathrm{~K}$ ) while Merry [1991] reports average summer and winter temperatures for the LBNL site of $17{ }^{\circ} \mathrm{C}$ and $9{ }^{\circ} \mathrm{C}$, respectively (implying an approximate average of $12.5{ }^{\circ} \mathrm{C}$, or $285 \mathrm{~K}$ ). The latter average annual temperature compares well with that observed at LLNL [Sims et al., 1989]. We use $12.5^{\circ} \mathrm{C}$ with a $\mathrm{CV}$ of 0.21 to represent the LBNL site.

\section{C.3 Humidity}

Merry [1991] reports average relative humidity ranges of $85-90 \%$ and $65-75 \%$ in the early morning and afternoon, respectively, for the LBNL site. The mean humidity obtained from these values is $79 \%$. Mean monthly relative humidity for San Francisco over a 12-year period has a mean annual value (and CV in parentheses) of $84 \%(0.03)$ at $7 \mathrm{am}, 70 \%(0.08)$ at $1 \mathrm{PM}$ and $77 \%(0.04)$ overall [NOAA, 1974]. We use a mean annual humidity of $77 \%$ and a CV of 0.04 to represent the LBNL site.

\section{C.4 Depth of Soil Compartment}

For the purposes of modeling, the soil compartment represents only the vertical extent of soil interacting with the air compartment. Theoretically, when HTO reaches a critical depth in soil it has such a small likelihood of re-emerging to air that it can effectively be treated as sequestered in the soil compartment. In our model, this critical depth is used to delimit the vertical extent of the soil compartment. The Damkoehler Number [Thibodeaux, L.]., personal communication] is used to define a "maximum depth of penetration." When the Damkoehler Number is one, radioactive decay and diffusion/advection are balanced. The depth which corresponds to a unit Damkoehler number is the maximum depth of penetration for that chemical. We estimate the depth 
corresponding to the unit Damkoehler number for tritium as roughly 2.5 meters. This depth is adopted as the vertical extent of the soil compartment. Murphy has noted that the vertical extent of soil interacting with the air compartment depends to a great extent on the depth of roots of the native vegetation since transpiration plays an important role in the interaction of the soil and air compartments [Murphy, 1993]. A typical depth of root penetration for the U.S. is $1 \mathrm{~m}$, which is compatible with the 2.5 meter depth adopted for this study. However, site-specific field measurements of soil penetration could help identify a better choice of depth for defining the soil compartment.

Vadose zone monitoring well observations of HTO levels at various depths in the soil are compatible with a 2.5 meter penetration depth. The measurements show a levelingoff of HTO levels beyond the $7 \mathrm{ft}(2.2 \mathrm{~m})$ depth ["Tritium Results for Soil Samples", BSVM-TS-1]. However, the observations originating from just one monitoring well are not necessarily representative of the entire soil body within the study area.

\section{C.5 Moisture Content of Soil}

The average mass percent of water measured in soil samples taken from boreholes made in the vicinity of the Grizzly Area is 17 percent (including only those samples taken between $0 \mathrm{ft}$ and $8 \mathrm{ft}$ deep, i.e., to get a water fraction representative of the soil compartment). The equivalent mass fraction can be converted to a volumetric fraction assuming the ratio of aggregate soil (i.e., including soil water and air fractions) to that of water to be 1.6. Using this factor, a nominal volumetric water fraction for the soil compartment is calculated as, 0.30 . We estimate the $C V$ in this value to be 0.10 .

\section{C.6 Precipitation}

The annual average precipitation reported for the LBNL site is $0.64 \mathrm{~m} / \mathrm{y}$ [Merry, 1991]. Monthly distributions of average precipitation for San Francisco give a mean annual rainfall of $0.47 \mathrm{~m}$ and a coefficient of variation (CV) of 1.0 [NOAA, 1974]. Based on these values, we use an average annual rainfall of $0.64 \mathrm{~m} / \mathrm{y}$ and a $\mathrm{CV}$ of 1.0 to model the LBNL site.

\section{C.7 Evapotranspiration}

No site-specific data for evapotranspiration are available. According to the Water Encyclopedia [van der Leeden et al., 1991], evapotranspiration is roughly $60 \%$ of rainfall in North America and is $65 \%$ worldwide with a CV of 0.14 . For dryer climates, such as Australia and Africa, it is as much as $90 \%$. Assuming the Berkeley climate is dryer than the average North American climate, we set the nominal evapotranspiration at $70 \%$ of the local precipitation rate or $0.45 \mathrm{~m} / \mathrm{y}$, with a CV of 0.14 . 


\section{C.8 Runoff}

No estimates of runoff are available for the LBNL site. Merry [1991] noted that rainfall intensities at LBNL are rarely greater than $1.3 \mathrm{~cm} / \mathrm{hr}$. With this relatively low intensity, one would expect a lower than average runoff, since runoff basically results when the rainfall rate exceeds the infiltration rate. However, the presence of parking lots around the facility should increase the rate of runoff above average. The Water Encyclopedia [van der Leeden et al., 1991] reports that runoff generally represents between 10 and $30 \%$ of the precipitation rate with a global average of $25 \%$ and global CV of 0.26 , and North American average of $30 \%$. We adopt $20 \%$ as the representative value for LBNL, which corresponds to a yearly average runoff of $0.13 \mathrm{~m} / \mathrm{y}$ with a $\mathrm{CV}$ of 0.26 .

\section{C.9 Infiltration to Ground Water}

Because no infiltration data are available for the LBNL site, the infiltration rate is taken as the difference between the precipitation rate and the sum of the runoff and evapotranspiration rates.

\section{C.10 Rain Scavenging Efficiency}

The scavenging efficiency is the fraction of HTO in air that is transferred to rain. Transfer occurs by one of two processes:

- Incorporation during the formation of raindrops in the atmosphere

- Rain-out of HTO as falling rain drops adsorb some fraction of HTO vapor.

A scavenging efficiency can be inferred from observed ratios of $A Q_{\text {rain }}$ to $A Q_{\text {air }}$. Murphy [1993] notes that this ratio is generally less than unity, implying lower HTO aquivalence in rain than in airborne vapor. He reports that the minimum, average, and maximum ratios are $0.20,0.40,0.55$, respectively. In the present analysis this range is assumed equivalent to a scavenging efficiency with a mean value of 0.40 and $C V$ of 0.2 . 


\section{Appendix D}

\section{Evaluating the Potential Legacy of Past Elevated HTO Emissions}

In the past the NTLF emitted HTO at a greater rate. Prior to 1989 the emissions were three times the current release rates. Depending on the effective residence time of HTO in the soil compartment, the pre-1989 releases may have left a legacy of non-negligible soil levels over and above those predicted under the premise of the current release rates. Here we investigate the potential significance of such a legacy. This analysis requires a dynamic treatment of the compartmental inventories because the HTO source is transient. From literature review and based on our experience with multi-media fate and transport modeling of other contaminants, the effective residence time of tritium in the soil can be far greater than that in air. Thus only the soil compartment must be treated as a dynamic compartment. Based on Equations 1 and 2, the following revised system of equations can be defined:

$$
S+T_{\mathrm{sa}} N_{\mathrm{s}}=L_{\mathrm{a}} N_{\mathrm{a}} \quad \text { (air) }
$$

and,

$$
\frac{d N_{s}}{d t}=T_{a s} \times N_{a}-L_{s} \times N_{s} \quad \text { (surface soil) }
$$

The above system of equations can be solved to determine the time-dependent inventory of the soil compartment, $N_{\mathcal{S}}(t)$, as:

$$
N_{s}(t)=\left[N_{s}(0)-\frac{T_{a s} \times S}{L_{a} \times Y}\right] \times \exp (-Y t)+\frac{T_{a s} \times S}{L_{a} \times Y}
$$

where, 


$$
Y=L_{s}-\frac{T_{s a} \times T_{a s}}{L_{a}}
$$

$\mathrm{N}_{\mathrm{s}}(0)$ is the HTO inventory (in $\mathrm{Bq}$ ) in the soil compartment at $\mathrm{t}=0$, and all other terms are as previously defined. Assuming that emissions prior to 1989 were continuous at three times the current level, a steady state inventory in soil due to the pre-1990 emissions can be expressed as:

$$
N_{s(1989)}=\frac{3 \times S \times T_{a s}}{L_{a} \times Y}
$$

Equation D-5 can be found by allowing $t->$ infinity in Equation D-3. Equation D-5 can be substituted into Equation D-3, as the initial concentration, i.e., for $\mathrm{N}_{\mathcal{S}}(0)$, to calculate a time-dependent inventory in soil reflecting the cumulative result of both the initial conditions established by the legacy of the early elevated emission rate and the subsequent post- 1989 continuous release of tritium at the rate of $\mathrm{S}$. The resultant inventory at 1994 due to both legacy and continuous release will be denoted $N_{s(t=1994)}$. The ratio of the latter to $\mathrm{N}_{\mathrm{s}}$, as calculated using Equation D-5 (i.e., under steady state conditions and neglecting the legacy of former operations) can be expressed as:

$$
\begin{gathered}
\frac{N_{s(t=1994)}}{N_{s}}=\left[\frac{3 \times S-S}{S}\right] \times \exp (-Y t)+1 \\
\frac{N_{s(t=1994)}}{N_{s}}=2 \times \exp (-Y t)+1
\end{gathered}
$$

The above ratio is used to evaluate the relative significance of the legacy from past elevated release in terms of affecting the current HTO inventory in soil. This analysis does not take into account the enhanced residence time in soil, which would be affected by OBT. However, Murphy [1993] asserts that the amount of HTO that would be converted to and reside in the organically bound form is negligible in terms of quantity.

\section{Conclusion}

The analysis presented here indicates that risk levels associated with releases larger than $100 \mathrm{Ci} / \mathrm{y}$ can be found by multiplying this report's risk levels by the ratio of the larger release rate (averaged over the same time period) to the $100 \mathrm{Ci} / \mathrm{y}$ release rate. For example, if past releases over a ten-year period averaged $200 \mathrm{Ci} / \mathrm{y}$ and then came down to $100 \mathrm{Ci} / \mathrm{y}$ and we want to assess the impact of this on the 40 -year estimated risk, we would effectively increase the estimated risk associated with the continuous release of $100 \mathrm{Ci} / \mathrm{y}$ by a factor of 1.25 , that is 10 years at $200 \mathrm{Ci} / \mathrm{y}$ plus 30 years at 100 $\mathrm{Ci} / \mathrm{y}$ divided by 40 years at $100 \mathrm{Ci} / \mathrm{y}$. 


\section{Appendix E}

\section{Results of the Risk Assessment Carried Out for NTLF Releases, Using the EPA CAP88 Computer Model}

CAP88-PC is a microcomputer radionuclide dispersion and dose-assessment code supplied and approved by US/EPA. This model was used to calculate doses to individuals at various distances from the NTLF. For the point of maximum off-site exposure, the dose represents the cumulative exposure from all significant exposure pathways (inhalation, ingestion, air immersion, and surface exposure). The methods and parameters used to calculate the dose are very conservative. For example, the model assumes that some portion of the food consumed by the hypothetical individual was grown within the assessed area. The individual was assumed to reside at this location continuously throughout the year. In addition, all of the tritium released was assumed to be the most hazardous form, tritium oxide. Consequently, this dose is not a dose actually received by anyone, but an upper-bound estimate. 


$$
\begin{gathered}
\text { C A P } 88-\text { P C } \\
\text { Version } 1.00 \\
\text { Clean Air Act Assessment Package - } 1988
\end{gathered}
$$

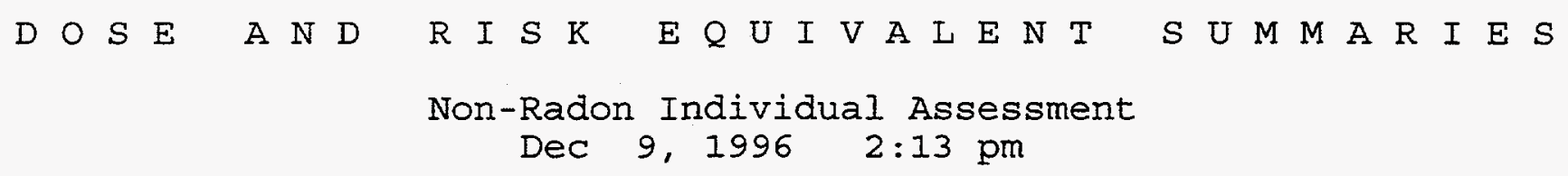

Facility: Lawrence Berkeley National Laboratory (LBNL) Address: EH\&S Environmental Protection Group One Cyclotron Road

City: Berkeley

State: CA Zip: 94720
Source Category: 'Building 75 NTLF (Risk Assessement)
Source Type: Stack
Emission Year: 1995

Comments: Henry H. Tran (Environmental Health Physicist)

(510) 486-7623 hhtran@lbl.gov

Dataset Name: RISK ASSESSSMENT

Dataset Date: Dec 9, 1996 2:13 pm

Wind File: WNDFILES $\backslash$ LBL95. WND 
ORGAN DOSE EQUIVALENT SUMMARY

\begin{tabular}{lc} 
Organ & $\begin{array}{c}\text { Selected } \\
\text { Individual } \\
\text { (mrem/y) }\end{array}$ \\
\hline GONADS & $1.35 E-01$ \\
BREAST & $1.35 E-01$ \\
R MAR & $1.34 E-01$ \\
LUNGS & $1.36 E-01$ \\
THYROID & $1.35 E-01$ \\
ENDOST & $1.07 E-01$ \\
RMNDR & $1.55 E-01$ \\
EFFEC & $1.40 E-01$
\end{tabular}

PATHWAY EFFECTIVE DOSE EQUIVALENT SUMMARY

Selected

Pathway

Individual

(mrem/y)

INGESTION

$5.21 \mathrm{E}-02$

INHALATION

8. $82 \mathrm{E}-02$

AIR IMMERSION

$0.00 \mathrm{E}+00$

GROUND SURFACE

$0.00 \mathrm{E}+00$

INTERNAI

1. $40 \mathrm{E}-01$

EXTERNAL

$0.00 E+00$

TOTAL

1. $40 \mathrm{E}-01$ 
Dec 9, $1996 \quad 2: 13 \mathrm{pm}$

NUCLIDE EFFECTIVE DOSE EQUIVALENT SUMMARY

\begin{tabular}{lc} 
Nuclide & $\begin{array}{c}\text { Selected } \\
\text { Individual } \\
\text { (mrem/y) }\end{array}$ \\
\hline $\mathrm{H}-3$ & $1.40 \mathrm{E}-01$ \\
TOTAI & $1.40 \mathrm{E}-01$
\end{tabular}


CANCER RISK SUMMARY

Cancer

Selected Individual

Total Lifetime

Fatal Cancer Risk

LEUKEMIA

$4.26 E-07$

BONE

1. $89 \mathrm{E}-08$

THYROID

6. $12 \mathrm{E}-08$

BREAST

5. $30 \mathrm{E}-07$

LUNG

$6.73 \mathrm{E}-07$

STOMACH

$4.87 E-07$

BOWEL

2. $63 \mathrm{E}-07$

LIVER

PANCREAS

URINARY

4. $72 \mathrm{E}-07$

3. $21 \mathrm{E}-07$

OTHER

1. $75 \mathrm{E}-07$

3. $92 \mathrm{E}-07$

TOTAI

$3.82 E-06$

\section{PATHWAY RISK SUMMARY}

Pathway

INGESTION

INHALATION

AIR IMMERSION

GROUND SURFACE

INTERNAL

EXTERNAL

TOTAL
Selected Individual

Total Lifetime

Fatal Cancer Risk

1. $4 I \mathrm{E}-06$

2. $41 \mathrm{IE}-06$

$0.00 \mathrm{E}+00$

$0.00 E+00$

3. $82 \mathrm{E}-06$

$0.00 E+00$

3. $82 \mathrm{E}-06$ 
Dec 9, $1996 \quad 2: 13 \mathrm{pm}$

NUCLIDE RISK SUMMARY

Selected Individual Total Lifetime

Nuclide Fatal Cancer Risk

$\mathrm{H}-3$

3. $82 E-06$

TOTAL

3. $82 E-06$ 
Dec 9, $19962: 13 \mathrm{pm}$

SUMMARY

Page 5

INDIVIDUAL EFFECTIVE DOSE EQUIVALENT RATE (mrem/y)

(All Radionuclides and Pathways)

Distance (m)

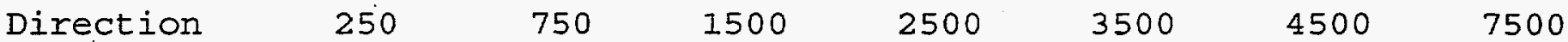

$\begin{array}{rlllllll}\mathrm{N} & 6.0 \mathrm{E}-02 & 4.4 \mathrm{E}-02 & 3.2 \mathrm{E}-02 & 2.8 \mathrm{E}-02 & 2.7 \mathrm{E}-02 & 2.6 \mathrm{E}-02 & 2.6 \mathrm{E}-02 \\ \mathrm{NNW} & 6.2 \mathrm{E}-02 & 5.6 \mathrm{E}-02 & 3.7 \mathrm{E}-02 & 3.1 \mathrm{E}-02 & 2.8 \mathrm{E}-02 & 2.7 \mathrm{E}-02 & 2.6 \mathrm{E}-02 \\ \mathrm{NW} & 9.9 \mathrm{E}-02 & 6.8 \mathrm{E}-02 & 4.2 \mathrm{E}-02 & 3.3 \mathrm{E}-02 & 3.0 \mathrm{E}-02 & 2.8 \mathrm{E}-02 & 2.6 \mathrm{E}-02 \\ \mathrm{WNW} & 9.8 \mathrm{E}-02 & 5.9 \mathrm{E}-02 & 3.8 \mathrm{E}-02 & 3.1 \mathrm{E}-02 & 2.8 \mathrm{E}-02 & 2.7 \mathrm{E}-02 & 2.6 \mathrm{E}-02 \\ \mathrm{~W} & 5.7 \mathrm{E}-02 & 4.5 \mathrm{E}-02 & 3.2 \mathrm{E}-02 & 2.8 \mathrm{E}-02 & 2.7 \mathrm{E}-02 & 2.6 \mathrm{E}-02 & 2.6 \mathrm{E}-02 \\ \mathrm{WSW} & 3.8 \mathrm{E}-02 & 3.5 \mathrm{E}-02 & 2.9 \mathrm{E}-02 & 2.7 \mathrm{E}-02 & 2.6 \mathrm{E}-02 & 2.6 \mathrm{E}-02 & 2.5 \mathrm{E}-02 \\ \mathrm{SW} & 2.9 \mathrm{E}-02 & 3.2 \mathrm{E}-02 & 2.8 \mathrm{E}-02 & 2.6 \mathrm{E}-02 & 2.6 \mathrm{E}-02 & 2.5 \mathrm{E}-02 & 2.5 \mathrm{E}-02 \\ \mathrm{SSW} & 3.2 \mathrm{E}-02 & 3.4 \mathrm{E}-02 & 2.9 \mathrm{E}-02 & 2.7 \mathrm{E}-02 & 2.6 \mathrm{E}-02 & 2.6 \mathrm{E}-02 & 2.5 \mathrm{E}-02 \\ \mathrm{~S} & 4.1 \mathrm{E}-02 & 4.1 \mathrm{E}-02 & 3.1 \mathrm{E}-02 & 2.8 \mathrm{E}-02 & 2.7 \mathrm{E}-02 & 2.6 \mathrm{E}-02 & 2.5 \mathrm{E}-02 \\ \mathrm{SSE} & 6.9 \mathrm{E}-02 & 5.0 \mathrm{E}-02 & 3.5 \mathrm{E}-02 & 2.9 \mathrm{E}-02 & 2.8 \mathrm{E}-02 & 2.7 \mathrm{E}-02 & 2.6 \mathrm{E}-02 \\ \mathrm{SE} & 7.3 \mathrm{E}-02 & 5.2 \mathrm{E}-02 & 3.5 \mathrm{E}-02 & 3.0 \mathrm{E}-02 & 2.8 \mathrm{E}-02 & 2.7 \mathrm{E}-02 & 2.6 \mathrm{E}-02 \\ \mathrm{ESE} & 1.2 \mathrm{E}-01 & 5.7 \mathrm{E}-02 & 3.6 \mathrm{E}-02 & 3.0 \mathrm{E}-02 & 2.8 \mathrm{E}-02 & 2.7 \mathrm{E}-02 & 2.6 \mathrm{E}-02 \\ \mathrm{E} & 1.4 \mathrm{E}-01 & 5.6 \mathrm{E}-02 & 3.6 \mathrm{E}-02 & 3.0 \mathrm{E}-02 & 2.8 \mathrm{E}-02 & 2.7 \mathrm{E}-02 & 2.6 \mathrm{E}-02 \\ \mathrm{ENE} & 7.7 \mathrm{E}-02 & 4.4 \mathrm{E}-02 & 3.2 \mathrm{E}-02 & 2.8 \mathrm{E}-02 & 2.7 \mathrm{E}-02 & 2.6 \mathrm{E}-02 & 2.5 \mathrm{E}-02 \\ \mathrm{NE} & 5.3 \mathrm{E}-02 & 4.1 \mathrm{E}-02 & 3.1 \mathrm{E}-02 & 2.8 \mathrm{E}-02 & 2.6 \mathrm{E}-02 & 2.6 \mathrm{E}-02 & 2.5 \mathrm{E}-02 \\ \mathrm{NNE} & 5.1 \mathrm{E}-02 & 4.0 \mathrm{E}-02 & 3.1 \mathrm{E}-02 & 2.7 \mathrm{E}-02 & 2.6 \mathrm{E}-02 & 2.6 \mathrm{E}-02 & 2.5 \mathrm{E}-02\end{array}$

Distance $(m)$

Direction $\quad 15000 \quad 25000 \quad 30000 \quad 35000 \quad 45000 \quad 55000 \quad 65000$

$\begin{array}{rlllllll}N & 2.5 E-02 & 2.5 E-02 & 2.5 E-02 & 2.5 E-02 & 2.5 E-02 & 2.5 E-02 & 2.5 E-02 \\ \text { NNW } & 2.5 E-02 & 2.5 E-02 & 2.5 E-02 & 2.5 E-02 & 2.5 E-02 & 2.5 E-02 & 2.5 E-02 \\ \text { NW } & 2.5 E-02 & 2.5 E-02 & 2.5 E-02 & 2.5 E-02 & 2.5 E-02 & 2.5 E-02 & 2.5 E-02 \\ \text { WNW } & 2.5 E-02 & 2.5 E-02 & 2.5 E-02 & 2.5 E-02 & 2.5 E-02 & 2.5 E-02 & 2.5 E-02 \\ W & 2.5 E-02 & 2.5 E-02 & 2.5 E-02 & 2.5 E-02 & 2.5 E-02 & 2.5 E-02 & 2.5 E-02 \\ \text { WSW } & 2.5 E-02 & 2.5 E-02 & 2.5 E-02 & 2.5 E-02 & 2.5 E-02 & 2.5 E-02 & 2.5 E-02 \\ \text { SW } & 2.5 E-02 & 2.5 E-02 & 2.5 E-02 & 2.5 E-02 & 2.5 E-02 & 2.5 E-02 & 2.5 E-02 \\ \text { SSW } & 2.5 E-02 & 2.5 E-02 & 2.5 E-02 & 2.5 E-02 & 2.5 E-02 & 2.5 E-02 & 2.5 E-02 \\ \text { S } & 2.5 E-02 & 2.5 E-02 & 2.5 E-02 & 2.5 E-02 & 2.5 E-02 & 2.5 E-02 & 2.5 E-02 \\ \text { SSE } & 2.5 E-02 & 2.5 E-02 & 2.5 E-02 & 2.5 E-02 & 2.5 E-02 & 2.5 E-02 & 2.5 E-02 \\ \text { SE } & 2.5 E-02 & 2.5 E-02 & 2.5 E-02 & 2.5 E-02 & 2.5 E-02 & 2.5 E-02 & 2.5 E-02 \\ \text { ESE } & 2.5 E-02 & 2.5 E-02 & 2.5 E-02 & 2.5 E-02 & 2.5 E-02 & 2.5 E-02 & 2.5 E-02 \\ E & 2.5 E-02 & 2.5 E-02 & 2.5 E-02 & 2.5 E-02 & 2.5 E-02 & 2.5 E-02 & 2.5 E-02 \\ \text { ENE } & 2.5 E-02 & 2.5 E-02 & 2.5 E-02 & 2.5 E-02 & 2.5 E-02 & 2.5 E-02 & 2.5 E-02 \\ N E & 2.5 E-02 & 2.5 E-02 & 2.5 E-02 & 2.5 E-02 & 2.5 E-02 & 2.5 E-02 & 2.5 E-02 \\ N N E & 2.5 E-02 & 2.5 E-02 & 2.5 E-02 & 2.5 E-02 & 2.5 E-02 & 2.5 E-02 & 2.5 E-02\end{array}$


Dec

9, $19962: 13 \mathrm{pm}$

SUMMARY

Page 6

INDIVIDUAL EFFECTIVE DOSE EQUIVALENT RATE (mrem/y)

(All Radionuclides and Pathways)

\section{Distance (m)}

\section{Direction $\quad 75000 \quad 80000$}

$\begin{array}{rll}N & 2.5 E-02 & 2.5 E-02 \\ N N W & 2.5 E-02 & 2.5 E-02 \\ N W & 2.5 E-02 & 2.5 E-02 \\ W N W & 2.5 E-02 & 2.5 E-02 \\ W & 2.5 E-02 & 2.5 E-02 \\ W S W & 2.5 E-02 & 2.5 E-02 \\ \text { SW } & 2.5 E-02 & 2.5 E-02 \\ \text { SSW } & 2.5 E-02 & 2.5 E-02 \\ S & 2.5 E-02 & 2.5 E-02 \\ \text { SSE } & 2.5 E-02 & 2.5 E-02 \\ \text { SE } & 2.5 E-02 & 2.5 E-02 \\ \text { ESE } & 2.5 E-02 & 2.5 E-02 \\ E & 2.5 E-02 & 2.5 E-02 \\ \text { ENE } & 2.5 E-02 & 2.5 E-02 \\ N E & 2.5 E-02 & 2.5 E-02 \\ N N E & 2.5 E-02 & 2.5 E-02\end{array}$


Dec 9, 1996. 2:13 pm

SUMMARY

Page 7

INDIVIDUAL LIFETIME RISK (deaths)

(All Radionuclides and Pathways)

Distance $(\mathrm{m})$

$\begin{array}{llllllll}\text { Direction } & 250 & 750 & 1500 & 2500 & 3500 & 4500 & 7500\end{array}$

$\begin{array}{rlllllll}N & 1.6 E-06 & 1.2 E-06 & 8.7 E-07 & 7.6 E-07 & 7.3 E-07 & 7.1 E-07 & 6.9 E-07 \\ \text { NNW } & 1.7 E-06 & 1.5 E-06 & 1.0 E-06 & 8.3 E-07 & 7.7 E-07 & 7.4 E-07 & 7.0 E-07 \\ \text { NW } & 2.7 E-06 & 1.9 E-06 & 1.1 E-06 & 8.8 E-07 & 8.0 E-07 & 7.6 E-07 & 7.2 E-07 \\ \text { WNW } & 2.7 E-06 & 1.6 E-06 & 1.0 E-06 & 8.3 E-07 & 7.7 E-07 & 7.4 E-07 & 7.0 E-07 \\ W & 1.5 E-06 & 1.2 E-06 & 8.8 E-07 & 7.7 E-07 & 7.3 E-07 & 7.1 E-07 & 6.9 E-07 \\ \text { WSW } & 1.0 E-06 & 9.4 E-07 & 7.7 E-07 & 7.2 E-07 & 7.0 E-07 & 6.9 E-07 & 6.8 E-07 \\ \text { SW } & 7.9 E-07 & 8.7 E-07 & 7.5 E-07 & 7.1 E-07 & 6.9 E-07 & 6.9 E-07 & 6.8 E-07 \\ \text { SSW } & 8.6 E-07 & 9.3 E-07 & 7.8 E-07 & 7.2 E-07 & 7.0 E-07 & 6.9 E-07 & 6.8 E-07 \\ \text { S } & 1.1 E-06 & 1.1 E-06 & 8.5 E-07 & 7.5 E-07 & 7.2 E-07 & 7.1 E-07 & 6.9 E-07 \\ \text { SSE } & 1.9 E-06 & 1.4 E-06 & 9.4 E-07 & 7.9 E-07 & 7.5 E-07 & 7.2 E-07 & 7.0 E-07 \\ \text { SE } & 2.0 E-06 & 1.4 E-06 & 9.6 E-07 & 8.0 E-07 & 7.5 E-07 & 7.3 E-07 & 7.0 E-07 \\ \text { ESE } & 3.4 E-06 & 1.6 E-06 & 9.9 E-07 & 8.1 E-07 & 7.6 E-07 & 7.3 E-07 & 7.0 E-07 \\ E & 3.8 E-06 & 1.5 E-06 & 9.7 E-07 & 8.0 E-07 & 7.5 E-07 & 7.2 E-07 & 7.0 E-07 \\ \text { ENE } & 2.1 E-06 & 1.2 E-06 & 8.6 E-07 & 7.6 E-07 & 7.2 E-07 & 7.1 E-07 & 6.9 E-07 \\ N E & 1.4 E-06 & 1.1 E-06 & 8.4 E-07 & 7.5 E-07 & 7.2 E-07 & 7.0 E-07 & 6.9 E-07 \\ N N E & 1.4 E-06 & 1.1 E-06 & 8.3 E-07 & 7.4 E-07 & 7.1 E-07 & 7.0 E-07 & 6.9 E-07\end{array}$

Distance $(m)$

Direction $\quad 15000 \quad 25000 \quad 30000 \quad 35000 \quad 45000 \quad 55000 \quad 65000$

$\begin{array}{rlllllll}N & 6.8 E-07 & 6.7 E-07 & 6.7 E-07 & 6.7 E-07 & 6.7 E-07 & 6.7 E-07 & 6.7 E-07 \\ \text { NNW } & 6.8 E-07 & 6.8 E-07 & 6.8 E-07 & 6.7 E-07 & 6.7 E-07 & 6.7 E-07 & 6.7 E-07 \\ \text { NW } & 6.9 E-07 & 6.8 E-07 & 6.8 E-07 & 6.8 E-07 & 6.7 E-07 & 6.7 E-07 & 6.7 E-07 \\ \text { WNW } & 6.8 E-07 & 6.8 E-07 & 6.8 E-07 & 6.7 E-07 & 6.7 E-07 & 6.7 E-07 & 6.7 E-07 \\ W & 6.8 E-07 & 6.7 E-07 & 6.7 E-07 & 6.7 E-07 & 6.7 E-07 & 6.7 E-07 & 6.7 E-07 \\ \text { WSW } & 6.7 E-07 & 6.7 E-07 & 6.7 E-07 & 6.7 E-07 & 6.7 E-07 & 6.7 E-07 & 6.7 E-07 \\ \text { SW } & 6.7 E-07 & 6.7 E-07 & 6.7 E-07 & 6.7 E-07 & 6.7 E-07 & 6.7 E-07 & 6.7 E-07 \\ \text { SSW } & 6.7 E-07 & 6.7 E-07 & 6.7 E-07 & 6.7 E-07 & 6.7 E-07 & 6.7 E-07 & 6.7 E-07 \\ \text { S } & 6.8 E-07 & 6.7 E-07 & 6.7 E-07 & 6.7 E-07 & 6.7 E-07 & 6.7 E-07 & 6.7 E-07 \\ \text { SSE } & 6.8 E-07 & 6.8 E-07 & 6.7 E-07 & 6.7 E-07 & 6.7 E-07 & 6.7 E-07 & 6.7 E-07 \\ \text { SE } & 6.8 E-07 & 6.8 E-07 & 6.7 E-07 & 6.7 E-07 & 6.7 E-07 & 6.7 E-07 & 6.7 E-07 \\ \text { ESE } & 6.8 E-07 & 6.8 E-07 & 6.7 E-07 & 6.7 E-07 & 6.7 E-07 & 6.7 E-07 & 6.7 E-07 \\ E & 6.8 E-07 & 6.8 E-07 & 6.7 E-07 & 6.7 E-07 & 6.7 E-07 & 6.7 E-07 & 6.7 E-07 \\ \text { ENE } & 6.8 E-07 & 6.7 E-07 & 6.7 E-07 & 6.7 E-07 & 6.7 E-07 & 6.7 E-07 & 6.7 E-07 \\ N E & 6.8 E-07 & 6.7 E-07 & 6.7 E-07 & 6.7 E-07 & 6.7 E-07 & 6.7 E-07 & 6.7 E-07 \\ \text { NNE } & 6.8 E-07 & 6.7 E-07 & 6.7 E-07 & 6.7 E-07 & 6.7 E-07 & 6.7 E-07 & 6.7 E-07\end{array}$


Dec 9, $1996 \quad 2: 13 \mathrm{pm}$

INDIVIDUAL LIFETIME RISK (deaths)

(AIl Radionuclides and Pathways)

\section{Distance (m)}

Direction $\quad 75000 \quad 80000$

$\begin{array}{rll}N & 6.7 E-07 & 6.7 E-07 \\ \text { NNW } & 6.7 E-07 & 6.7 E-07 \\ \text { NW } & 6.7 E-07 & 6.7 E-07 \\ \text { WNW } & 6.7 E-07 & 6.7 E-07 \\ W & 6.7 E-07 & 6.7 E-07 \\ \text { WSW } & 6.7 E-07 & 6.7 E-07 \\ \text { SW } & 6.7 E-07 & 6.7 E-07 \\ \text { SSW } & 6.7 E-07 & 6.7 E-07 \\ S & 6.7 E-07 & 6.7 E-07 \\ \text { SSE } & 6.7 E-07 & 6.7 E-07 \\ \text { SE } & 6.7 E-07 & 6.7 E-07 \\ \text { ESE } & 6.7 E-07 & 6.7 E-07 \\ E & 6.7 E-07 & 6.7 E-07 \\ \text { ENE } & 6.7 E-07 & 6.7 E-07 \\ \text { NE } & 6.7 E-07 & 6.7 E-07 \\ \text { NNE } & 6.7 E-07 & 6.7 E-07\end{array}$




\section{Appendix F}

\section{Validation of the Input Data for Risk Assessment}

This appendix compares the input tritium concentrations used in the risk assessment with site-specific data from special studies and with information that is provided in the 1995 LBNL Site Environmental Report [Thorson, 1996]. It includes a summary comparison for air, rain water, surface water, soil and sediment, vegetation and other biota, and urine measurements. Table F-1 provides a summary comparison of the estimates and measurements.

\section{F.1 Comparison of Risk Assessment Estimates to Measured Air Quality Data}

To assess the environmental impact of tritium releases, a network of eight sampling locations collected samples for atmospheric tritium analysis in 1995 [Thorson, 1996]. Of particular interest in these results is the rapid drop-off in tritium levels from Zone 1 sample location (ENV-69A) toward Zone 2 locations and other sites as the distance from the main source on site increases. ENV-69A is located near the base of the NTLF's tritium stack and measured a 1995 average tritium concentration of $24 \mathrm{~Bq} / \mathrm{m}^{3}$. All other sample locations correspond to Zone 2 and measured yearly average tritium concentrations in the range 3.3 to $6.8 \mathrm{~Bq} / \mathrm{m}^{3}$, with a mean value of $4.5 \mathrm{~Bq} / \mathrm{m}^{3}$. One of the samplers is located at the Lawrence Hall of Science and measured a 1995 average tritium level of $5.3 \mathrm{~Bq} / \mathrm{m}^{3}$. No air sample measurements are available for Zone 3. The air sample measurements for 1995 are compared to the risk assessment estimates in Table F-1. 
Table F-1

Estimated and Measured Tritium Levels

\begin{tabular}{|c|c|c|c|}
\hline & Zone 1 & Zone 2 & Zone 3 \\
\hline \multicolumn{4}{|l|}{ Emission rate, GBq/d } \\
\hline assumed & 10 & & \\
\hline measured & 5.4 & & \\
\hline assumed/measured & 1.8 & & \\
\hline \multicolumn{4}{|l|}{ Air concentrations, $\mathrm{Bq} / \mathrm{m}^{3}$} \\
\hline estimated & 96 & 5.2 & 0.35 \\
\hline measured & 24 & 4.5 & $\mathrm{na}$ \\
\hline estimated/measured & 4.0 & 1.2 & - \\
\hline \multicolumn{4}{|l|}{ Rain water, Bq/L } \\
\hline estimated & 1600 & 130 & 7 \\
\hline measured & 290 & 20 & $<$ detection \\
\hline estimated/measured & 5.5 & 6.5 & - \\
\hline \multicolumn{4}{|l|}{ Surface water, $\mathrm{Bq} / \mathrm{L}$} \\
\hline estimated & 580 & 48 & 11 \\
\hline measured & 100 & 15 & 10 \\
\hline estimated/measured & 5.8 & 3.2 & 1.1 \\
\hline \multicolumn{4}{|l|}{ Soil and sediments, $\mathrm{Bq} / \mathrm{kg}$} \\
\hline estimated & 175 & 9 & $\mathrm{na}$ \\
\hline measured & 44 & 3 & na \\
\hline estimated/measured & 4.0 & 3.0 & - \\
\hline \multicolumn{4}{|l|}{ Ground water, $\mathrm{Bq} / \mathrm{L}$} \\
\hline estimated & 580 & 48 & na \\
\hline measured & 280 & 10 & n/a \\
\hline estimated/measured & 2.1 & 4.8 & - \\
\hline \multicolumn{4}{|c|}{ Vegetation (free water) $\mathrm{Bq} / \mathrm{L}$} \\
\hline estimated & 1350 & 110 & 7 \\
\hline measured & 1600 & 100 & na \\
\hline estimated/measured & 0.84 & 1.1 & - \\
\hline \multicolumn{4}{|c|}{ Body water levels (urine), Bq/L } \\
\hline estimated & 468 & 28 & 4 \\
\hline measured & 48 & $20^{*}$ & na \\
\hline estimated/measured & 9.8 & 1.4 & - \\
\hline
\end{tabular}

- Recent results of urine analysis from five individuals working in the Lawrence Hall of Science did not show any tritium above the detection limit. 


\section{F.2 Comparison of Risk Assessment Estimates to Measured Rain Water Data}

Rain water yields a useful measure of tritium levels in atmospheric water. During the rainfall season, generally October through April, rainwater is collected monthly or during periods of significant rainfall [Thorson, 1996]. During 1995, rainwater was collected at six locations on site and analyzed for tritium. In Zone 1 rain water was collected at a rain gauge at Building 75 and analyzed for tritium. At this site, tritium was always detected in varying amounts, ranging from a low of $77 \mathrm{~Bq} / \mathrm{L}$ to a maximum of $496 \mathrm{~Bq} / \mathrm{L}$, with an average of $290 \mathrm{~Bq} / \mathrm{L}$, which we consider representative of Zone 1 .

In Zone 2 most rain water samples are below the detection limit. At Building 4 ( $200 \mathrm{~m}$ southwest of Building 75), one sample was as high as $24 \mathrm{~Bq} / \mathrm{L}$ and at location ENV-B13D on the hill below Lawrence Hall of Science one sample was $52 \mathrm{~Bq} / \mathrm{L}$. We estimate from the samples reported in the 1995 Site Environmental Report that the average tritium concentration in Zone 2 rainwater is about $20 \mathrm{~Bq} / \mathrm{L}$.

There was one rain water sample location in Zone 3 (ENV13B), and in 1995 it did not have a sample above the detection limit.

See Table F-1 for comparison of rain water sample measurements for 1995 with the risk assessment estimates.

\section{F.3 Comparison of Risk Assessment Estimates to Measured Surface Water Data}

The 1995 Site Environmental Report lists 11 creeks in the LBNL vicinity that were sampled for tritium. Of these, five had no detectable levels of tritium and six had tritium levels above the detection level. These findings are discussed below according to the zone with which the runoff from that creek is associated.

Chicken Creek, which is associated with Zone 1 and drains from the area near Building 75 , had average tritium levels of $44 \mathrm{~Bq} / \mathrm{L}$ and a maximum reported level of $180 \mathrm{~Bq} / \mathrm{L}$. Creeks associated with Zone 2 include Botanical Garden Creek, Claremont Creek, North Fork of Strawberry Creek, No-Name Creek, Ravine Creek, Ten-Inch Creek, and Wildcat Creek. Samplings from these creeks averaged no greater than $15 \mathrm{~Bq} / \mathrm{L}$. Lower Strawberry Creek, which flows into Zone 3, had average tritium levels no greater than $10 \mathrm{~Bq} / \mathrm{L}$ in 1995.

Routine storm-water samples are also analyzed for the presence of tritium. Tritium values range from none detected at the North Fork of Strawberry Creek to $103 \mathrm{~Bq} / \mathrm{L}$ at 69-Storm Drain Manhole, an influent site near the NTLF. Other samples of storm-water runoff in the vicinity of NTLF were in the range of $32 \mathrm{~Bq} / \mathrm{L}$ to $74 \mathrm{~Bq} / \mathrm{L}$. 
See Table F-1 for comparison of surface water sample measurements for 1995 with the risk assessment estimates.

\section{F.4 Comparison of Risk Assessment Estimates to Measured Soil and Sediment Data}

During 1995, soil samples were taken from two onsite sampling locations and one offsite environmental monitoring station and analyzed for tritium. The soil samples correspond to Zone 2 . These samples averaged $3 \mathrm{~Bq} / \mathrm{kg}$. Sediments collected in Chicken Creek, which are assumed to be associated with runoff from Zone 1, had observed tritium levels of $44 \mathrm{~Bq} / \mathrm{kg}$. Sediment levels in the North Fork of Strawberry Creek, which are assumed to be associated with Zone 2, had tritium levels of $2.6 \mathrm{~Bq} / \mathrm{kg}$.

See Table F-1 for comparison of soil and sediment sample measurements for 1995 with the risk assessment estimates.

\section{F.5 Comparison of Risk Assessment Estimates to Measured Ground Water Data}

The 1995 Site Environmental Report indicates a tritium plume in the vicinity of Buildings $75,76,77$, and 78 . The source of the tritium is emissions from the NTLF stack. The maximum reported concentration of tritium detected in monitoring wells in 1995 was $277 \mathrm{~Bq} / \mathrm{L}$. Thus the average concentration of tritium in ground water in Zone 1 is assumed to be $280 \mathrm{~Bq} / \mathrm{L}$. Tritium has not been detected in groundwater samples from monitoring wells near the site boundary. Since most of the monitoring wells in Zone 2 show no detectable level of tritium, the average concentration of tritium in Zone 2 is assumed to be about $10 \mathrm{~Bq} / \mathrm{L}$. (See Table F-1 for the comparison.)

\section{F.6 Comparison of Risk Assessment Estimates to Measured Vegetation Data}

Menchaca [1996a] has made measurements of tritium levels in foliage samples in trees from eight locations within LBNL. In trees from Zone 1 she found tritium levels ranging from 350 to $2900 \mathrm{~Bq} / \mathrm{L}$ (assumed average of $1600 \mathrm{~Bq} / \mathrm{L}$ ). The highest level corresponds to a tree just two meters from the NTLF stack. In Zone 2, Menchaca reported tritium levels at distances of 100 to 300 meters from the stack ranging from 23 to $180 \mathrm{~Bq} / \mathrm{L}$, with an average of $92 \mathrm{~Bq} / \mathrm{L}$. Menchaca [1996b] has also reported on measured tritium activity in excreta, milk, and pasture for goats grazing at LBNL. These tritium activities range from none detected to as high as $55 \mathrm{~Bq} / \mathrm{L}$, with an average on the order of $20 \mathrm{~Bq} / \mathrm{L}$. In the Site Environmental Report [Thorson, 1996] vegetation 
samples from the area surrounding the Building 85 site were reported to have tritium levels in the range of 12 to $670 \mathrm{~Bq} / \mathrm{L}$, with an average of about $200 \mathrm{~Bq} / \mathrm{L}$. We combined these data to estimate the tritium level in Zone 2 to be of the order of $100 \mathrm{~Bq} / \mathrm{L}$. See Table F-1 for comparison of vegetation sample measurements for 1995 and 1996 with the risk assessment estimates.

\section{F.7 Analysis of Urine Data}

LBNL monitors the level of tritium exposure for employees by taking and analyzing urine samples from employees working near the NTLF and at other locations. During the period of March-June 1995 samples of urine were collected weekly from workers in Buildings 75, 75B, 69, 26, 76, and 90. Tap water samples from the East Bay Municipal Utility District (EBMUD) water supply were analyzed concurrently. Figures F-1 and F-2 show the weekly distribution of tritium activity (reported in $\mathrm{Bq} / \mathrm{L}$ ) in Zone 1 and Zone 2 , respectively.

Tritium concentrations in urine samples collected in Zone 1 (Buildings 69, 75 and 75B) during the above period ranged between $189 \mathrm{~Bq} / \mathrm{L}$ and $4.4 \mathrm{~Bq} / \mathrm{L}$ with an average of $48 \mathrm{~Bq} / \mathrm{L}$. The tritium concentrations collected in Zone 2 (Buildings 26, 76, and 90) during the above period ranged between $90 \mathrm{~Bq} / \mathrm{L}$ and $1.5 \mathrm{~Bq} / \mathrm{L}$ with an average of $20 \mathrm{~Bq} / \mathrm{L}$. The estimated values of these concentrations for the risk assessment were $468 \mathrm{~Bq} / \mathrm{L}$ and $28 \mathrm{~Bq} / \mathrm{L}$, respectively, as shown in Table 4-15. 


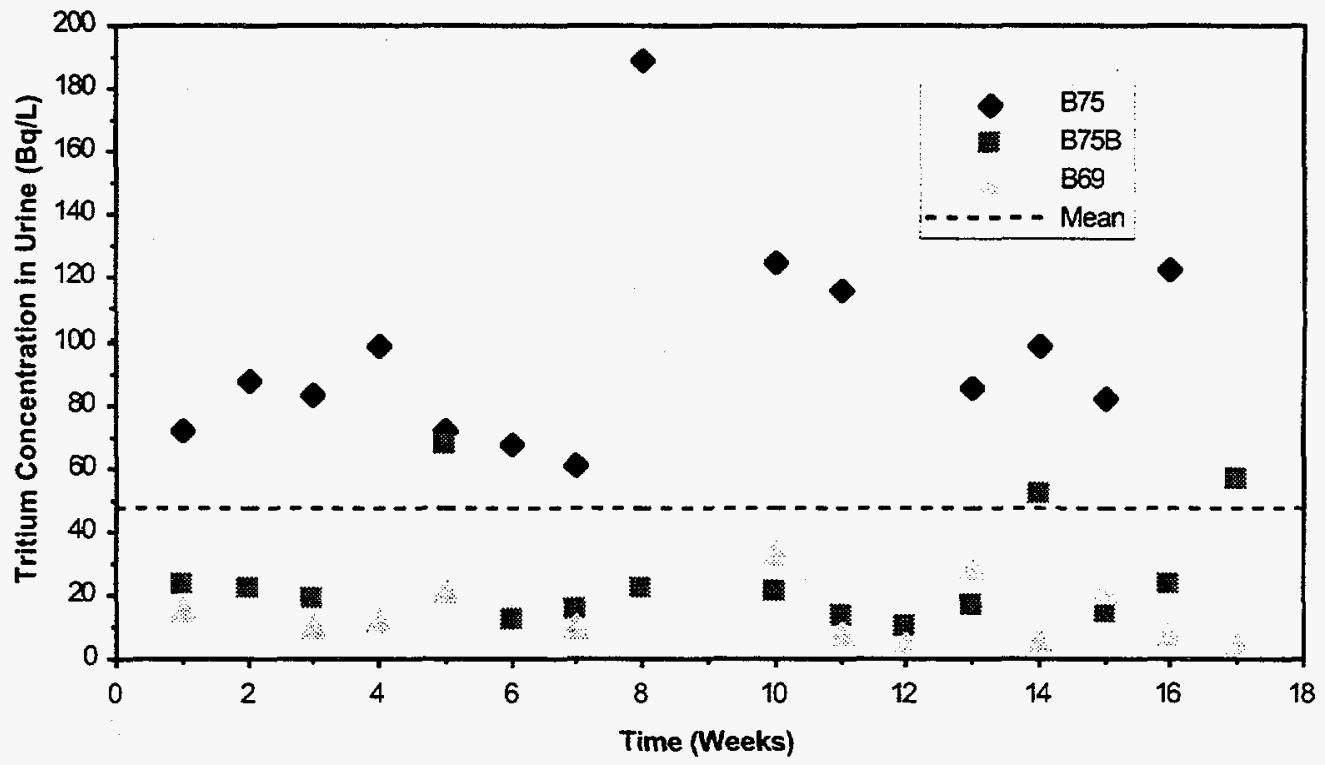

Figure F-1 Distributions of tritium concentration in urine samples in Zone 1

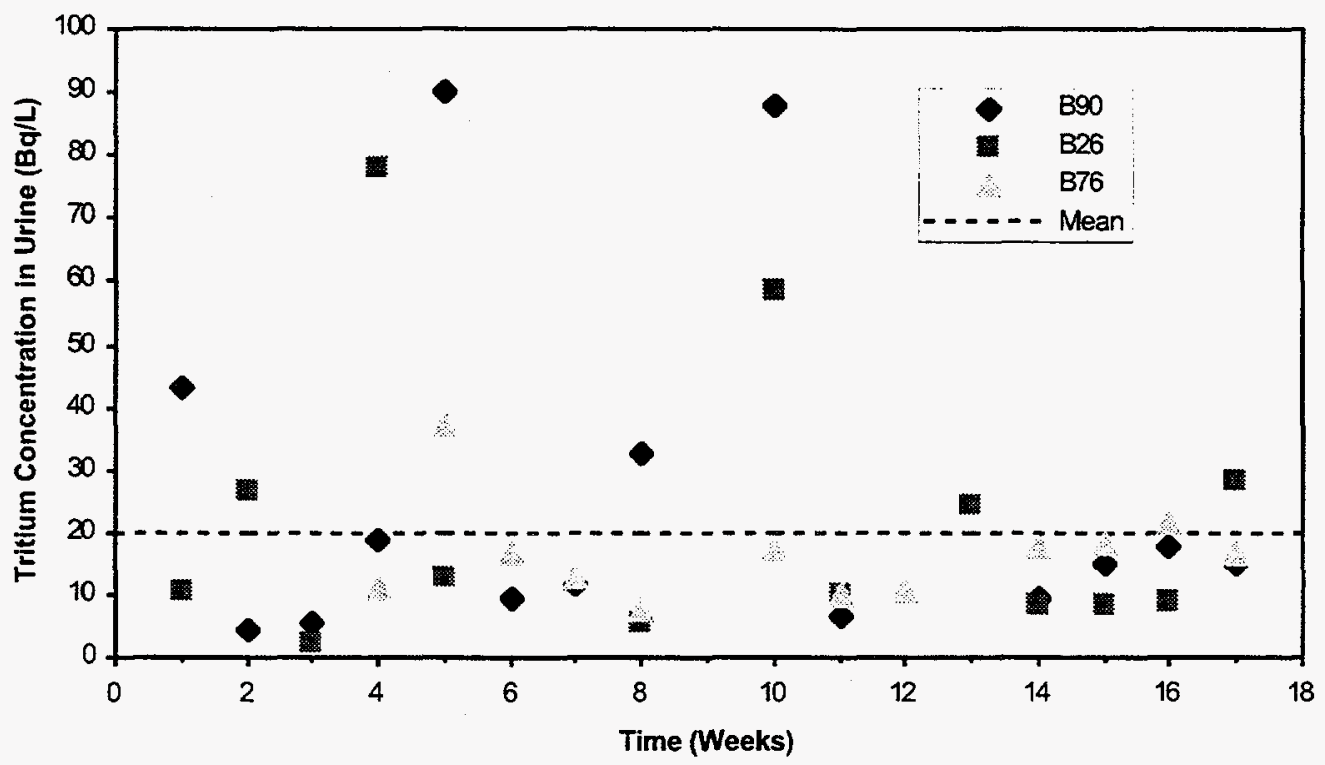

Figure F-2 Distributions of tritium concentration in urine samples in Zone 2 


\section{Appendix G}

\section{Conversion Table for Radiation Units}

\begin{tabular}{|l|c|c|c|}
\hline \multicolumn{1}{|c|}{ Unit Classification } & US Unit & St Unit & Conversion \\
\hline Radioactivity & $\mathrm{Ci}$ & $\mathrm{Bq}$ & $1 \mathrm{Ci}=3.7 \times 10^{10} \mathrm{~Bq}$ \\
\hline Radiation Dose & $\mathrm{rad}$ & $\mathrm{Gy}$ & $1 \mathrm{rad}=0.01 \mathrm{~Gy}$ \\
\hline Dose Equivalent & $\mathrm{rem}$ & $\mathrm{Sv}$ & $1 \mathrm{rem}=0.01 \mathrm{~Sv}$ \\
\hline \hline
\end{tabular}

*: Equivalent Dose = Radiation Dose $\times$ RBE

where RBE is the Relative Biological Effectiveness of the radiation 

Appendix $\mathrm{H}$

Review Comments 
Mr. Iraj Javandel

Lawrence Berkeley National Laboratory

University of California

Environmental Restoration Program

Mail Stop 90-2148

Berkeley, CA 94720

Dear Mr. Javandel:

The Radiologic Health Branch (RHB) appreciates the opportunity to review the draft Environmental Health-Risk Assessment for Tritium Released at the National Tritium Labeling Facility (NTLF) at Lawrence Berkeley National Laboratory (LBNL), October 1995. The approach used in the draft report appears to be appropriate and adequate for the purpose. However, RHB has the following comments:

1. The dose and risk estimates indicated in Tables 1-2, 4-12, 4-13 and 4-14 are confusing. These estimates are not demonstrated by step-by-step calculations in the report. Risk values in Table 4-12 do not match those stated in Table 1-2. Reference also should be made as footnotes of the table to indicate what risk model was used, e.g., UNSCEAR, 1993, NCRP Report \# 116 or any other international report. In addition, the report only mentions the cancer mortality risk; perhaps, the cancer incidence risk needs to be included. A possible typographical error, Table 1-3, is found in the footnote of page 3-1;

2. Comparisons of annual exposures and associated risks to consensus standards is not consistent throughout the report. Since LBNL operates under contract with U.S. Department of Energy (DOE), either DOE regulations or NCRP report should be used for such comparisons;

3. Section 1.8 describes the three zones where the assessment are performed. Atmospheric pathway is considered for zones $1 \& 2$; but, zone 3 , west of Building 75 , only considers the pathway via the runoff. Since the predominant wind is in the easterly direction, airborne tritium monitoring to the east of the Building 75 would provide useful data for pathway analysis and dose assessment; 
Mr. Iraj Javandel

Page 2

April 1, 1996

4. Section 1.15 states that exposure to tritiated rain water washed down from Strawberry Creek is considered for the risk assessment of zone 3. But, in the 1991 Annual Site Environmental Report for LBNL, it indicates that the tritium concentration in ground water and surface water runoff is used in such risk assessment in addition to the rain water. It is unclear whether these source terms are addressed in the report being reviewed;

5. Since the Agreement-In-Principle with DOE is terminated, the reference regarding Department of Health Services (DHS) oversight made in the Section 1.16 should be clarified. DHS maintains the regulatory functions in the areas that are not under exclusive federal jurisdiction. In other words, any impacts in the offsite areas caused by LBNL are under DHS' jurisdiction. Title 17, California Code of Regulations, contains the regulations governing release limits for radioactive material into unrestricted areas;

6. Many equations are listed in Appendix $\mathrm{D}$, but no conclusion is made in the evaluation of the potential legacy of past elevated HTO emissions as stated in Section 1-16;

7. It may be necessary to address the dose/risk assessment to the impacted personnel in the accidental release scenario mentioned in Section 4.7.1.1; and

8. No correlation between the results described in Appendix F and the risk values indicated in Tables 1-2, 4-12, 4-13 and 4-14 was made. It is unclear whether the result stated in Appendix $F$ is for zone 1 , zone 2 or zone 3.

Generally, it is felt that the report should focus on the method, the computer model and the associated site specific parameters used in the dose and risk assessment as a result of the tritium release at LBNL. Necessary references should be made clearly and consistently. The health effects including non-fatal cancer risk should also be addressed. 
Mr. Iraj Javandel

Page 3

April 1, 1996

If you have any questions concerning this matter, please feel free to call me at (916) 322-3482 or Mr. Stephen Hsu of this office, at (916) 322-4797.

Sincerely,

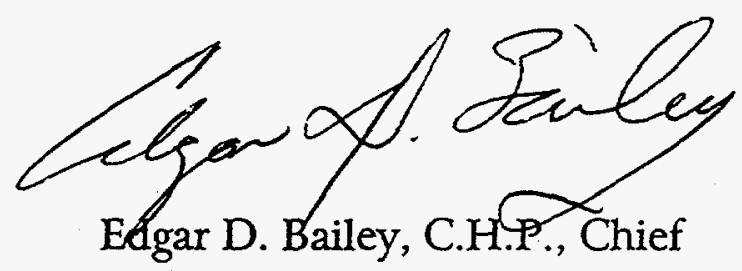

Radiologic Health Branch 
Ms. Susan Fields

Environmental Restoration Division

Oakland Operations Office

U.S. Department of Energy

1301 Clay Street

Oakland, California 94612-5208

Dear Ms. Fields:

The Agency for Toxic Substances and Disease Registry (ATSDR) received your request to review and comment on the "Environmental Health-Risk Assessment for Tritium Released at the National Tritium Labeling Facility at Lawrence Berkeley National Laboratory."

ATSDR re-calculated several of the dose scenarios as discussed in the document using different assumptions, conversion factors, and risk coefficients. As a result, ATSDR agrees with the overall findings of the risk assessment for the released tritium.

ATSDR is enclosing comments regarding several sections that we found to be confusing or, in our opinion, contradictory with other information in the risk assessment. We have also included suggestions to clarify issues or to use to reevaluate other potential release categories.

If you have any additional questions or wish to discuss these comments, please feel free to contact me at your convenience at 404-639-6068.

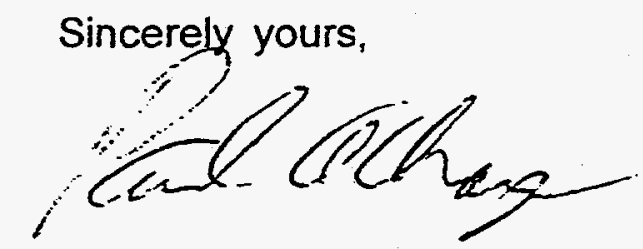

Paul A. Charp, Ph.D.

Senior Health Physicist

Federal Facilities Assessment Branch

Division of Health Assessment

and Consultation 
Page $1-8$, third paragraph:

In discussing "high levels of radiation from HTO" it would be prudent to quantitate the high levels. High levels mean one thing to radiation professionals but quite a different thing to members of the public. Disease states resulting from HTO exposure may be expressed in the range of 10-20 millisieverts (mSv) which is much higher that your estimated doses resulting from site releases.

Fourth paragraph:

I question that there is no experimental evidence in animals for HTO genetic effects (See Health Physics Journal, December 1993 which is referenced in the assessment). If you mean genetic effects transferred to the next generation this most likely is true for humans but there is a great amount of evidence to show transfer of damage to off-spring and HTO damage to DNA. See your Sections 2.2.2 and 4.6.1 for discrepancies in statements with this paragraph.

Section 1.10

Clarify workplace exposure to indicate internal and external doses. The NRC regulations codified at 10 CFR 1201 discuss total effective dose equivalent. The ICRP 60 value of 20 millisievert is for internal dose only and is the limiting factor for the Annual Limit on Intake (ALI). For workers, the ICRP recommend $1 \mathrm{mSv}$ effective dose equivalent.

Table 1-1

Suggest authors review the United Nations UNSCEAR 1993 report for genetic effects and developmental effects which can be passed to successive generations.

Page 4-5, middle of third paragraph:

"..result in an annual dose of $0.05 \mu$ Gy per year (or $0.125 \mu$ Sv per year)." This suggests a weighing factor of 2.5 which, for tritium, is not too far from the high end as some tritium research suggests. If you are employing a weighing factor, additional information to explain this to the public will be necessary. I would also suggest that you use similar notation. For example you use microsieverts throughout the paragraph but when you mention the UNSCEAR background radiation dose, you have $0.0024 \mathrm{SV}$. I would suggest using $2.400 \mu \mathrm{Sv}$ to indicate the magnitude of difference z- Etween norma! background and dose arising from tritium. 
Page 4-11, Section 4.5

Consider adding the additional pathway of a pica child (dirt eating) and consuming perhaps as much as $500 \mathrm{mg}$ of tritium-containing soil per day.

Section 4.5 .1

For the discussion of dermal route, I would have expected the expression to be related to the permeability of the system, surface area or surface volume of the individual since it is these factors most important for the dermal route more than the mass of the body. In later sections, the concept of body surface is discussed (Section 4.5.2.4 for air uptake and in Section 4.5.2.4 for

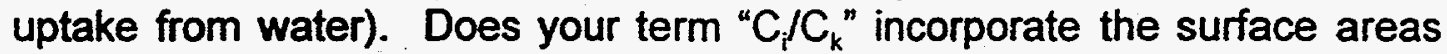
available for absorption? Where do equations 4-8 and 4-9 enter into your equation 4-7?

Page 4-19, second paragraph

It is true that federal regulations in 10 CFR 20 limit worker exposure to 50 $\mathrm{mSv}$ from both internal and external sources but it also limits public exposure to $1 \mathrm{mSv}$ (10 CFR 20.1301). The draft DOE 10 CFR 834 also lists this value to protect the public. Consider updating the discussion to address this variance in regulations.

Last paragraph

Consider adding statement that CFR regulations for tritium in drinking water are based on ICRP 30 values but with the newer ICRP 61 values, the tritium limit increases to approximately $2,250 \mathrm{~Bq}(60,900 \mathrm{pCi} / \mathrm{L})$.

Page 4-20, Section 4.6 .4

You state that the "detrimental effects of body burdens of tritiated water are stochastic." Yet earlier in the document you state that there are no studies of adverse health effects from tritium exposure. This is especially true as the linear no threshold statements were apparently developed as regulatory statements, not scientific fact. It is true that radioactive decay and absorption of the decay energy does result in cellular alterations but these alterations may or may not be deleterious; hence a potential for nonstochastic effects. Straume's papers, in my opinion, do not specifically discuss stochastic events but his Monte Carlo simulations suggest linear effects once a small threshold is reached. 
The studies showing deleterious effects from tritium uptake were in the kilobecquerel per milliiter range which may not be applicable to the concentrations around LBL tritium facility. You may want to consider this in your discussion of the doses expected at the LBL site.

\section{Section 4.7.1.1}

Is the source term release fairly uniform over the period of one year or are there periods of release that account for the majority of the tritium release? The frequency of release could alter equations used to determine inhalation rates as well as other intake/absorption rates as calculated in Section 4.7.2 and associated sections.

\section{Section 4.7.2.1}

Is it appropriate to use the resting inhalation rates for average inhalation rates? Perhaps if municipal workers or other targets such as students are sedentary this would be a likely option; however, students in the area, maintenance workers and other occupations should be evaluated using the appropriate breathing rate parameters. 


\section{UNITED STATES ENVIRONMENTAL PROTECTION AGENCY}

REGION IX

75 Hawthorne Street

San Francisco, CA 94105-3901

November 19, 1996

Ms. Susan Fields

U.S. Department of Energy

OOakland Operation Office

1301 Clay Street

Oakland, CA 94612

Dear Ms. Fields:

Subject:

LBNL Report on Environmental Health-Risk Assessment for Tritium Released at the NTLF.

I have reviewed the LBNL draft report "Environmental Health-Risk Assessment for Tritium Released at the National Tritium Labeling Facility at Lawrence Berkeley ational boratory", LBL-37760, by McKone and Brand dated October, 1995 and have several major concerns:

Since they are trying to convince the community that the risk from tritium is small, they should use cancer incidence and not fatal cancers. They should use the reasonable maximally exposed individual instead of using an average individual. They should use concentric circles around the source instead of a special partial circle around the campus since, for example, they have omitted the community north of the laboratory which would receive higher doses than that received on campus. They use measurements of tritium in urine to calculate the maximum annual exposure of employees in zone 1 intead of using their model numbers which they state (but don't show) are five times higher. This is not being conservative. They don't say how many urine samples were taken or the standard deviation of the measurements. They also don't state how they calculated the annual exposure from the urine measurements. I suspect they would get a more accurate exposure by using air dose measurements which they can get from their monitoring. Otherwise, they had to assume the tritium uptake from air, water, soil, etc., and this should not be as accurate as using air measurements. 
Some minor concerns are:

1) Why are they using world radiation background number $(2.4 \mathrm{mSv})$ instead of the background in Berkeley? They should give the mrem number as well as the Sv number as most people are not familiar with Sv. Also, Table 4-1 should give the conversion factor.

2) They are confused on population dose and don't say what significance it has. They should discuss the collective dose concept instead of just multiplying the individual dose by 70 years and the population (Table 1-1).

3). They assume swimming in Strawberry Creek one hour for fifteen days per year. This may be ok for an average but not for the maximally exposed individual.

4) In Table 1-2, how did they calculate the individual risk from the population risk? I can't figure it out and what is the significance of individual risk? It is not for the maximally exposed individual.

5) Is the model they describe and use in their risk assessment in Chapter 4, one that they developed at LBNL or are they using a standard program that they do not reference?

6) In Section 4.7.1, they mention using the average tritium concentrations in each exposure zone. They should be using the highest reasonable concentration.

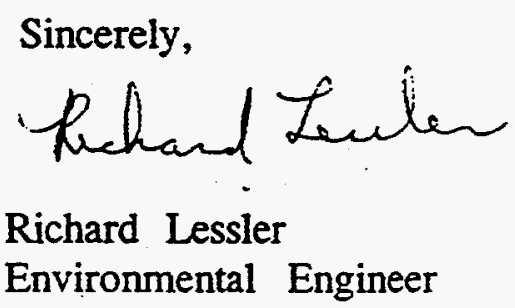




\section{Appendix I}

\section{Questions and Answers About Tritium}




\section{Questions \& Answers about Tritium}

\section{What is tritium?}

Tritium is a radioactive form of hydrogen. Since tritium is just like hydrogen chemically, it is usually found attached to molecules in place of hydrogen. For example, a water molecuie may exchange one of its hydrogen atoms for a tritium atom, resulting in "tritiated water" sometimes referred to as "HTO."

Tritium is produced both by natural processes (the interaction of cosmic rays with the atmosphere) and by man-made processes (in nuclear reactions). A great deal of tritium was released to the general environment in the 1950 s and early 1960 s by aboveground nuclear weapons testing. Relatively small amounts of tritium are released from nuclear reactors and related facilities in various locations around the world. Tritium is also used in a wide variety of consumer products such as illuminated watches, thermostat dials, and airplane exit lights. Both the natural and man-made sources have contributed (and continue to contribute) to a worldwide "background" level of tritium.

\section{Why is tritium used at Lawrence Berkeley Laboratory?}

Only one facility at Lawrence Berkeley Laboratory (LBL) uses tritium in large quantities: the National Tritium Labeling Facility (NTLF - Building 75 on Map 1). Established as a National Institutes of Health (NIH) national resource center in 1982, the facility's role is to conduct research and to supply educational and tritium labeling support for biomedical researchers in North America. NIH funds the NTLF's operations. LBL's Environmental Health and Safety Division closely monitors all of the NTLF's activities for compliance with environmental health and safety regulations.

The NTLF provides benefits to public health by helping biomedical researchers test new products that car be useful in curing disease. Facility staff and visiting researchers "label" pharmaceuticals and other materials with tritium by adding a tritium atom in place of a hydrogen atom in materials used in experiments. For example, a potential cancer drug might be labeled so that researchers can track the deposition of the tritium-labeled drug in the body and evaluate its effectiveness in treating a particular type of cancer. It is unique in the United States as a facility that provides the technology to do labeling and analysis at the same place.

Collaborative research projects initiated over the past three years have shown new ways for studying cell metabolism and biomolecular structure and function. The seven staff members of the facility actively publish . articles and reports and present their work at a wide range of meetings. In addition, more than 100 users have visited the NTLF since 1982 to label upwards of 250 compounds. These visitors have represented university and industrial concerns from throughout the U.S. Service to outside users represents about $25 \%$ of the total effort of the staff.

\section{What are tritium's radiological characteristics?}

The very low energy radiation emitted by tritium is too weak to present a radiation hazard outside of the human body. The radiation from tritium can only travel about 5 millimeters in air, and can be stopped completely by a sheet of paper or by ordinary clothing.

Tritium can deliver a radiation dose if it is taken inside the body. Such an intake could occur by eating or drinking tritium-contaminated foods or water, or by breathing tritium in the air.

Any tritium taken into the body is rapidly distributed throughout the body as tritiated water, HTO. Since these HTO molecules behave just like normal water molecules, they are subject to the normal rate of removal of water from the body. Thus, the amount of tritium in the body is reduced by a factor of 2 about every ten days. 


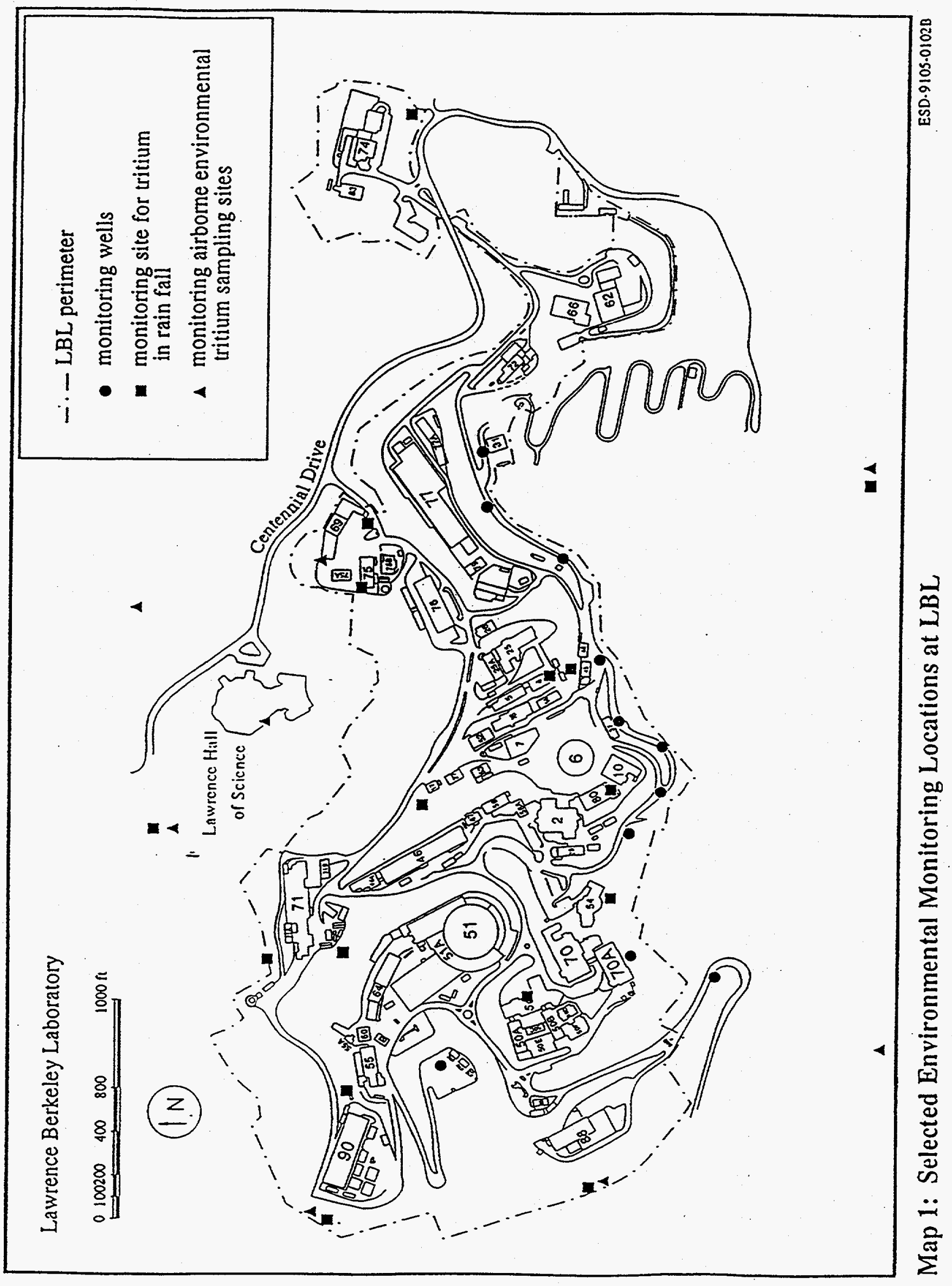


Are there health risks from exposure to tritium?

The fact that tritium emits very low-energy radiation, is diluted throughout the body, and is eliminated fairly quickly from the body makes tritium one of the least hazardous of radioactive materials. Again, tritium could pose a potential health risk only if it were taken inside the body. Exposure to radiation has the potential to cause cancer. The risk of cancer from exposure to tritium is related to the magnitude of the dose and the time period in which that cose is received.

Radiation doses are measured in units of "millirem." Very high doses of radiation (hundreds of thousands or millions of millirem) can deposit enough energy in the organs of the body to cause immediate illness and, in some cases, death. More moderate doses of radiation do not cause immediate health effects, but can increase the risk of cancer.

Low doses of radiation (up to thousands or a few tens of thousands of millirem) do not cause any observable increases in cancer incidence or mortality. However, for the purposes of setting public health regulations, it is assumed that low doses of radiation may result in an increased risk of cancer. The presumed risk is assumed to be proportional to the dose; that is, the lower the dose, the lower the risk.

\section{How much radiation are workers and the community exposed to from the NTLF?}

The presence of tritium in the environment is due to tritium gas and tritiated water (HTO) emitted from the ventilation stack at Building 75. The level of these emissions is monitored both on-site and off-site by LBL environmental staff as part of LBL's overall environmental monitoring program (see Maps 1 and 2). LBL takes samples of stack emissions, air, local rainfall, ground water, streams, and sewers to check for tritium.

The radiological impacts of the National Tritium Labeling Facility on people and the environment in and around LBL are minimal because exposure levels are very low. LBL monitors the level of exposure to employees by doing weekly testing of urine samples from those employees working at or near the NILF. The allowable workplace exposure to tritium radiation for a one-year period is 5,000 millirem under federal Occupational Safety and Health regulations. For comparison's sake, you might receive a radiation dose of approximately 295 millirem from natural sources during the course of a year. The exposure for NTLF employees is measured at approximately 60 millirem per year. For some LBL workers at places other than the NTLF, exposures are less than 2 millirem per year. The largest possible exposure to offsite individuals was measured at 0.07 millirem for all of 1991. (See LBL's 1991 Environmental Report, LBL-27170, 1992.)

\section{Where has tritium contamination been found?}

Tritium has been detected in soil, rainwater, and groundwater in the immediate area of Building 75. The levels detected in the water at some locations are slightly above the EPA-established drinking water standard. However, none of this water is used for drinking, or would flow into any sources of drinking water for Berkeley. The tritium levels are very low in other drainage channels on-site.

The creeks flowing out of the LBL area also are monitored for tritium (see Map 2). Tritium has been detected in Strawberry and Blackberry Creeks, but at levels that are less than one-tenth of the U.S. Environmental Protection Agency's (EPA) drinking water standard.

\section{What can be done to cleanup the contamination?}

Right now, there is no easy way to treat the low levels of tritium found in water or soil at LBL. Options for addressing tritium contamination will be explored after LBL has completed its investigations to determine exactly how much tritium contamination is present and where it is located. Depending on the final results of investigations, one option might be to keep monitoring water and soil and to let the tritium decay naturally into its non-radioactive components. Tritium decays relatively quickly into helium. It has a half-life of 123 years, meaning that half of the tritium will have decayed into non-radioactive helium in that amount of time. LBL will explore all available options and will ask for public comments before a final decision is made on how the tritium contamination will be handled. In the meantime, the best way to address the tritium contamination is to continue improving operations to minimize tritium emissions in the future and contain the tritium contamination currently on site. 


\section{What is LBL doing to minimize tritium emissions?}

Since the source of contamination is the tritium emissions from the NTLF stack, an emissions reduction plan was implemented by NTLF in April 1990. The goal was to reduce tritium discharges by at least $75 \%$ and tritium waste shipments by an equivalent or greater percentage. As of 1992, HTO releases from the NTLF stack had been decreased by an estimated $84 \%$ from the 1989 levels. Airborne HTO levels and tritium in rainfall measured at sites within 100 meters of Building 75 have decreased by at least a factor of ten over the period from January 1989 to December 1992.

Emissions and exposures have been reduced as a result of improvements in the efficiency of techniques at the NTLF, changes in the form in which tritium waste is stored; improved disposal methods, redesign of equipment to contain the tritium, and improved monitoring. In addition, the majority of the tritium supplies which were previously disposed of as radioactive waste at the DOE's Hanford facility in Washington State are now being purified and recycled for reuse. This recyciing and source reduction concept formed the basis for California Assembly Bill.3798.
What governmental agencies are overseeing the cleanup?

The lead agency for the environmental restoration at LBL is the California Environmental Protection Agency's Department of Toxic Substances Control (DTSC). Many other regulatory agencies are involved in oversight activities, including U.S. EPA, Regional Water Quality Control Board, East Bay MUD, and the City of Berkeley. Emissions from the NTLF stack are monitored continuously and the results are included in LBL's Annual Environmental Report, which is distributed to agencies and is available in the Berkeley Public Library.

\section{How can I get more information?}

For more information or to make comments, please contact Shaun Fennessey, LBL's Community Relations Coordinator, at (510) 486-5122. Writtencorrespondence may be sent to: LBL Community Relations Office/ER, LBL, Building 50A, Room 4112, Berkeley, CA 94720.

If you would like more technical information on environmental investigations at $L B L$, you can refer to LBL's Annual Environmental Report (LBL-27170, 1992). Copies can be found at the Berkeley Public Library Reference Desk.

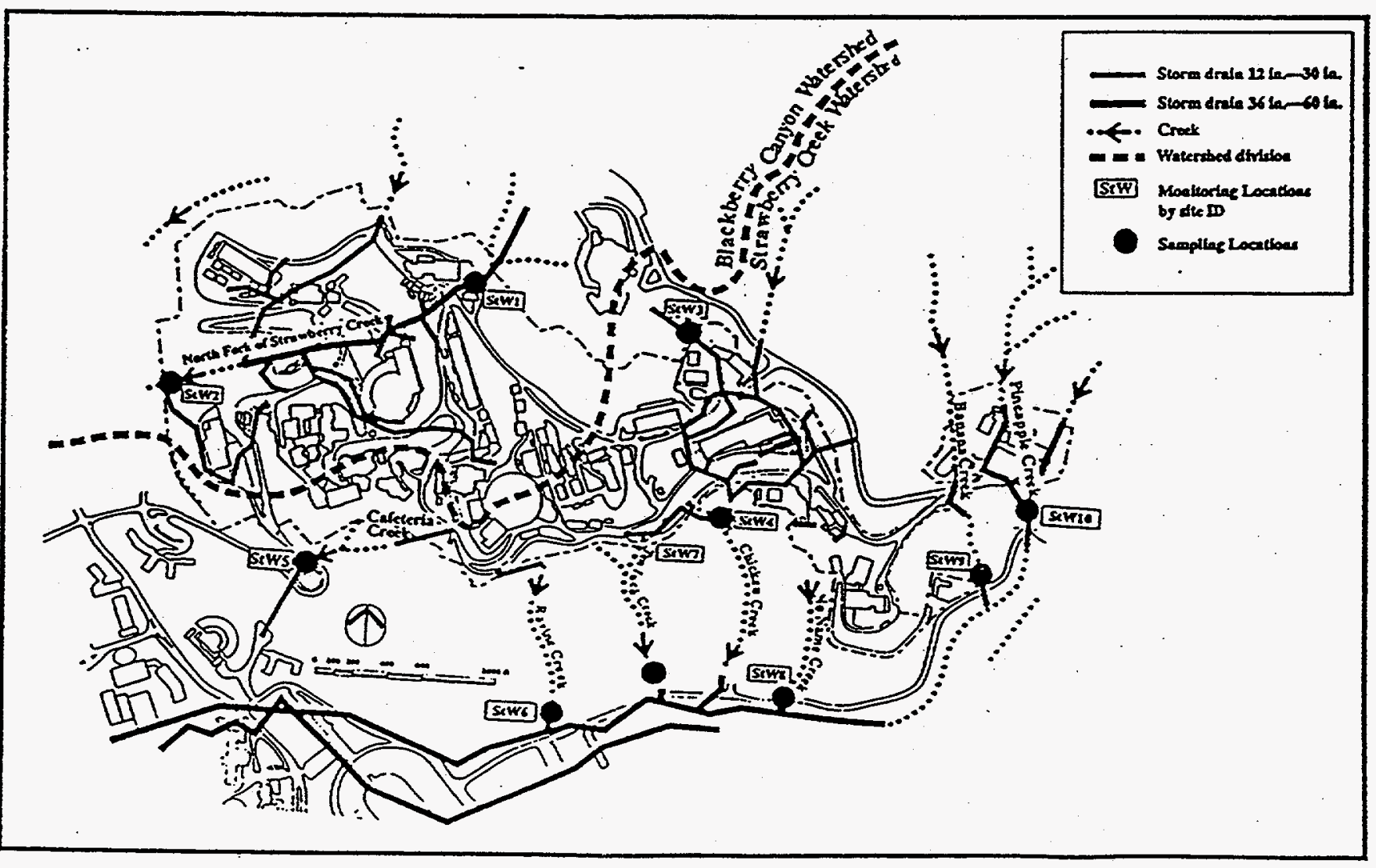

Map 2: Site Storm Drainage and Monitoring Locations 
Appendix J

Reviewers' Letters 
Lawrence Berkeley National Laboratory

University of California

Environmental Restoration Program

Attn: Iraj Javandel, Ph.D.

Mail Stop 90-2148

Berkeley, CA 94720

Dear Dr. Javandel:

The Radiologic Health Branch (RHB) has reviewed the Draft Environmental Health-Risk Assessment for Tritium Released at the National Tritium Labeling Facility (NTLF) at Lawrence Berkeley National Laboratory (IBNL), December 1996. Based on the information presented in the Draft Report, it appears that the report adequately addresses the risk assessment of the tritiated water vapor (HTO) released from NTLF.

If you have any question concerning this matter, please feel free to call me at (916) 323-2759 or Mr. Stephen Hsu of this office at (916) $322-4797$.

sincerely,

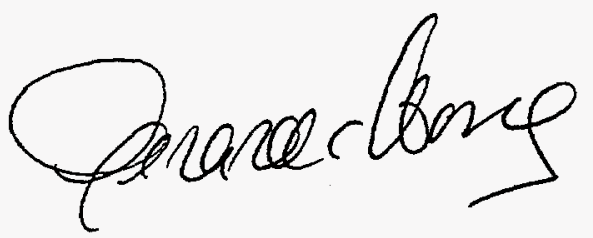

Gerard Wong, Ph.D., Chief

Radioactive Material Iicensing Section Radiologic Health Branch 
Iraj Javandel, Ph.D.

Lawrence Berkeley National Laboratory

Environmental Restoration Program

Mail Stop 90-1116

Berkeley, California 94720

Dear Dr. Javandet:

The Agency for Toxic Substances and Disease Registry (ATSDR) has completed its review of the Environmental health-risk assessment for tritium released at the National Tritium Labeling Facility at Lawrence Berkeley National Laboratory. ATSDR is satisfied that all its concerns raised in our letter of May 14, 1996, have been addressed.

If I can be of further assistance, please contact me at (404)639-6004.

Sincerely yours,

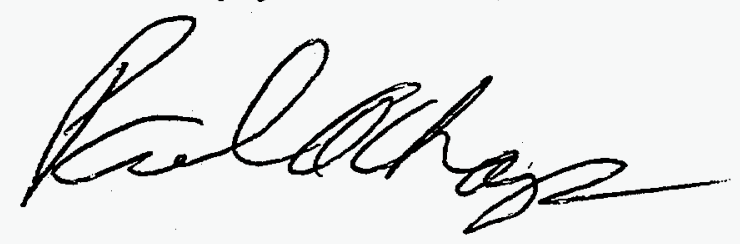

Paul A. Charp, Ph.D.

Senior Health Physicist

Federal Facilities Assessment Branch

Division of Health Assessment and Consultation 


\section{UNITED STATES ENVIRONMENTAL PROTECTION AGENCY \\ REGIONIX \\ 75 Hawthorne Street \\ San Francisco, CA 94105-3901}

April 14, 1997

Iraj Javandel

Lawrence Berkeley Laboratory

University of California

Environmental Restoration Program

Mail Stop 90-116

Berkeley, CA 94720

Subject: $\quad$ LBNL Report on Environmental Health-Risk Assessment for Tritium Released at the NTLF.

Dear Mr. Javandel:

I have reviewed your March 6, 1997 letter that responded to my February 24, 1997 letter to you on the LBNL revised draft report "Environmental Health-Risk Assessment for Tritium Released at the National Tritium Labeling Facility at Lawrence Berkeley National Laboratory", LBL-37760, by McKone and Brand dated December, 1996. I am pleased to see that you have responded to the suggestions that I made in my review. As previously indicated, my review was mainly a general review to see that you met the EPA NESHAP standards, which you have, and I did not review the calculations or models. If I can be of any further assistance to you, please let me know.

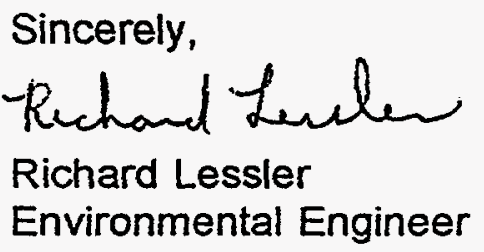




\section{Glossary of Technical Terms}

absorbed dose

activity

alpha particle

alpha radiation

becquerel

beta particle

curie

dermal uptake

developmental and reproductive effects
Energy imparted to a body by radiation, measured per unit mass $(\mathrm{kg})$ of tissue.

The number of transformations that take place each second in a given amount of radioactive material.

A positively charged particle, indistinguishable from a helium atom nucleus and consisting of two protons and two neutrons.

Same as alpha particle.

The special name for the unit that expresses a measure of activity. One becquerel corresponds to one disintegration per second of any radionuclide.

A high-speed electron or positron, emitted in radioactive decay.

A unit of radioactivity, equal to the amount of a radioactive isotope that decays at the rate of $3.7 \times 10^{10}$ disintegrations per second.

The transfer of a contaminant from air, water, or soil into or through the outer skin layer; considered an exposure route in an exposure assessment.

Effects caused by some physical, chemical, or biological agent, such as radiation, to the formation and development of a fetus, that results in one or more observed defects, which are not passed on to succeeding generations. 
displacement

dissociation

dose

dose assessment

dose equivalent

excitation

exposure

exposure assessment

gamma radiation

gray

half life

heritable genetic effects
A chemical reaction in which one kind of atom or molecule is removed from combination and replaced by another.

A chemical process by means of which a change in physical condition causes a molecule to split into simple groups of atoms, single atoms, or ions.

The quantity of energy or chemical agent delivered to a specific living tissue following exposure.

The process by which uptake and dose of a toxic substance are identified and quantified.

An absorbed dose that is adjusted or weighted to account for the potential of different radiations with the same damage.

The addition of energy to a system, transferring it from a ground state to an excited state.

The condition of having contact with a physical or chemical agent of harm.

The process by which contact with a toxic substance is identified and quantified.

Electromagnetic radiation emitted by radioactive decay and having energies in a range from ten thousand $\left(10^{4}\right)$ to ten million (107) electron volts.

The special name for the unit that expresses a measure of absorbed dose. One gray corresponds to an energy deposition of one joule per $\mathrm{kg}$ of living tissue.

1. For a quantity of radiation-the time required for half of the nuclei in a sample of a specific isotopic species to undergo radioactive decay.

2. For ingested quantities - the time required for the radioactivity of material taken in by a living organism to be reduced to half its initial value by a combination of biological elimination processes and radioactive decay. Known as the biological half-life.

Genetic damage caused by an external agent such as radiation, which manifests itself in the gene carrier and is capable of being passed on to succeeding generations. 
ingestion

inhalation

ionizing radiation

isotope

model

monitor

neutron

nuclide

probability

proton

radiation

radioactivity

relative biological effectiveness (RBE)
To take into the body by the mouth for digestion or absorption; considered an exposure route in an exposure assessment.

To draw air into the lungs by breathing; considered an exposure route in an exposure assessment.

Radiation that converts the target totally or partially into ions on impact.

One of two or more atoms having the same atomic number but different numbers of neutrons in their nuclei.

A schematic description of a system, theory, or phenomenon that accounts for its known or inferred properties and may be used for further study of its characteristics

To test or sample on a regular or ongoing basis the air or an object's surface for radiation level.

An electrically neutral subatomic particle, which is stable when bound in an atomic nucleus. Neutrons and protons form nearly the entire mass of atomic nuclei.

A type of atom specified by its atomic number, atomic mass, and energy state, such as carbon 14 .

A number expressing the likelihood that a specific event will occur, expressed as the ratio of the number of actual occurrences to the number of possible occurrences.

A stable, positively charged subatomic particle. Neutrons and protons form nearly the entire mass of atomic nuclei.

Energy emitted in the form of rays, waves, or particles by the atoms and molecules of a radioactive substance as a result of nuclear decay.

Spontaneous emission of radiation, either directly from unstable atomic nuclei or as a consequence of a nuclear reaction. This radiation includes alpha particles, nucleons, electrons, and gamma rays, emitted by a radioactive substance.

An adjustment factor used to adjust an absorbed dose to account for its relative potential to do damage in biological tissue. 
risk

risk assessment

sampling

sievert (Sv)

transport

transformation
The estimated probability of injury, loss, or detriment. A measure of the deleterious effects that may be expected as the result of an action or inaction.

The process by which the risks associated with an action or inaction are identified and quantified.

The act, process, or technique of selecting an appropriate environmental sample.

A unit for expressing the equivalent magnitude of an absorbed dose which has been adjusted by a factor that expresses the relative tissue damage potential of absorbed doses of radiation; equivalent to one joule of $x$-ray energy deposited per $\mathrm{kg}$ of target.

To move or be conveyed from one place to another. In the context of environmental contamination, a contaminant is transported from one location to another by advection (e.g., wind) or diffusion (e.g., dilution in air) processes.

Alteration of a chemical substance from one chemical form to another through a chemical or physical reaction.

Radioactive decay is a nuclear transformation whereby an atom changes from one nuclide to another. 


\section{References}

Anspaugh, L.R., J.J. Koranda, W.L. Robison, and J.R. Martin 1973, “The Dose to Man Via Food-chain Transfer Resulting from Exposure to Tritiated Water Vapor," in Tritium, ed. A.A. Moghissi and M.W. Carter, Messenger Graphics, Las Vegas Nevada, p 405-422.

Benarie, M.M. 1980, Urban Air Pollution Modeling, (MIT Press, Cambridge, MA).

Bevington, P.R. 1969, Data Reduction and Error Analysis for the Physical Sciences, McGrawHill, New York, pp 56-65.

Butte, N.F., C. Garza, J.E. Stuff, E.O. Smith, and B.L. Nichols 1984, "Effect of Maternal Diet and Body Composition on Lactational Performance," American Journal of Clinical Nutrition 39, 296-306.

Diamond, M.L., D. Mackay, and P.M. Welboum 1992, "Models of Multi-Media Partitioning of Multi-Species Chemicals: The Fugacity/Aquivalence Approach," Chemosphere 25, 1907-1921.

Diabate, S. and S. Strack 1993, "Organically Bound Tritium," Health Phys. 65, 698-712.

Ershow, A.G. and F.P. Cantor 1989, Total Water Intake and Tapwater Intake in the United States: Population-Based Estimates of Quantiles and Sources, a report prepare under National Cancer Institute Order \#263-MD-810264 with the Life Sciences Research Office, Federation of American Societies for Experimental Biology, Bethesda, MD.

Etnier, E.L., C.C. Travis, and D.M. Hetrick 1984, "Metabolism of Organically Bound Tritium in Man," Radiat. Res. 100, 487-502. 
Hill, R.L. and J.R. Johnson 1993, "Metabolism and Dosimetry of Tritium," Health Phys. 65, 628-647.

International Commission on Radiological Protection (ICRP) 1975, Report of the Task Group on Reference Man, ICRP Publication No. 23 (Pergamon Press, New York, NY).

International Commission on Radiological Protection (ICRP) 1977, Recommendations of the International Commission on Radiological Protection, ICRP Publication No. 26 (Pergamon Press, New York, NY).

International Commission on Radiological Protection (ICRP) 1978, Limits for Intakes of Radionuclides by Workers, ICRP Publication No. 30, Part 1 (Pergamon Press, Oxford).

International Commission on Radiological Protection (ICRP) 1991, 1990 Recommendations of the International Commission on Radiological Protection. 1st ed., Series title: ICRP publication 60 (Pergamon Press, Oxford, New York.)

International Commission on Radiological Protection (ICRP) 1991, Annual Limits on Intake of Radionuclides by Workers Based on the 1990 Recommendations, ICRP Publication No. 61 (Pergamon Press, Oxford).

Jury, W., W. Spencer, and W. Farmer 1983, “Behavior Assessment Model for Trace Organics in Soil: I. Model Description," J. Environ. Qual. 12, 558-564.

Koranda J.J., and J.R. Martin 1973, "The Movement of Tritium in Ecological Systems," in Tritium, A.A. Moghissi and M.W. Carter, Eds. (Messenger Graphics, Las Vegas, NV, p 430).

Layton, D.W. 1992, "Metabolically Consistent Breathing Rates for Use in Dose Assessments," submitted to the journal Health Physics, Lawrence Livermore National Laboratory preprint UCRL-JC-109779.

Mackay, D. and M. Diamond 1989, "Application of the QWASI (Quantitative Water Air Sediment Interaction) Model to the Dynamics of Inorganic Chemicals in Lakes," Chemosphere 18, 1343-1365.

McKone, T.E. 1993, CalTOX, A Multimedia Total-Exposure Model for Hazardous-Wastes Sites Part II: The Dynamic Multimedia Transport and Transformation Model, prepared for the State of California, Department Toxic Substances Control, Lawrence Livermore National Laboratory, Livermore, CA, UCRL-CR-111456PtII.

McKone, T.E. and J.I. Daniels 1991, "Estimating Human Exposure Through Multiple Pathways from Air, Water, and Soil," Regul. Toxicol. Pharmacol. 13, 36-61.

Menchaca, L.B. 1996a, "Tritium Activity in Trees marekd for Removal by the Maintenance Program for a Safe Sustainable Environment at Berkeley Lab," 
memorandum report prepared for the Environmental Health and Safety Program at Lawrence Berkeley National Laboratory.

Menchaca, L.B. 1996b, "Tritium Activity in Excreta, Milk, and Pasturage for Goats Grazing at the Lawrence Berkeley National Laboratory," memorandum report prepared for the Environmental Health and Safety Program at Lawrence Berkeley National Laboratory.

Merry, M.H. 1991, Meteorological Monitoring Program Plan for the University of California Berkeley, Lawrence Berkeley Laboratory, Lawrence Berkeley Laboratory Report, October 1991.

Murphy, C.E. 1984, "The Relationship Between Tritiated Water Activities in Air, Vegetation, and Soil Under Steady-State Conditions," Health Phys., 47, 635-639.

Murphy, C.E., Jr. 1993, "Tritium Transport and Cycling in the Environment," Health Phys. 65, 6683-697.

National Council on Radiation Protection and Measurements (NCRP) 1979, Tritium in the Environment, NCRP Report No. 62 (National Council on Radiation Protection and Measurements, Bethesda, MD).

Najjar, M.F. and M. Roland 1987, Anthropometric Reference Data and Prevalence of Overweight United States 1976-1980 Vital and Health Statistics of the U.S. Department of Health and Human Services (DHHS), DHHS publication No. (PHS) 87-1688, U.S. Department of Health and Human Services, Public Health Service National Center for Health Statistics, Hyattsville, MD.

NRC 1990 Health Effects of Exposure to Low Levels of Ionizing Radiation: BEIR $V$, Committee on the Biological Effects of Ionizing Radiations, Board on Radiation Effects Research, Commission on Life Sciences, National Research Council (NRC), National Academy Press, Washington, D.C.

Okada, S. and N. Momoshima 1993, “Overview of Tritium: Characteristics, Sources, and Problems," Health Phys. 65, 595-609.

Price, P.N. and A.V. Nero 1996, "Joint Analysis Long- Short-Term Radon Monitoring Data from the Northern United States," Environment International, 23.

Sims, J.M., K.A. Surano, K.C. Lamson, and M.G. Brown 1989, Environmental Report for 1989, Lawrence Livermore National Laboratory, UCRL-50027-89.

Straume, T. and A.L. Carsten 1993, "Tritium Radiobiology and Relative Biological Effectiveness," Health Phys. 65, 657-672.

Straume, T. 1993, "Tritium Risk Assessment," Health Phys. 65, 673-682. 
Southworth, G.R. 1979, "The Role of Volatilization in Removing Polycyclic Aromatics from Aquatic Environments," Bull. Environ. Contamin. Toxicol. 21, 507-514.

Thorson, P. (editor), 1995 LBNL Site Environmental Report, LBL-27170 (1996); UC-600.

Turner, D.B. 1970, Workbook of Atmospheric Dispersion Estimates, Office of Air Programs, U.S. Environmental Protection Agency, Research Triangle Park, NC.

United Nations Environment Program (UNEP) 1985, Radiation Doses, Effects, Risks (United Nations Publications, Nairobi, Kenya).

United Nations Scientific Committee on the Effects of Atomic Radiation (UNSCEAR) 1993, Sources and Effects of Ionizing Radiation (United Nations, New York).

U.S. Code of Federal Regulations (10 CFR-835, 1-1-1994 edition) Section 10 Department of Energy, Part 835 Occupational Radiation Protection, US. National Archives and Records Administration, Washington, D.C.

U.S. Code of Federal Regulations (40 CFR-61, 7-1-1993 edition) Section 40 Environmental Protection Agency, Part 61, Subpart H, National Emissions Standards for Emissions of Radionuclides Other than Radon from U.S. Department of Energy Facilities, US. National Archives and Records Administration, Washington, D.C.

U.S. Code of Federal Regulations (40 CFR-61, 7-1-1994 edition) Section 40 Environmental Protection Agency, Part 141, National Primary Drinking Water Regulations, Subpart B, Maximum Contaminant Levels, US. National Archives and Records Administration, Washington, D.C.

U.S. Department of Agriculture (USDA) 1983, Food Intakes: Individuals in 48 States, Year 1977-1978, NFCS 1977-1978, Human Nutrition Information Service, U.S. Department of Agriculture, Washington, DC, Report No. I-1.

U.S. Environmental Protection Agency (U.S. EPA) 1985, Development of Statistical Distributions or Ranges of Standard Factors Used in Exposure Assessments, Office of Health and Environmental Assessment, EPA/600/8-85/010.

U.S. Environmental Protection Agency (U.S. EPA) 1989a, Exposure Factors Handbook, Office of Health and Environmental Assessment, EPA/600/8-89/043.

U.S. Environmental Protection Agency (U.S. EPA) 1989b, Risk Assessment Guidance for Superfund Volume I Human Health Evaluation Manual (Part A), Office of Emergency and Remedial Response, EPA/540/1-89/002.

U.S. Environmental Protection Agency (U.S. EPA) 1992, Dermal Exposure Assessment: Principles and Applications, Report No. EPA/600/8-91/011B. Office of Health and Environmental Assessment, U.S. Environmental Protection Agency, Washington, DC. 
United States National Oceanic and Atmospheric Administration (NOAA) 1974, Climates of the States, Volume II Western States (Water Information Center, Inc., Port Washington, NY).

van der Leeden, F., F.L. Troise, and D.K. Todd 1991, The Water Encyclopedia (Lewis Publishers, Chelsea, MI), second edition.

Weast, R.C., M.J. Astle, and W.H. Beyer, Eds. 1986, CRC Handbook of Chemistry and Physics: A Ready Reference Book of Chemical and Physical Data, 67th Edition (CRC Press, Inc., Boca Raton, FL).

Whitehead, R.G., and A.A. Paul 1981, "Infant Growth and Human Milk Requirements," Lancet 2, 161-163.

Yang, Y.Y., and C.B. Nelson 1986, "An Estimation of Daily Food Usage Factors for Assessing Radionuclide Intakes in the U.S. Population," Health Phys. 50, 245-257. 